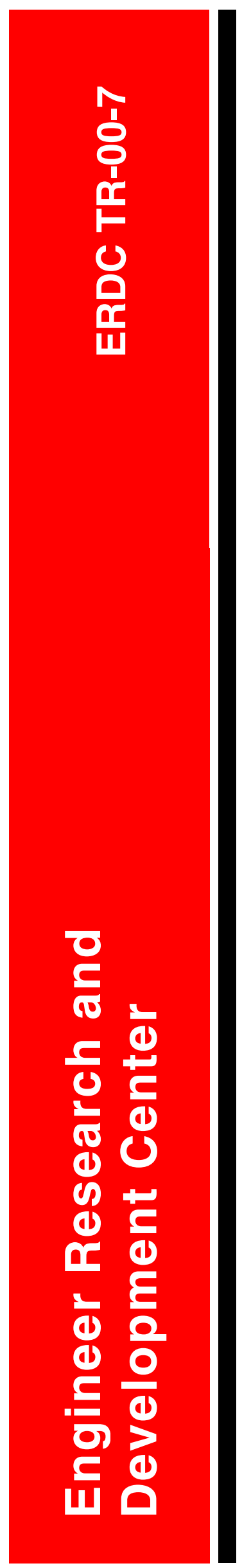

Olmsted Wicket Blank Experiment in 1:5-Scale Hydraulic Flume Model

Mostafiz R. Chowdhury and W. Glenn Davis

September 2000

Approved for public release; distribution is unlimited. 
The contents of this report are not to be used for advertising, publication, or promotional purposes. Citation of trade names does not constitute an official endorsement or approval of the use of such commercial products.

The findings of this report are not to be construed as an official Department of the Army position, unless so designated by other authorized documents. 
ERDC TR-00-7

September 2000

\section{Olmsted Wicket Blank Experiment in 1:5-Scale Hydraulic Flume Model}

by Mostafiz R. Chowdhury

Structures Laboratory

U.S. Army Engineer Research and Development Center 3909 Halls Ferry Road

Vicksburg, MS 39180-6199

W. Glenn Davis

Coastal and Hydraulics Laboratory

U.S. Army Engineer Research and Development Center 3909 Halls Ferry Road

Vicksburg, MS 39180-6199

Final report

Approved for public release; distribution is unlimited

\footnotetext{
Prepared for U.S. Army Corps of Engineers

Washington, DC 20314-1000

and U.S. Army Engineer District, Louisville

Louisville, KY 40201-0059
} 


\section{Engineer Research and Development Center Cataloging-in-Publication Data}

Chowdhury, Mostafiz R.

Olmsted Wicket Blank Experiment in 1:5-scale hydraulic flume model / by Mostafiz R. Chowdhury, W. Glenn Davis ; prepared for U.S. Army Corps of Engineers and U.S. Army Engineer District, Louisville.

73 p. : ill. ; 28 cm. -- (ERDC ; TR-00-7)

Includes bibliographic references.

1. Hydraulic gates -- Ohio River. 2. Hydraulic models 7 Ohio River. 3. Olmsted Locks and Dam Project. I. Davis, W. G. II. United States. Army. Corps of Engineers. III. United States. Army. Corps of Engineers. Louisville District. IV. Engineer Research and Development Center (U.S.) V. Structures Laboratory (U.S.) VI. Coastal and Hydraulics Laboratory (U.S.) VII. Title. VIII. Series: ERDC TR ; 00-7.

TA7 E8 no.ERDC TR-00-7 


\section{Contents}

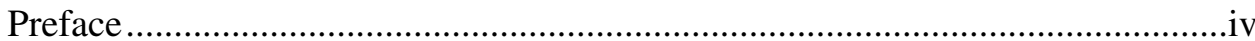

Conversion Factors, Non-SI to SI Units of Measurement......................................

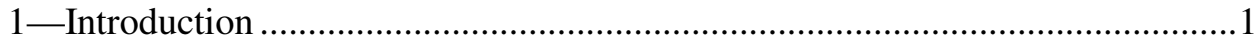

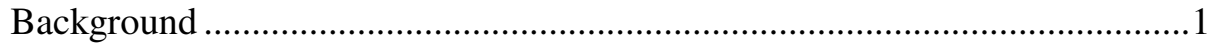

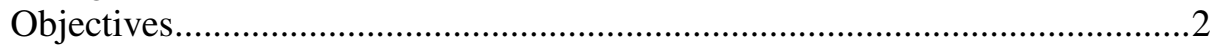

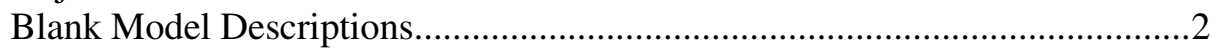

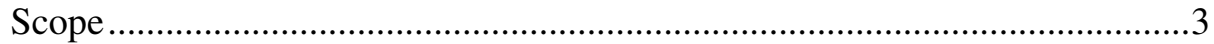

2-Instrumentation, Data Acquisition, and Analysis.............................................5

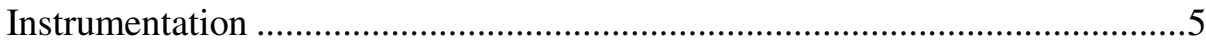

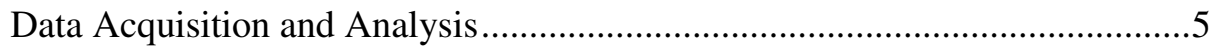

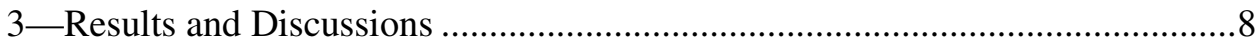

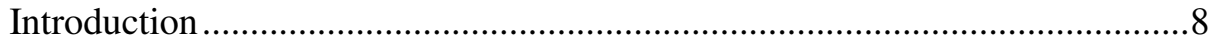

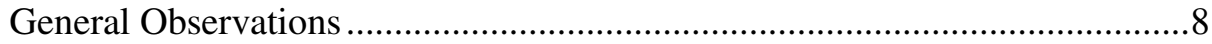

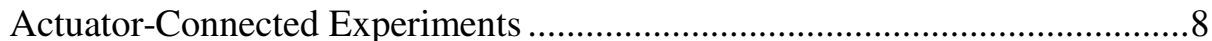

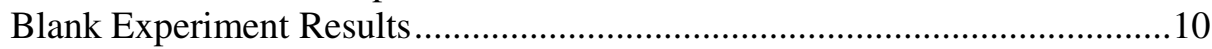

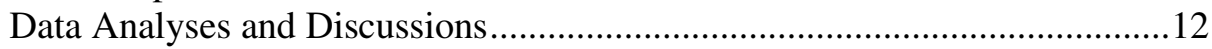

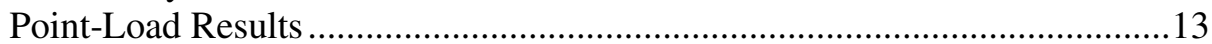

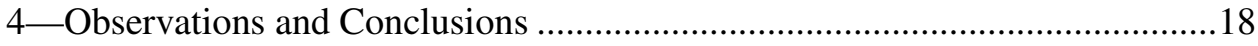

Figures 1-63

Appendix A: Shop Drawings ..........................................................................

SF 298

\section{List of Tables}

Table 1. General Outline of Experimental Results for the ActuatorConnected Blank Wicket.

Table 2. General Layout of Blank Gate Experimental Results .........................11

Table 3. Maximum Response Table for the Blank Gate Experiments...............14

Table 4. Point-Load Experimental Results for the Blank Gate Operation ........15 


\section{Preface}

The research reported herein was sponsored by the U.S. Army Engineer District (USAED), Louisville, in support of the Olmsted Navigational Model Study Program. Mr. Rick Schultz, USAED, Louisville, was the Program Monitor for the physical model studies.

All work was carried out by Dr. Mostafiz R. Chowdhury, Structural Mechanics Division (SMD), Structures Laboratory (SL), U.S. Army Engineer Research and Development Center (ERDC), under the general supervision of Dr. Michael J. O'Connor, Acting Director, SL; Dr. Reed Mosher, Chief, SMD; Dr. Robert L. Hall, Chief, Structural Analysis Group; and Mr. Winston Glenn Davis, Spillways and Channels Branch, Coastal and Hydraulics Laboratory (CHL), ERDC, under the general supervision of Dr. James Houston, Director, CHL; Mr. Tom Richardson, Assistant Director, CHL; Dr. Phil Combs, Chief, Rivers and Structures Division; and Mr. James R. Leech, Chief, Spillways and Channels Branch. The work was conducted during May 1999 through May 2000 under the direct supervision of Dr. Chowdhury and Mr. Davis.

Mr. Ken Vitaya-udom, SL, prepared the model shop drawings. Mr. Bill W. Tennant, Welding Shop, and Mr. Robert D. Parman, Machine Shop, are credited for fabrication of the blank gate. Mr. Wallace S. Guy, Information Technology Laboratory (ITL), ERDC, was responsible for instrumentation, and Mr. David Mobley (CHL) was responsible for operation of the model during experiments. Mr. Terry W. Warren, ITL, wrote the program for data acquisition, and Mr. Homer C. Greer, ITL, was responsible for coordinating instrumentation and data acquisition tasks.

At the time of publication of this report, the Director of ERDC was Dr. James R. Houston, and Commander was COL James S. Weller, EN.

The contents of this report are not to be used for advertising, publication, or promotional purposes. Citation of trade names does not constitute an official endorsement or approval of the use of such commercial products. 


\section{Conversion Factors, Non-SI to SI Units of Measurement}

Non-SI units of measurement used in this report can be converted to SI units as follows:

\begin{tabular}{|c|c|c|}
\hline Multiplv & Bv & To Obtain \\
\hline cubic feet & 0.02831685 & cubic metres \\
\hline cubic inches & 0.000016387 & cubic metres \\
\hline degrees (angle) & 0.01745329 & radians \\
\hline Fahrenheit degrees & $5 / 9$ & Celsius degrees $^{1}$ \\
\hline feet & 0.3048 & metres \\
\hline G (standard acceleration of free fall) & 9.80665 & metres per second squared \\
\hline inches & 0.0254 & metres \\
\hline ksi (kips per square inch) & 6.894757 & megapascals \\
\hline kips & 4.4484 & kilonewtons \\
\hline pounds (force) & 4.4484 & newtons \\
\hline pounds (mass) & 0.4535924 & kilograms \\
\hline pounds (force) per square inch & 0.006894757 & megapascals \\
\hline tons & 1,000 & kilograms \\
\hline
\end{tabular}




\section{Introduction}

\section{Background}

The U.S. Army Engineering Research and Development Center (ERDC) has conducted research to determine the adequacy and constructibility of the current horse-style wicket gate design and to evaluate the operability of the proposed wicket blank ${ }^{1}$. A series of 1:5-scale wicket blank model experiments were conducted at the existing 1:5 model facility in ERDC. The experimental data presented in this document support the design development of the prototype wicket blank for the Olmsted Dam.

The proposed Olmsted Dam will replace two existing Locks and Dams on the lower Ohio River (Locks \& Dam No. 52 and 53). The new dam will consist of twin 1,200-ft-long by 110 -ft-wide navigation locks, five tainter gate bays, and approximately a 1,400 -ft-wide navigable pass. The navigable pass portion of the dam will use wicket gates to facilitate the barge/tow traffic approximately 60 percent of a given year. During low-flow periods, the wicket gates will be raised to provide navigable depths upstream of the dam. The wicket gates will be manually raised and lowered from a workboat. The possibility exists that during the operation of raising the dam, a single wicket may not be able to be raised, thus leaving a hole or gap in the dam. The wicket blank was designed to temporarily fill the gap left from an inoperable gate.

The 1:5-scale wicket blank was constructed and tested in the existing 1:5scale hydraulic model. The suggested overall width of the wicket blank was 10 $\mathrm{ft}, 11 \mathrm{in}$. The wicket blank was geometrically scaled and fabricated in accordance to the design drawings previously furnished to ERDC. The 1:5 scalemodel facility with 12 hydraulically operated wicket gates was modified to simulate gate widths of $9 \mathrm{ft}, 8 \mathrm{in}$. and gate heights to elevation $(\mathrm{el})^{2} 302$ in the operating or raised position. The existing instrumented wicket gate presently installed in the model facility was used to determine the forces exerted on wicket gates during wicket blank installation. Additional instrumentation was added to measure the forces required to get the blank in place and the loads transferred to the wicket at various heads. The experimental results for blank installation, removal, and in-place operations are presented in this document.

\footnotetext{
${ }^{1}$ Memorandum from the office of the U.S. Army Engineer District (USAED), Louisville (CELRL-ED-TH), 30 April 1999, subject: Olmsted L\&D 1:5 Model Testing.

${ }^{2}$ Elevations cited herein are in feet and referred to the Ohio River Datum.
} 


\section{Objectives}

The objective of the 1:5-scale wicket blank experiments was to simulate the functional behavior of the wicket blank during its operation in the Olmsted Dam. The simulated experiments were conducted to identify operational difficulties, determine loads during blank installation and removal, and to evaluate the overall performance of the wicket blank for various operational configurations.

\section{Blank Model Descriptions}

The wicket blank experiments were conducted in the model facility to evaluate the overall operability of the wicket blank. The model wicket blank was fabricated such that the material, material thickness, size, and weight of the prototype wicket blank were simulated in the model.

Figure 1 shows the blank model operation in the dry 1:5 model facility. Typically during the installation process, the upright blank will ride over the adjacent gates as shown in Figure 1. A winch cable is used to lower the blank until it reaches its seated position, which is el 279 in the model. It should be noted that because of differences between the hydraulically operated wicket design simulated in the model and the new horse-wicket design, the blank could not be lowered to its proposed seated depth at el 275.85 during model operations. The effect of this discrepancy in the model and prototype base elevations must be accounted for when estimating prototype responses using the model data presented in this report. When the blank reaches the seated position (see Figures 2 and 3), the actuator force is released such that the flow induced load tilts the blank about the dam axis and closes the gap between the adjacent gates. Figures 4 and 5 show the upstream and downstream view of the seated blank. This completes the installation operation and the reverse of the process is used for removing the blank from the gap.

The instrumented existing 1:5-scale wicket gate on the right (looking downstream) and the aluminum gate on the left provide the supports for the blank. Any forces, hydrodynamic or static, acting on the blank will be transferred to the supporting gates through the gate-bottom attachment points. The actuator arm provides the necessary forces to keep the blank vertically aligned within a tolerable degree of freedom during an in-flow operation. An actuator, sensitive to the gate-top rotation about the dam axis, was used to keep the blank vertical during its insertion process and the actuator forces required to keep the gate vertically aligned were recorded. A winch mounted above the spillway crest was used to raise or lower the blank during installation or removal procedures. The winch cable was equipped with a load cell and the forces in the cable were measured during the tests.

A typical wicket blank installation experiment required that all of the wicket gates in the 1:5 model to be in raised position except for one (see Figures 6 and 7). Blank experiments were conducted with and without the actuator connected to the blank during its installation process. Figure 6 shows an installation 
operation in which the actuator was disconnected. A sequence of blank wicket installing configurations is presented in Figures 8 to 13. As seen in Figure 8, when the actuator is engaged, the lifting force required to install the blank is the summation of the vertical components of forces on the actuator and the winch cable. When the actuator was disconnected, the lifting is solely a result of the wench cable tension registered during the installation process. In these figures, both 65- and 90-deg positions of the blank wicket are presented to illustrate the physical environment of the blank operations.

The wicket blank experiments were performed with the down wicket being adjacent to the instrumented wicket so that loads on the wicket and prop can be determined using the existing instrumentation. The overall operability of the blank was observed and documented. In the event when the wicket blank did not seat under its own weight, known weights were added to the top of the wicket to determine the force required inserting the blank (Figure 7). As seen in this figure, the additional weights were added to the top two channels of the blank. Experiments were also conducted to see the effects of changing the location of weights from top to the bottom channels. For various pool elevations, the hinge and prop rod forces on the instrumented adjacent wicket, and the actuator and winch cable forces were recorded.

The scaled blank model weighed about $152.75 \mathrm{lbf}$ which corresponds to a prototype weight of 9.55 tons. This upscale prototype weight is about 12.32 percent higher than the original estimate of 8.5 tons. This increase in weight resulted partly because of the widening of the flange width of the blank edge tee-beams. The edge tee-beam outer flanges were widened by adding a strip of plate to each edge of the blank to ensure the proper placement of the blank over the adjacent wickets. ${ }^{1}$ A safe placement of the blank over a gap requires that its edges ride adequately over the adjacent wickets. Observations of blank placement in a gap indicated that an inadvertent lateral shift of the blank towards one edge could cause the other end to slide off the adjacent wicket. This required expanding the width by $3 / 4$ in. on each side of the blank from its original model width dimension of $26.2 \mathrm{in}$. The new width of the blank in prototype scale becomes $11 \mathrm{ft}, 6 \frac{1}{2} \mathrm{in}$.

\section{Scope}

The scope of the work presented in this document included the measurements of forces required to install the blank in an open gap created by one inoperable wicket gate and the loads transferred to the adjacent wickets for the actual operational configurations listed in the following text. This testing plan was based on the instructions from the USAED, Louisville, in a memorandum dated 25 May 1999, subject: The Wicket Blank Testing Plan. These operational configurations included:

\footnotetext{
${ }^{1}$ Telecon Memorandum, Sverdrup/Gerwick, Date: December 1, 1999, Sub: DACW2796-C-0099 Olmsted Dam Plans \& Specs - Phase II.
} 
a. Installation. During this operation, the wicket blank was initially positioned with the bottom edges of the blank in contact with the top of the gates adjacent to the lowered gate and then lowered slowly by the winch (Figures 6 and 7). This test was done for the five headwater/tailwater conditions as shown:

(1) Headwater $=300$, tailwater $=300$

(2) Headwater $=298$, tailwater $=295$

(3) Headwater $=300$, tailwater $=295$

(4) Headwater $=301$, tailwater $=294$

(5) Headwater $=301$, tailwater $=291$

b. Removal. This test required the raising of the wicket blank by the winch from its fully seated position. The removal of the actuator-connected blank from its seated position is illustrated in Figures 14 to 16. The same operating sequences for the blank when the actuator was disconnected from it are shown in Figures 17 through 19. Two headwater/tailwater conditions were evaluated for this operation. These conditions were:

(1) Headwater $=300$, tailwater $=295$

(2) Headwater $=300$, tailwater $=290$

c. Inplace. This test measured the static forces transmitted to the instrumented gate for the installed and fully seated wicket blank (see Figure 14 for example). The test was conducted for headwater and tailwater elevations of 302.0 and 278.0, respectively.

d. Point load. This test measured the contact load transmitted to the adjacent wickets during blank gate operation for the fixed blank gate positions. Two orientations of the gate, one at $65 \mathrm{deg}$ and another at $90 \mathrm{deg}$, were used to record the static loads transmitted at the contact points. Figure 20 shows a typical 65 -deg dry position of the blank gate. Figure 1 shows a 90-deg dry position of the blank gate. Two load cells were pinned to the bottom of blank to measure the transmitted load at the contact points as shown in Figures 20 and 21. For 10 fixed elevations, point load tests were conducted for four different pool elevations as listed below.

(1) Headwater $=298$, tailwater $=295$

(2) Headwater $=300$, tailwater $=295$

(3) Headwater $=301$, tailwater $=294$

(4) Headwater $=301$, tailwater $=291$ 


\section{Instrumentation, Data Acquisition, and Analysis}

\section{Instrumentation}

A total of 18 different transducers recorded dynamic data for the 1:5-scale blank model. Figure 22 shows the sensor locations for the existing instrumented gate. These transducers included:

a. Force normal to the face of the existing gate at the right hinge (r.h.) and the left hinge (1.h.).

$b$. Force parallel to the face of the existing gate at the r.h. and the 1.h.

c. Prop load normal to the face of the existing gate.

d. Winch cable force.

$e$. Winch cable release indicator (measured the extension of the winch cable due to lowering of the blanket).

f. Contact loads on the left and right contact points.

g. Loads on the actuator that keeps the blank in upright position.

h. U/S pool elevation (measured with a pressure transducer).

$i$. $\mathrm{D} / \mathrm{S}$ pool elevation (measured with a pressure transducer).

j. Gate rotation. (Gate orientation was measured by a tiltmeter attached to the base of the gate.).

$k$. Hoist cable rotation.

l. Trigger mark indicator.

Figure 23 shows the general layout of the blank model orientation in the spillway cross section. As seen in the figure, the actuator pivots at el 312.35 mounted on the catwalk. Another end of the actuator is connected to the blank at 
$0.5 \mathrm{ft}$ (model dimension) down from the top of the blank wicket. The locations of the load cells at bottom of the blank gate are also shown in Figure 20.

\section{Data Acquisition and Analysis}

\section{System and operation}

The data acquisition system for the Olmsted 1:5 Model Study consisted of one personal computer (PC) for data storage, data processing, and process control, an analog-to-digital converter (ADC), signal conditioning amplifiers, and a printer. Signal conditioning included continuous variable gain amplifiers, tracking filters, and antialias filters. The signal conditioning amplifiers were manufactured by Vishay and could supply gains up to 10,000. Custom-made programs were installed in the $\mathrm{PC}$ to regulate data acquisition and control gate position. The PC used to record data also contained a National Instruments ATMIO-16F-5 ADC board and a Real Time Devices digital input/output (DIO) board. The DIO were used to activate the desired hydraulic system function for the experiment to be run. The ADC had a 12-bit resolution and was configured for -5 to +5 volt input range. The ADC was a printed circuit board that plugged into a PC expansion slot.

Custom software was written to take calibration measurements, record data during an experiment, and make time-history plots of the data recorded. MATLAB matrix analysis software was used for much of the data analysis; it contains many powerful numerical and graphical tools to manipulate matrices, perform frequency analyses, and plot graphs, as well as perform other crucial mathematical functions (The MathWorks, Inc. 1992). ${ }^{1}$

\section{Time domain analysis}

The measured input was originally an analog signal. The front end converted the analog signal to a series of digital values. The digitized input signal as a set of $\mathrm{N}$ discrete values, evenly spaced in the period $\mathrm{T}$, are recorded to display the time signal for each channel. Each channel is sampled at 500 samples per sec for about $205 \mathrm{sec}$ (model dimension).

The real-time scope displays a number of input channels in a variety of formats. MATLAB (The MathWorks, Inc. 1992) was used to generate the timedomain data presented in this report. All packages allow mathematical operations of the recorded channel such that the units of measurement could be converted, the analytical operations could be performed, and data could be displayed in model or prototype units. As mentioned earlier, a custom program was used during the experiment to check the consistency and quality of the recorded data by observing each recorded channel on site. Time-domain signals could be displayed as function of time or as a function of gate insertion depth.

\footnotetext{
${ }^{1}$ The MathWorks, Inc. (1992). Matlab 5.3 product family, User's Guide, Natick, MA.
} 
For a meaningful representation of the acquired data, all responses presented in this document are converted as a function of insertion depth. The insertion depth is the distance traversed by the blank gate as it is installed from the top to the seated position. A total depth of $4.6 \mathrm{ft}$ is thus traversed by the blank model to close the gap completely. The insertion depth is 0 at the top during the start of the installation process (see Figure 6) and $4.6 \mathrm{ft}$ at its seated position (see

Figure 3). Data plots reference blank displacement or insertion depth as a direct relation to the measured value of cable length spooled from the winch drum. However, for some test conditions during installation/insertion of the wicket blank, the blank would stop moving and at the end of the tests when the blank seated and stopped moving, the winch cable would become slack. This resulted in slight discrepancies between the actual location (insertion depth) of the blank and the reported location. It should be noted that the amount of cable slack was minimized during the tests. 


\section{Results and Discussions}

\section{Introduction}

The experimental results for various blank operations are presented in this section of the document. These operations included installation, removal, and in-place conditions of the blank wicket. For each test, actual forces exerted on the adjacent gates and the lifting force required placing the blank in the gap were recorded. The maximum amplitude of these responses for each test configurations is tabulated and the force-history as a function of insertion depth is presented. All numbers mentioned in this document are in model units. For conversion to prototype equivalents, the magnitude of force must be multiplied by a force scale multiplier of 125 or $\left(5^{3}\right)$.

\section{General Observations}

These experiments were conducted to determine the overall operability of the blank wicket. The gate was lowered slowly by the winch from the top of the gates. Figures 6 and 7 show the beginning of the installation of blank wicket operation. As seen in the figures, the raised blank wicket is suspended from the top, and its bottom edges are in contact with the adjacent wickets. The gate is slowly inserted into the gap as the wench cable is released and the loads are recorded. The gate is inserted from the top as shown in Figures 8 through 10 and continued to go down until the gate is fully seated at el 279 (Figures 3 and 15). All elevations presented here are in prototype units. In the event the wicket blank does not seat on its own weight, incremental additional weights were inserted in the top channels until the gate smoothly closed the gap without getting stopped on its way down. Figure 7 shows such a situation in which the additional weights were inserted in the top channels to allow the gate to reach the fully seated position. Results for the actuator connected blank experiments are discussed below.

\section{Actuator-Connected Experiments}

A series of installation experiments using the actuator-connected blank indicated the difficulties in inserting the blank wicket to its full depth. For a 7-ft pool difference, the blank would not seat properly with an additional weight of 
$144.8 \mathrm{lbf}$, nor would it seat by tilting the gate about the dam axis over $11.5 \mathrm{deg}$ from its upright position. Table 1 summarizes the experimental results for the actuator-connected blank wicket during the installation process. As seen in the table, several attempts have been made to insert the actuator-connected blank by changing the location of the added weights from bottom to top channels and by tilting the gate around its vertical axis. It is interesting to note that for the 5 - $\mathrm{ft}$ pool difference, the blank could be lowered to its seated position when the additional weights were added on the bottom channels. For the same head difference, however, placing the weights on the top channels that simulate the actual prototype operation of the blank would not install the blank to its seated position. By tilting the blank about the dam axis (tilting the top of the gate in the downstream direction), however, the blank was able to reach its fully seated position.

\begin{tabular}{|c|c|c|c|c|c|}
\hline \multicolumn{6}{|c|}{$\begin{array}{l}\text { Table } 1 \\
\text { General Outline of Experimental Results for the Actuator-Connected } \\
\text { Blank Wicket }\end{array}$} \\
\hline \multirow[b]{2}{*}{ Test Number } & \multicolumn{2}{|c|}{ Pool Levels, ft } & \multirow[b]{2}{*}{$\begin{array}{l}\text { Gate Angle, } \\
\text { deg }\end{array}$} & \multirow[b]{2}{*}{$\begin{array}{l}\text { Added } \\
\text { Weight, Ibf }\end{array}$} & \multirow[b]{2}{*}{$\begin{array}{l}\text { Remarks on the Status of } \\
\text { the Blank Test }\end{array}$} \\
\hline & $\begin{array}{l}\text { Up- } \\
\text { stream }\end{array}$ & $\begin{array}{l}\text { Down- } \\
\text { stream }\end{array}$ & & & \\
\hline \multicolumn{6}{|c|}{ Installation Experiments } \\
\hline Blank1-6 & Dry & Dry & 65 & $n / a$ & Gate weight, $152.75 \mathrm{lbf}$ \\
\hline WBT1-3 & 300 & 300 & $"$ & None & Blank gate seats properly \\
\hline WBT4-6 & 298 & 295 & $"$ & None & Blank gate seats properly \\
\hline WBT7-9 & 300 & 295 & $"$ & None & Stops \\
\hline WBT10 & 301 & 294 & $"$ & None & Stops \\
\hline WBT11-12 & 300 & 295 & $"$ & $\begin{array}{l}20 \text { (bottom } \\
\text { loaded) }\end{array}$ & $\begin{array}{l}\text { Almost went down to seated } \\
\text { position }\end{array}$ \\
\hline WBT13-14 & 300 & 295 & $"$ & $\begin{array}{l}39.66 \text { (bottom } \\
\text { loaded) }\end{array}$ & Blank gate seats properly \\
\hline WBT15-19 & 300 & 295 & $"$ & $\begin{array}{l}39.66 \text { to } 144.8 \\
\text { (top loaded) }\end{array}$ & $\begin{array}{l}\text { Stops and could not be } \\
\text { lowered further down }\end{array}$ \\
\hline WBT20 & 300 & 295 & $"$ & None & $\begin{array}{l}\text { Did not go down by tilting the } \\
\text { blank } \sim 2 \text { deg }\end{array}$ \\
\hline WBT21-23 & 300 & 295 & “ & None & $\begin{array}{l}\text { Tilting the blank gate } \\
\text { whenever needed }(\sim 3.5 \text { deg }) \\
\text { enabled the blank to seat } \\
\text { properly }\end{array}$ \\
\hline WBT24-27 & 301 & 294 & $"$ & None & $\begin{array}{l}\text { Could not be dropped by } \\
\text { tilting the gate over } 11.5 \text { deg }\end{array}$ \\
\hline
\end{tabular}

The difficulties in inserting the blank passed a certain position along its insertion depth (stopped at about three-fourths of the full depth) was due to the vertical restraint provided by the actuator arm. The upward components of the actuator force required to keep the gate vertical barred the blank to move downward. Figure 23 shows the actuator position with respect to the blank gate. 
To avoid this inadvertent situation of halting the blank placement to its seated position, experiments were conducted without removing the actuator and the results are presented in the following text.

\section{Blank Experiment Results}

General observation of the operability of the blank for various operating configurations and different pool conditions are summarized in Table 2. As indicated in the table, the blank wicket seated properly on its own weight when the pool differences were less than $5 \mathrm{ft}$ (cases OLMWBT2 to OOLMWBT4). However, additional weights were needed to insert the blank to its full depth when pool difference exceeded $5 \mathrm{ft}$ (cases OLMWBT5 to OLMWBT 6). A 7-ft pool difference required $68.32 \mathrm{lbf}$ of additional weights on the channels (see Figures 24 through 27) to insert the gate to full depth. A 10-ft pool difference required 117.26 lbf of weights for smooth installation of the blank wicket. Five headwater/tailwater conditions were included for these installation experiments. The actuator was not connected to the blank during the installation experiments presented in Table 2.

Table 2 also presents the summary of the removal and in-place blank operations. During the removal, the wicket blank is raised by the winch from its fully seated position. Two headwater/tailwater conditions were included for this operation. In all cases, the gate was removed with no difficulty. The first two removal cases (OMWBT7 and OLMWBT8) used no actuator, and the gate remained at approximately a $65-\mathrm{deg}$ position during the procedure. In the last two cases, the gate was initially rotated from its fully seated position at $65 \mathrm{deg}$ to a 90-deg position using the actuator, and then the gate was removed using the winch cable.

The last two sets of data generated from conditions listed in Table 2 are for the in-place static test results for with and without the actuator connected blank operation. As mentioned earlier, the actuator was needed to keep the blank vertical during its installation process, to rotate the blank from its vertical orientation to a 65 -deg position during installation, and to rotate the blank from its 65 -deg seated position to a vertical orientation during removal. This test measured the static forces transmitted to the instrumented gate for the installed and fully seated wicket gate. The test was conducted for headwater and tailwater elevations of 302.0 and 278.0, respectively. 


\begin{tabular}{|c|c|c|c|c|c|}
\hline \multirow[b]{2}{*}{ Test Number } & \multicolumn{2}{|c|}{ Pool Levels, ft } & \multirow[b]{2}{*}{$\begin{array}{l}\text { Gate Angle, } \\
\text { deg }\end{array}$} & \multirow{2}{*}{$\begin{array}{l}\text { Load Added to } \\
\text { Lower the Gate } \\
\text { into Full Depth, } \\
\text { lbf }\end{array}$} & \multirow[b]{2}{*}{$\begin{array}{l}\text { Remarks on Status of } \\
\text { Blank Test }\end{array}$} \\
\hline & $\begin{array}{l}\text { Up- } \\
\text { stream }\end{array}$ & $\begin{array}{l}\text { Down- } \\
\text { stream }\end{array}$ & & & \\
\hline \multicolumn{6}{|c|}{ Installation Experiments } \\
\hline OLMWBT1 & Dry & Dry & 65 & None & Gate weight, $152.75 \mathrm{lbf}$ \\
\hline OLMWBT2B & 300 & 300 & $"$ & None & Blank gate seats properly \\
\hline OLMWBT3B & 298 & 295 & $"$ & None & Blank gate seats properly \\
\hline OLMWBT4 & 300 & 295 & $"$ & None & Blank gate seats properly \\
\hline OLMWBT5 & 301 & 294 & $"$ & None & Stops \\
\hline OLMWBT5C-E & 301 & 294 & $"$ & 68.32 & Blank gate seats properly \\
\hline OLMWBT6 & 301 & 291 & $"$ & None & Stops \\
\hline OLMWBT6C-I & 301 & 291 & $"$ & 78.18 to 112.26 & Did not go all the way down \\
\hline OLMWBT6J-P & 301 & 291 & $"$ & 117.26 & Blank closes the gap \\
\hline \multicolumn{6}{|c|}{ Removal Experiments } \\
\hline OLMWBT7B & 300 & 295 & 65 & None & $\begin{array}{l}\text { Removed gate without } \\
\text { actuator }\end{array}$ \\
\hline OLMWBT8B & 300 & 290 & 65 & None & $\begin{array}{l}\text { Removed gate without } \\
\text { actuator }\end{array}$ \\
\hline OLMWBT9C & 300 & 290 & $65-90$ & None & $\begin{array}{l}\text { Started at } 65 \text { deg, moved to } \\
90 \text { deg, then gate removed, } \\
\text { actuator connected }\end{array}$ \\
\hline OLMWBT10 & 300 & 295 & $65-90$ & & $\begin{array}{l}\text { Started at } 65 \text { deg, moved to } \\
90 \text { deg, then gate removed, } \\
\text { actuator connected }\end{array}$ \\
\hline \multicolumn{6}{|c|}{ Static Load Experiments } \\
\hline OLMWBT11 & 302 & 278 & 65 & None & $\begin{array}{l}\text { In-place static load at } \\
65 \text { deg, no actuator } \\
\text { connected }\end{array}$ \\
\hline OLMWBT12 & 302 & 278 & 65 & None & $\begin{array}{l}\text { In-place static load at } \\
65 \text { deg, actuator connected }\end{array}$ \\
\hline
\end{tabular}




\section{Data Analyses and Discussions}

Selected sensor data for the experiments presented in Table 2 are presented in Figures 28 through 63 . Note that the results presented in these figures correspond to the test numbers shown in Table 2. For repeated experiments, only the results for the successful one that enabled the blank to seat properly are selected for presentation. For example, among the four tests conducted for 7 - $\mathrm{ft}$ pool elevations (OLMWBT5 and OLMWBT5C-E, see table above for test designations), only results for OLMWBT5D are presented for illustrations. As discussed previously, these figures are generated as a function of insertion depth starting from the top of the supporting wicket at el 302 to the seated bottom at el 279. Time-domain sensor responses and the blank displacement data are correlated to determine the forces (presented in these figures) as a function of insertion depth. The blank displacement is measured from the cable release from the wench drum. Note that the insertion depth is measured along the vertical direction, normal to the stream direction.

As seen in these figures, the apparent total insertion depth of about $5.1 \mathrm{ft}$ exceeds the actual distance of $4.6 \mathrm{ft}$ traversed by the blank model to close the gap completely. This discrepancy resulted because of sagging of the winch cable during the installation procedure. As explained earlier, during installation/ insertion of the wicket blank, the blank would stop moving. At the end of the tests when the blank seated and stopped moving, the winch cable would become slack. For each experiment, seven plots are generated to show the forces transmitted on the existing wicket and the lifting force required installing the blank. Forces parallel and normal to the existing wicket for both hinges, and the prop rod forces indicate the variation of transmitted forces on the existing instrumented wicket as the gate is inserted or removed from the gap. Left and right directions correspond to the model orientation looking from upstream toward downstream. The blank orientation shows the rotation of the blank top from its upright position. As seen in the plots for the blank gate operation with and without the actuator connected (test numbers: OLMWBT8B and OLMWBT9C in Figures 59 and 63), the effects of actuator in holding the blank upright is noticeable. In cases when the actuator was not connected to the blank (Figure 59), the gate tilted over $30 \mathrm{deg}$ from its upright position. While for the actuator-connected gate, the blank remained almost vertical during the course of its placement in the gap (Figure 63). The lifting force is the summation of the vertical forces measured during the operation of the blank in the model. For the actuator-connected blank, the summation of the vertical components of actuator force and the wench cable are used to compute the lifting force as a function of insertion depth. A free body diagram showing the directions of cable and actuator forces can be used to determine the lifting force as a function of time for the blank using the equation shown below (Figure 8).

When the insertion depth (ID) lies between 0 to $3.16 \mathrm{ft}$, the lifting force $\left(F_{\text {lifting }}\right)$ equals: 


$$
F_{\text {Lifting }}(t)=F_{\text {Cable }}(t) * \operatorname{Cos} \theta(t)-F_{\text {Actuator }} * \operatorname{Sin} \alpha(t), \quad 0 \leq I D \leq 3.16
$$

and, for ID $>3.16$,

$$
F_{\text {Lifting }}(t)=F_{\text {cable }}(t) * \operatorname{Cos} \theta(t)+F_{\text {Actuator }} * \operatorname{Sin} \alpha(t)
$$

where

$$
\begin{aligned}
& \theta(t)=\text { angle between the cable and the vertical axis of the upright blank } \\
& \text { gate } \\
& \alpha(t)=\text { angle that the actuator arm makes with the horizontal axis }
\end{aligned}
$$

The magnitude of $\alpha(t)$ can be obtained as a function of time using the equation shown below:

$$
\begin{aligned}
& \alpha(t)=\left[27^{\mathrm{o}}-\left(\frac{27^{\mathrm{o}}}{3.16}|I D|\right)\right], \cdots(0<I D \leq 3.16) \\
& \alpha(t)=\left[28.77^{\mathrm{o}}-\left(\frac{28.77^{\mathrm{o}}}{2.07}|5.23-I D|\right)\right], \cdots(I D>3.16)
\end{aligned}
$$

Maximum amplitude of responses for all three operations are tabulated in Table 3. Forces include reaction forces on the existing gate and the lifting force recorded during the scheduled operations. In addition to the forces listed in Table 3, forces transmitted directly at contact points on the supporting existing wickets were measured. As shown in Figure 20, two load cells pinned to the bottom of blank measured the transmitted load at the contact points for fixed blank gate position.

\section{Point-Load Results}

During the point load test, the blank was kept stationary at 10 fixed elevations (see Figure 23 for elevation levels) and the data were recorded for fixed pool elevations as shown in Table 4. As seen in the table, eight cases with different pool and gate orientations were used to measure the contact point load (Figure 1). For the 65-deg position, the blank lay on the adjacent gates as shown in Figures 18 and 20. A 90-deg position of the point load test is shown in Figures 1 and 15. In this table, the gate angle is the blank gate orientation (clockwise) with respect to the stream direction. The maximum point forces is the maximum contact loads transmitted at the attachment points. The actuator force is the force required to keep the blank in position, and the gate elevation corresponds to the bottom of the blank location (position of load cell pinned to the bottom of blank) during the point-load test. 
Table 3

Maximum Response Table for the Blank Gate Experiments

\begin{tabular}{|c|c|c|c|c|c|c|c|c|}
\hline \multirow[b]{2}{*}{ File Name } & \multirow[b]{2}{*}{$\begin{array}{l}\text { Upstream } \\
\text { Pool, ft }\end{array}$} & \multirow{2}{*}{$\begin{array}{l}\text { Down- } \\
\text { stream Pool, } \\
\text { ft }\end{array}$} & \multicolumn{2}{|c|}{ Right Hinge Pin } & \multicolumn{2}{|c|}{ Left Hinge Pin } & \multirow[b]{2}{*}{$\begin{array}{l}\text { Prop Rod } \\
\text { Force, Ibf }\end{array}$} & \multirow[b]{2}{*}{$\begin{array}{l}\text { Lifting } \\
\text { Force, Ib }\end{array}$} \\
\hline & & & $\begin{array}{l}\text { Normal Z } \\
\text { Force, Ibf }\end{array}$ & $\begin{array}{l}\text { Parallel Y } \\
\text { Force, Ibf }\end{array}$ & $\begin{array}{l}\text { Normal Z } \\
\text { Force, Ibf }\end{array}$ & $\begin{array}{l}\text { Parallel Y } \\
\text { Force, Ibf }\end{array}$ & & \\
\hline \multicolumn{9}{|c|}{ Installation Experiments } \\
\hline OLMWBT2B & 300 & 300 & -7 & 4.5 & 29 & 8 & 20 & 151 \\
\hline OLMWBT3B & 298 & 295 & -137.5 & 100.6 & 189.7 & 61 & 390 & 151 \\
\hline OLMWBT4 & 300 & 295 & -225 & 102.9 & 267.8 & 93.5 & 535.8 & 151 \\
\hline OLMWBT5 & 301 & 294 & -317 & 97.8 & 355.4 & 161.3 & 740.8 & 215 \\
\hline OLMWBT6N & 301 & 291 & -322 & 116.4 & 416.6 & 86.3 & 550.3 & 265 \\
\hline \multicolumn{9}{|c|}{ Removal Experiments } \\
\hline OLMWBT7B & 300 & 295 & -130 & 37 & 228 & 125 & 174.5 & 163.5 \\
\hline OLMWBT8B & 300 & 290 & -238.5 & 87 & 395 & 198 & 365 & 162 \\
\hline OLMWBT9C & 300 & 290 & -84 & -69.5 & 328 & 185.5 & 242 & 155 \\
\hline OLMWBT10 & 300 & 295 & -60 & 28 & 174 & 60 & 130 & 155 \\
\hline \multicolumn{9}{|c|}{ Static Load Experiments } \\
\hline OLMWBT11 & 302 & 278 & 110.33 & 145.5 & 779.3 & 407.5 & 1,167 & $n / a$ \\
\hline OLMWBT12 & 302 & 278 & -177 & 200 & 767 & 650.2 & $1,688.1$ & $\mathrm{n} / \mathrm{a}$ \\
\hline
\end{tabular}




\begin{tabular}{|c|c|c|c|c|c|c|c|}
\hline \multicolumn{8}{|c|}{\begin{tabular}{|l} 
Table 4 \\
Point-Load Experimental Results for the Blank Gate Operation
\end{tabular}} \\
\hline \multirow[b]{2}{*}{ File Name } & \multirow{2}{*}{$\begin{array}{l}\text { Up- } \\
\text { stream } \\
\text { Pool, ft }\end{array}$} & \multirow{2}{*}{$\begin{array}{l}\text { Down- } \\
\text { stream } \\
\text { Pool, ft }\end{array}$} & \multirow{2}{*}{$\begin{array}{l}\text { Gate } \\
\text { Angle, } \\
\text { deg }\end{array}$} & \multicolumn{2}{|c|}{ Max. Point Forces } & \multirow{2}{*}{$\begin{array}{l}\text { Actuator } \\
\text { Max. Force, } \\
\text { Ibf }\end{array}$} & \multirow{2}{*}{$\begin{array}{l}\text { Gate } \\
\text { Elevation, } \mathrm{ft}\end{array}$} \\
\hline & & & & Left, Ibf & Right, Ibf & & \\
\hline \multicolumn{8}{|c|}{ CASE- 1} \\
\hline OLMWBT14 & 298 & 295 & 90 & 90.2 & 94.0 & 37.5 & 279 \\
\hline OLMWBT15C & 298 & 295 & 90 & 77.4 & 81.7 & 34.4 & 281 \\
\hline OLMWBT16B & 298 & 295 & 90 & 75.7 & 94.0 & 8.0 & 283 \\
\hline OLMWBT17C & 298 & 295 & 90 & 74.0 & 76.5 & 11.1 & 285 \\
\hline OLMWBT18B & 298 & 295 & 90 & 62.4 & 55.4 & 15.8 & 287 \\
\hline OLMWBT19C & 298 & 295 & 90 & 53.3 & 58.1 & 19.9 & 289 \\
\hline OLMWBT20B & 298 & 295 & 90 & 43.2 & 57.8 & 22.9 & 291 \\
\hline OLMWBT21C & 298 & 295 & 90 & 27.3 & 47.4 & 18.9 & 293 \\
\hline OLMWBT22B & 298 & 295 & 90 & 14.6 & 28.8 & 20.9 & 295 \\
\hline OLMWBT23C & 298 & 295 & 90 & 10.2 & 20.3 & 19.9 & 297 \\
\hline \multicolumn{8}{|c|}{ CASE- 2} \\
\hline OLMWBT25C & 298 & 295 & 65 & 170.9 & 121.9 & 51.8 & 279 \\
\hline OLMWBT26B & 298 & 295 & 65 & 155.8 & 112.2 & -37.6 & 281 \\
\hline OLMWBT27 & 298 & 295 & 65 & 140.9 & 99.2 & -45.8 & 283 \\
\hline OLMWBT28B & 298 & 295 & 65 & 128.4 & 72.4 & -72.2 & 285 \\
\hline OLMWBT29 & 298 & 295 & 65 & 117.1 & 63.6 & -71.2 & 287 \\
\hline OLMWBT30 & 298 & 295 & 65 & 112.1 & 81.2 & -28.5 & 289 \\
\hline OLMWBT31B & 298 & 295 & 65 & 94.4 & 45.4 & -80.3 & 291 \\
\hline OLMWBT32 & 298 & 295 & 66.5 & 64.6 & 41.7 & -85.4 & 293 \\
\hline OLMWBT33 & 298 & 295 & 69.3 & 44.5 & 29.1 & -72.2 & 295 \\
\hline OLMWBT34C & 298 & 295 & 72 & 29.7 & 13.3 & -61.1 & 297 \\
\hline \multicolumn{8}{|c|}{ CASE- 3} \\
\hline OLMWBT35B & 300 & 295 & 90 & 130.9 & 132.4 & 99.6 & 279 \\
\hline OLMWBT36C & 300 & 295 & 90 & 122.5 & 121.3 & 100.6 & 281 \\
\hline OLMWBT37B & 300 & 295 & 90 & 114.6 & 116.7 & 54.8 & 283 \\
\hline OLMWBT38B & 300 & 295 & 90 & 116.1 & 109.4 & 60.9 & 285 \\
\hline OLMWBT39B & 300 & 295 & 90 & 115.8 & 115.1 & 50.5 & 287 \\
\hline OLMWBT40C & 300 & 295 & 90 & 99.6 & 91.7 & 53.5 & 289 \\
\hline OLMWBT41B & 300 & 295 & 90 & 75.0 & 73.9 & 42.4 & 291 \\
\hline OLMWBT42C & 300 & 295 & 90 & 46.6 & 50.5 & 33.2 & 293 \\
\hline OLMWBT43 & 300 & 295 & 90 & 22.2 & 28.0 & 31.2 & 295 \\
\hline OLMWBT44 & 300 & 295 & 90 & 4.8 & 9.6 & 31.2 & 297 \\
\hline
\end{tabular}




\begin{tabular}{|c|c|c|c|c|c|c|c|}
\hline \multicolumn{8}{|c|}{ Table 4 (Continued) } \\
\hline \multirow[b]{2}{*}{ File Name } & \multirow{2}{*}{$\begin{array}{l}\text { Up- } \\
\text { stream } \\
\text { Pool, ft }\end{array}$} & \multirow{2}{*}{$\begin{array}{l}\text { Down- } \\
\text { stream } \\
\text { Pool, } \mathrm{ft}\end{array}$} & \multirow{2}{*}{$\begin{array}{l}\text { Gate } \\
\text { Angle, } \\
\text { deg }\end{array}$} & \multicolumn{2}{|c|}{ Max. Point Forces } & \multirow{2}{*}{$\begin{array}{l}\text { Actuator } \\
\text { Max. Force, } \\
\text { Ibf }\end{array}$} & \multirow{2}{*}{$\begin{array}{l}\text { Gate } \\
\text { Elevation, } \mathrm{ft}\end{array}$} \\
\hline & & & & Left, lbf & Right, Ibf & & \\
\hline \multicolumn{8}{|c|}{ CASE- 4} \\
\hline OLMWBT45 & 300 & 295 & 65 & 197.0 & 168.3 & 138.8 & 279 \\
\hline OLMWBT46B & 300 & 295 & 65 & 184.2 & 157.8 & 32.2 & 281 \\
\hline OLMWBT47 & 300 & 295 & 65 & 175.2 & 144.9 & -26.6 & 283 \\
\hline OLMWBT48C & 300 & 295 & 65 & 158.4 & 128.0 & -59.1 & 285 \\
\hline OLMWBT49 & 300 & 295 & 65 & 141.9 & 106.6 & -91.6 & 287 \\
\hline OLMWBT50C & 300 & 295 & 65 & 124.0 & 93.4 & $\mid-108.6$ & 289 \\
\hline OLMWBT51 & 300 & 295 & 65 & 106.8 & 67.2 & -130.9 & 291 \\
\hline OLMWBT52 & 300 & 295 & 66.3 & 82.8 & 57.6 & -122.8 & 293 \\
\hline OLMWBT53C & 300 & 295 & 69.2 & 57.3 & 44.1 & -96.4 & 295 \\
\hline OLMWBT54B & 300 & 295 & 72.3 & 32.3 & 25.2 & -76.1 & 297 \\
\hline \multicolumn{8}{|c|}{ CASE- 5} \\
\hline OLMWBT55C & 301 & 294 & 90 & 186.0 & 172.8 & 145.2 & 279 \\
\hline OLMWBT56 & 301 & 294 & 90 & 162.8 & 165.5 & 124.9 & 281 \\
\hline OLMWBT57 & 301 & 294 & 90 & 161.1 & 159.4 & 98.5 & 283 \\
\hline OLMWBT58 & 301 & 294 & 90 & 156.7 & 151.2 & 89.4 & 285 \\
\hline OLMWBT59C & 301 & 294 & 90 & 147.4 & 135.2 & 89.4 & 287 \\
\hline OLMWBT60 & 301 & 294 & 90 & 130.9 & 113.3 & 57.9 & 289 \\
\hline OLMWBT61B & 301 & 294 & 90 & 98.1 & 86.7 & 34.6 & 291 \\
\hline OLMWBT62C & 301 & 294 & 90 & 59.0 & 65.1 & 27.5 & 293 \\
\hline OLMWBT63C & 301 & 294 & 90 & 30.6 & 30.7 & 12.2 & 295 \\
\hline OLMWBT64C & 301 & 294 & 90 & 12.9 & 8.3 & 18.3 & 297 \\
\hline \multicolumn{8}{|c|}{ CASE- 6} \\
\hline OLMWBT65 & 301 & 294 & 65 & 278.8 & 241.7 & 193.0 & 279 \\
\hline OLMWBT66B & 301 & 294 & 65 & 262.3 & 206.7 & 2.9 & 281 \\
\hline OLMWBT67 & 301 & 294 & 65 & 235.6 & 169.0 & -56.8 & 283 \\
\hline OLMWBT68 & 301 & 294 & 65 & 212.9 & 120.8 & -127.9 & 285 \\
\hline OLMWBT69 & 301 & 294 & 65 & 190.3 & 88.7 & -183.7 & 287 \\
\hline OLMWBT70B & 301 & 294 & 65 & 170.5 & 129.6 & -117.7 & 289 \\
\hline OLMWBT71 & 301 & 294 & 65 & 147.9 & 132.2 & -82.2 & 291 \\
\hline OLMWBT72 & 301 & 294 & 66.4 & 113.3 & 84.3 & -114.7 & 293 \\
\hline OLMWBT73B & 301 & 294 & 69.2 & 78.8 & 52.8 & -91.3 & 295 \\
\hline OLMWBT74C & 301 & 294 & 72.4 & 51.5 & 30.9 & -79.1 & 297 \\
\hline
\end{tabular}




\begin{tabular}{|c|c|c|c|c|c|c|c|}
\hline \multicolumn{8}{|c|}{ Table 4 (Concluded) } \\
\hline \multirow[b]{2}{*}{ File Name } & \multirow{2}{*}{$\begin{array}{l}\text { Up- } \\
\text { stream } \\
\text { Pool, ft }\end{array}$} & \multirow{2}{*}{$\begin{array}{l}\text { Down- } \\
\text { stream } \\
\text { Pool, ft }\end{array}$} & \multirow{2}{*}{$\begin{array}{l}\text { Gate } \\
\text { Angle, } \\
\text { deg }\end{array}$} & \multicolumn{2}{|c|}{ Max. Point Forces } & \multirow{2}{*}{$\begin{array}{l}\text { Actuator } \\
\text { Max. Force, } \\
\text { Ibf }\end{array}$} & \multirow[b]{2}{*}{$\begin{array}{l}\text { Gate } \\
\text { Elevation, ft }\end{array}$} \\
\hline & & & & Left, Ibf & Right, Ibf & & \\
\hline \multicolumn{8}{|c|}{ C ASE- 7} \\
\hline OLMWBT75C & 301 & 291 & 65 & 322.7 & 317.1 & 301.6 & 279 \\
\hline OLMWBT76 & 301 & 291 & 65 & 325.3 & 255.1 & -7.0 & 281 \\
\hline OLMWBT77B & 301 & 291 & 65 & 290.4 & 236.5 & -82.2 & 283 \\
\hline OLMWBT78B & 301 & 291 & 65 & 257.9 & 187.1 & -84.2 & 285 \\
\hline OLMWBT79C & 301 & 291 & 65 & 244.8 & 227.3 & 27.6 & 287 \\
\hline OLMWBT80B & 301 & 291 & 65 & 198.9 & 176.1 & -24.2 & 289 \\
\hline OLMWBT81C & 301 & 291 & 65 & 147.7 & 88.0 & -151.3 & 291 \\
\hline OLMWBT82B & 301 & 291 & 66.4 & 107.2 & 50.9 & -122.8 & 293 \\
\hline OLMWBT83D & 301 & 291 & 69.2 & 66.8 & 38.6 & -86.2 & 295 \\
\hline OLMWBT84 & 301 & 291 & 72.3 & 40.7 & 41.5 & -41.5 & 297 \\
\hline \multicolumn{8}{|c|}{ CASE- 8} \\
\hline OLMWBT85C & 301 & 291 & 90 & 263.5 & 238.6 & 168.5 & 279 \\
\hline OLMWBT86B & 301 & 291 & 90 & 249.9 & 233.6 & 144.1 & 281 \\
\hline OLMWBT87 & 301 & 291 & 90 & 233.7 & 227.8 & 118.7 & 283 \\
\hline OLMWBT88B & 301 & 291 & 90 & 217.2 & 234.5 & 91.3 & 285 \\
\hline OLMWBT89D & 301 & 291 & 90 & 198.0 & 181.1 & 65.9 & 287 \\
\hline OLMWBT9OC & 301 & 291 & 90 & 165.0 & 148.4 & 15.1 & 289 \\
\hline OLMWBT91C & 301 & 291 & 90 & 109.0 & 107.5 & 18.1 & 291 \\
\hline OLMWBT92C & 301 & 291 & 90 & 66.4 & 76.3 & -7.3 & 293 \\
\hline OLMWBT93 & 301 & 291 & 90 & 36.8 & 48.3 & -8.3 & 295 \\
\hline OLMWBT94B & 301 & 291 & 90 & 19.2 & 23.7 & -1.2 & 297 \\
\hline
\end{tabular}




\section{Observations and Conclusions}

The overall width of the wicket blank was increased from $10 \mathrm{ft}, 11 \mathrm{in}$. to $11 \mathrm{ft}, 6.5 \mathrm{in}$. This modification to the blank design was necessary to ensure adequate contact area between both edges of the wicket blank and the adjacent wicket gates.

No significant operational problems were discovered during this investigation. The wicket blank and the proposed installation and removal procedures proved to be adequate. The experimental results for various blank operations are presented in this document.

It should again be noted that because of differences between the hydraulically operated wickets reproduced in the model and the proposed horse wicket design, the insertion depth of the wicket blank will be greater in the field. The model simulated an insertion depth to el 279.0, and the proposed insertion depth is at el 275.85. The primary difference will be additional hydrostatic forces that were not simulated in the model below el 279.0. With this in mind, the results of this model investigation can be used to design necessary equipment and appurtenances for wicket blank operations in the field. 


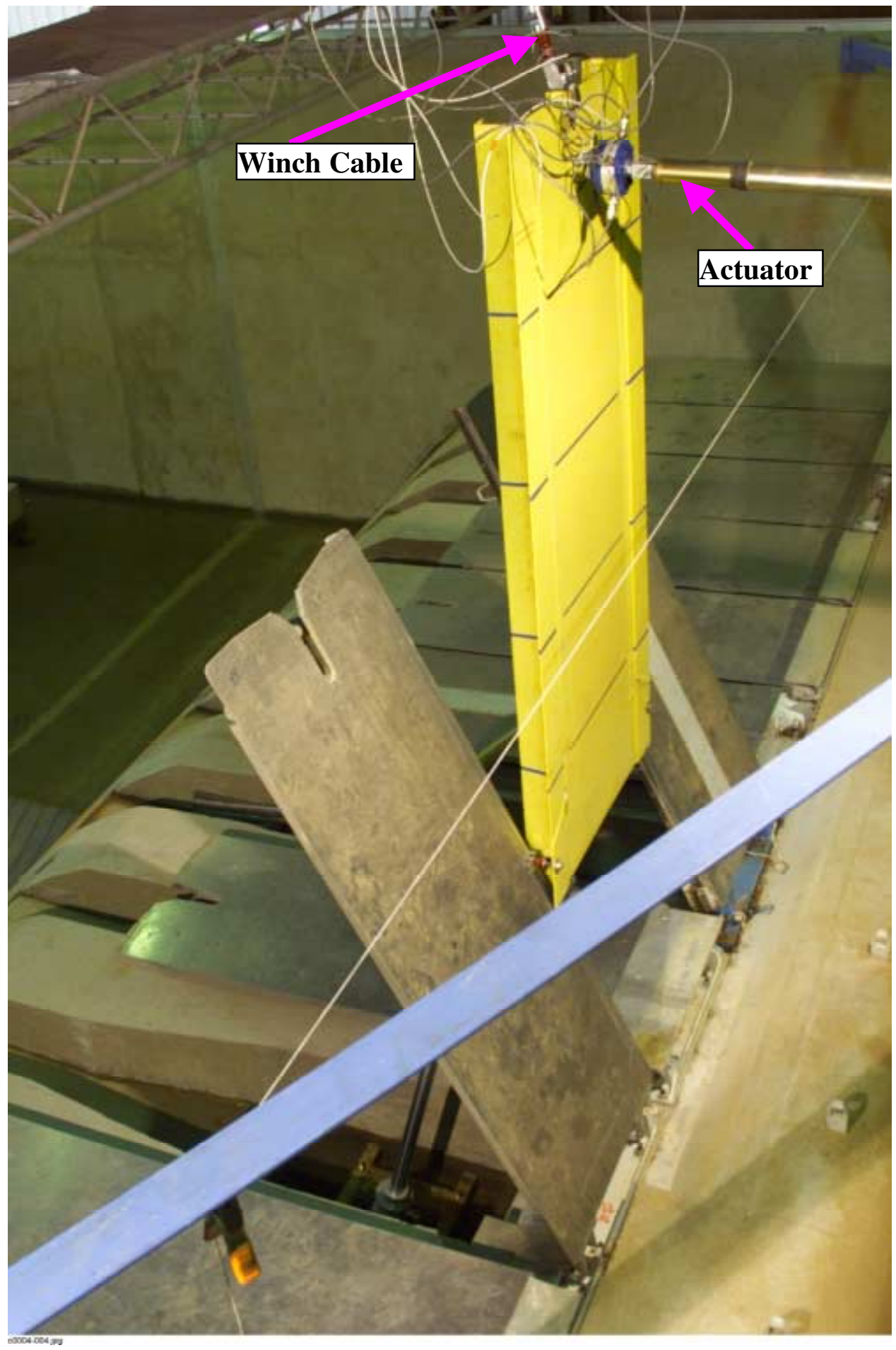

Figure 1. View from the walk, looking downstream at the wicket blank and wicket gates \#4, \#5, and \#6. The bottom of the blank is at el 287 and at an angle of 90 deg. Dry bed photo 


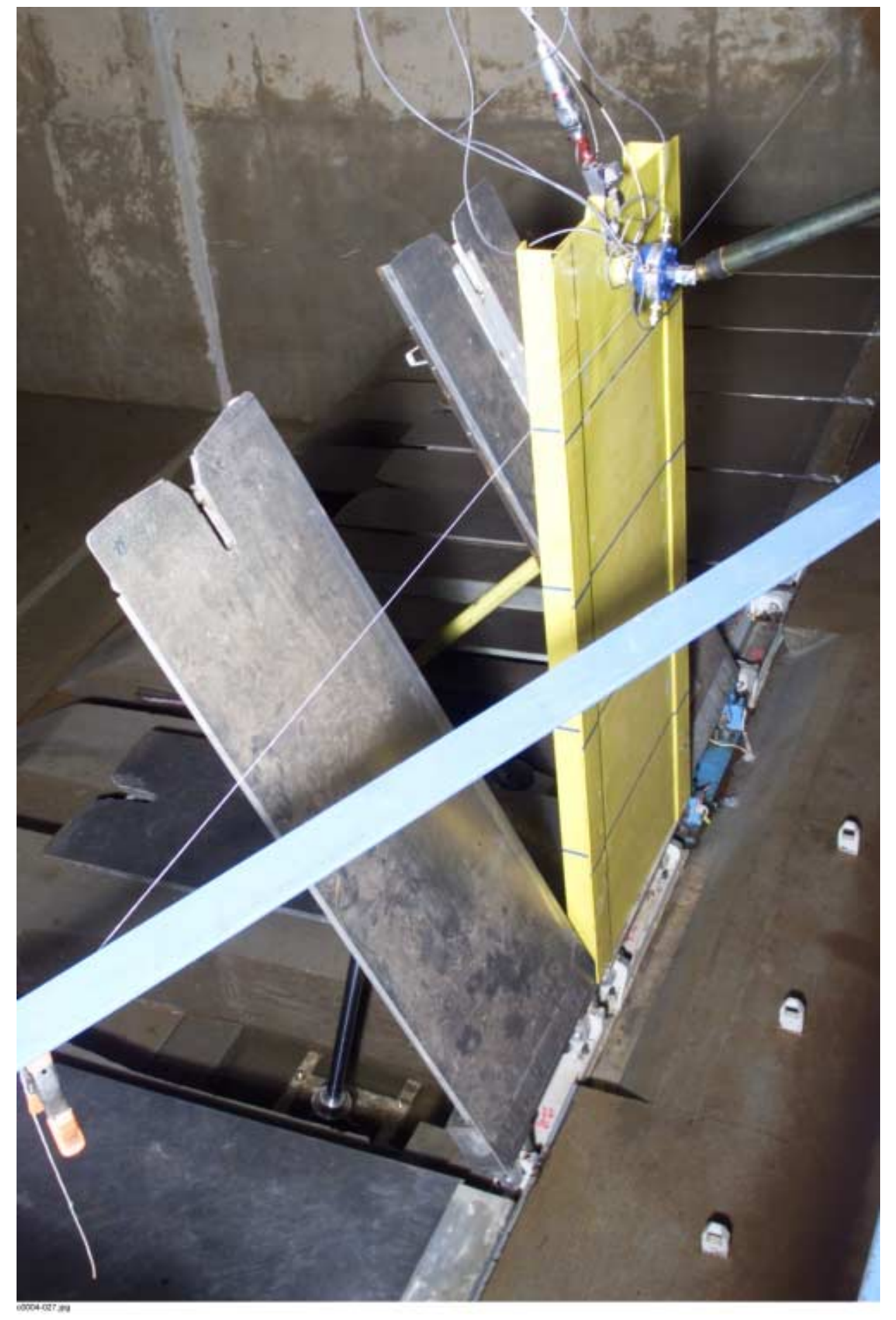

Figure 2. View from the walk, looking downstream at the blank seated on wicket gate \#5 at an angle of 90 deg. Dry bed photograph 


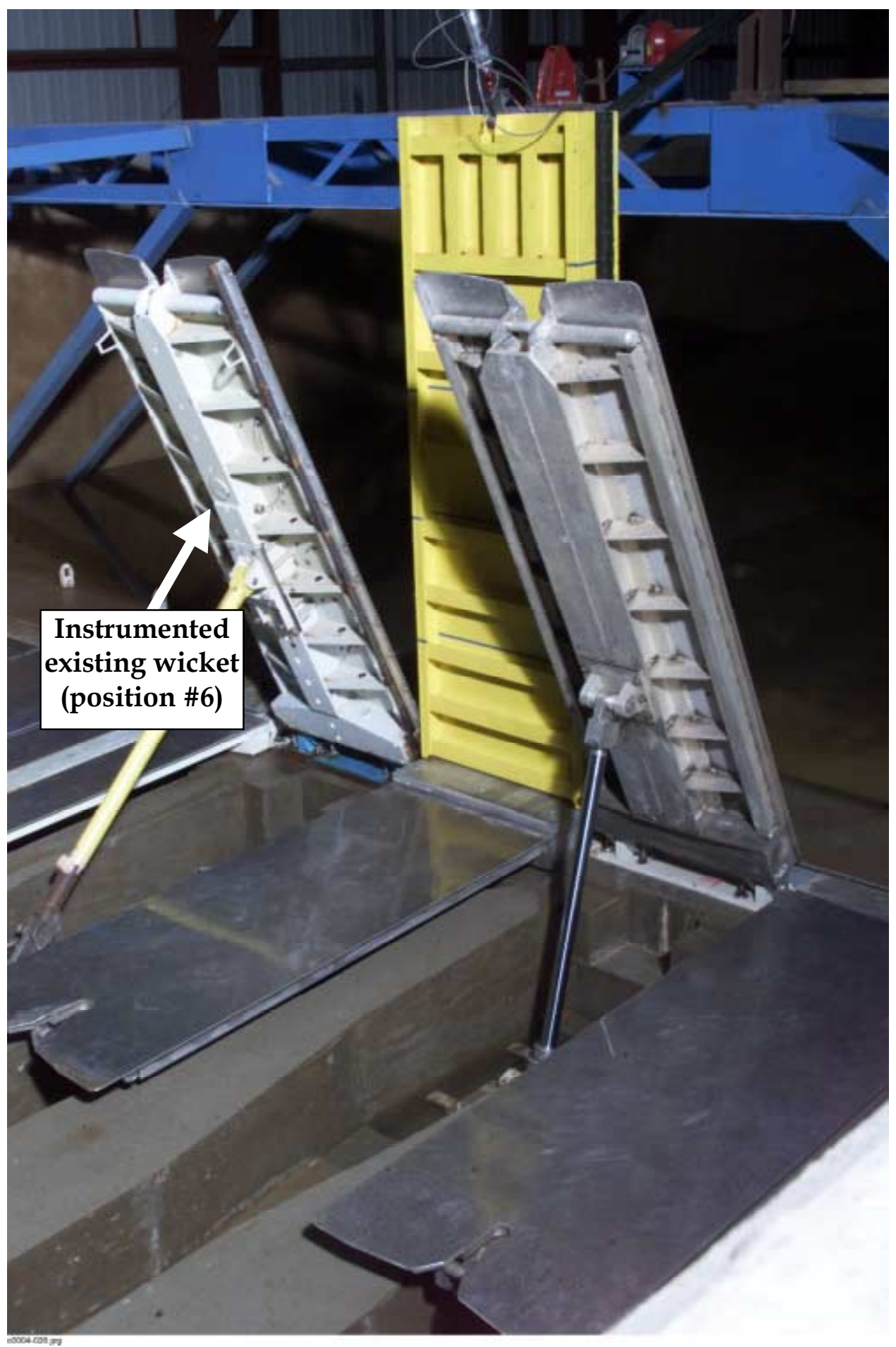

Figure 3. View from the walk, looking upstream at the blank seated on wicket gate \#5 at an angle of $90 \mathrm{deg}$. Dry bed photograph 


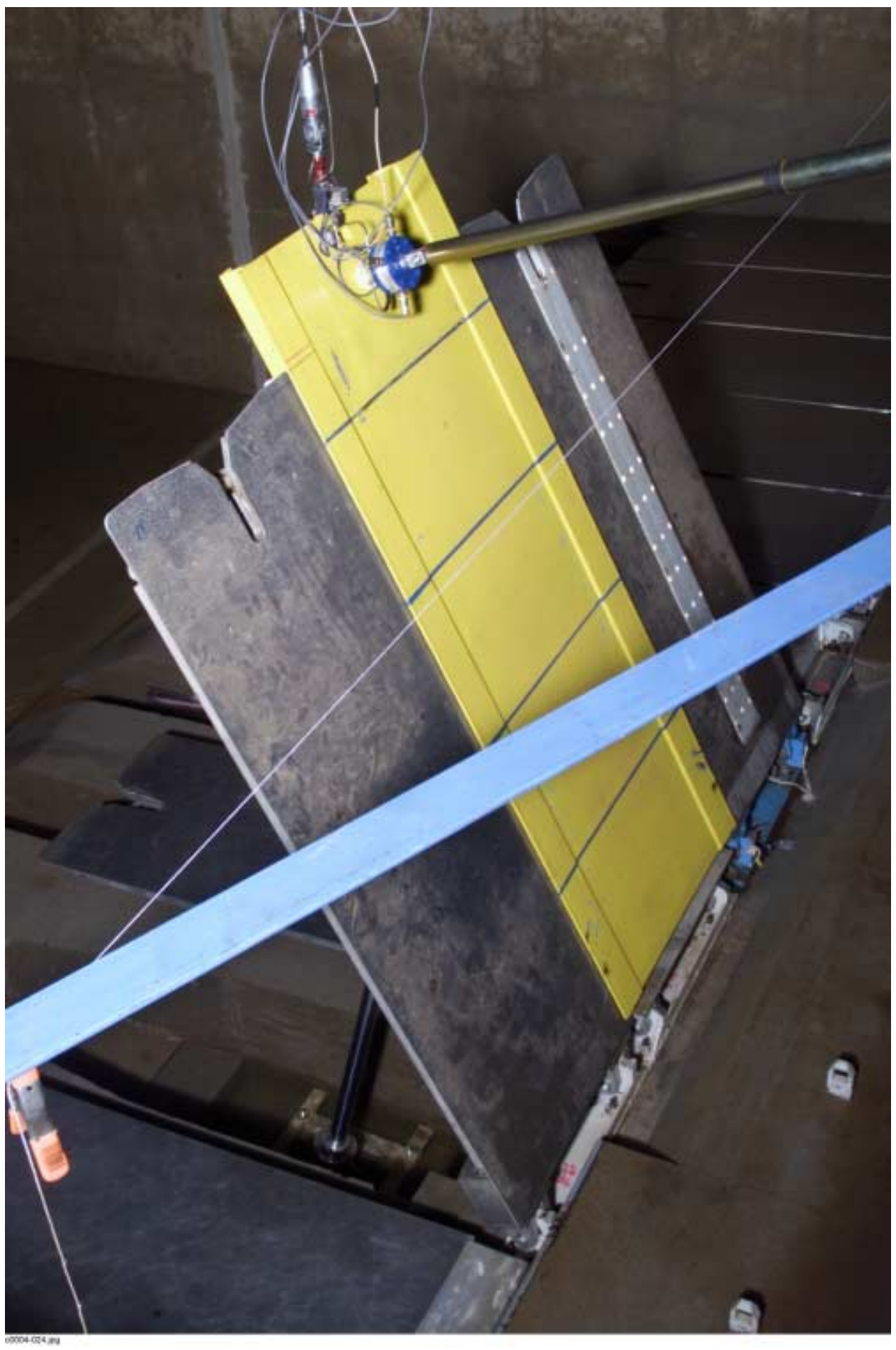

Figure 4. View from the walk, looking downstream at the blank seated on wicket gate \#5 at an angle of 65 deg. Dry bed photograph 


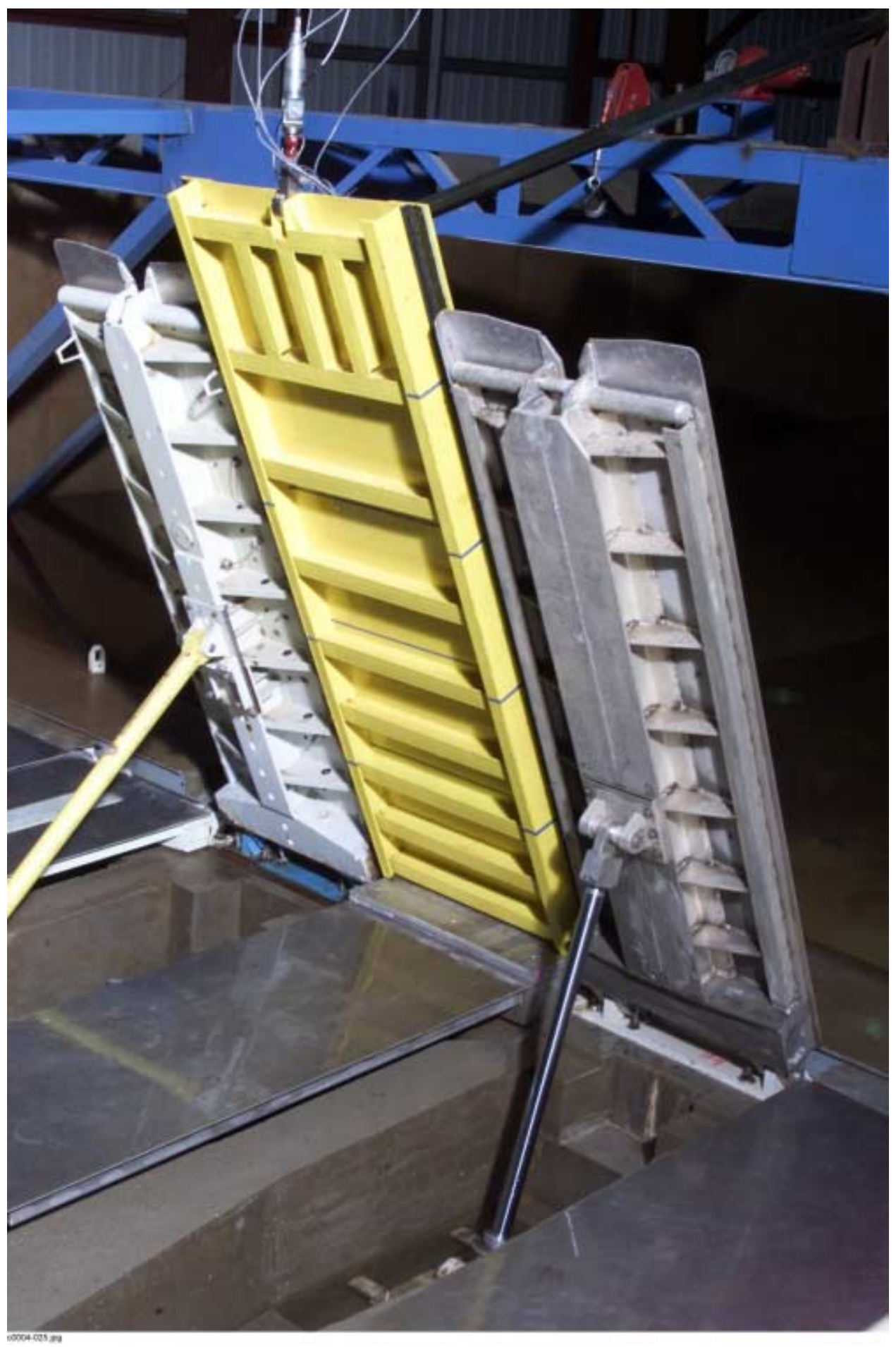

Figure 5. View from the walk, looking upstream at the blank seated on wicket gate \#5 at an angle of 65 deg. Dry bed photograph 
Part C; Blank installation; cylinder disconnected:

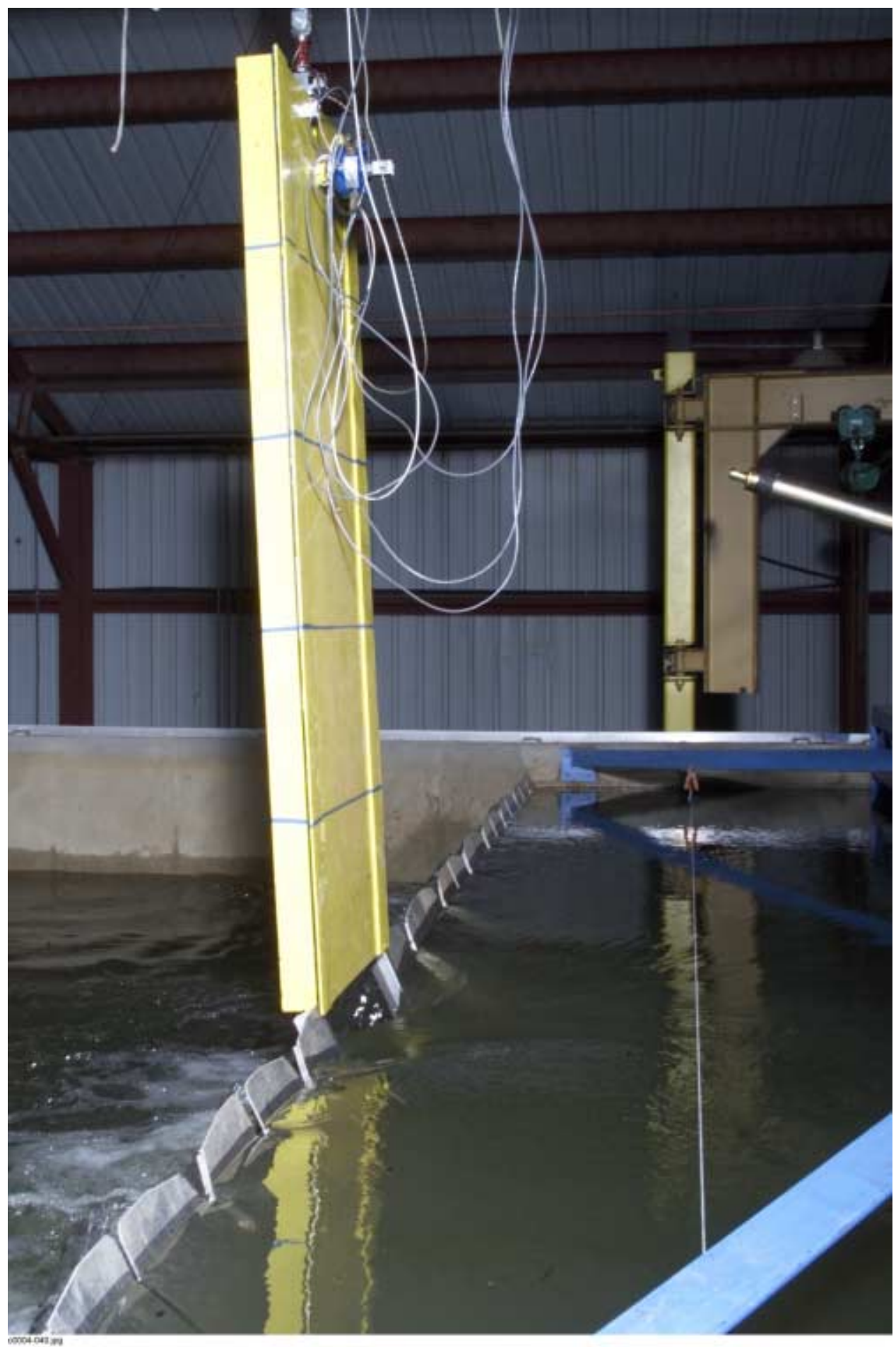

Figure 6. View from the walk, looking downstream at the blank in the raised position for installation. The blank has been weighted with $68.32 \mathrm{lb}$ of lead positioned in the upper three channels. Headwater 301 ; Tailwater 294; 7-ft differential 


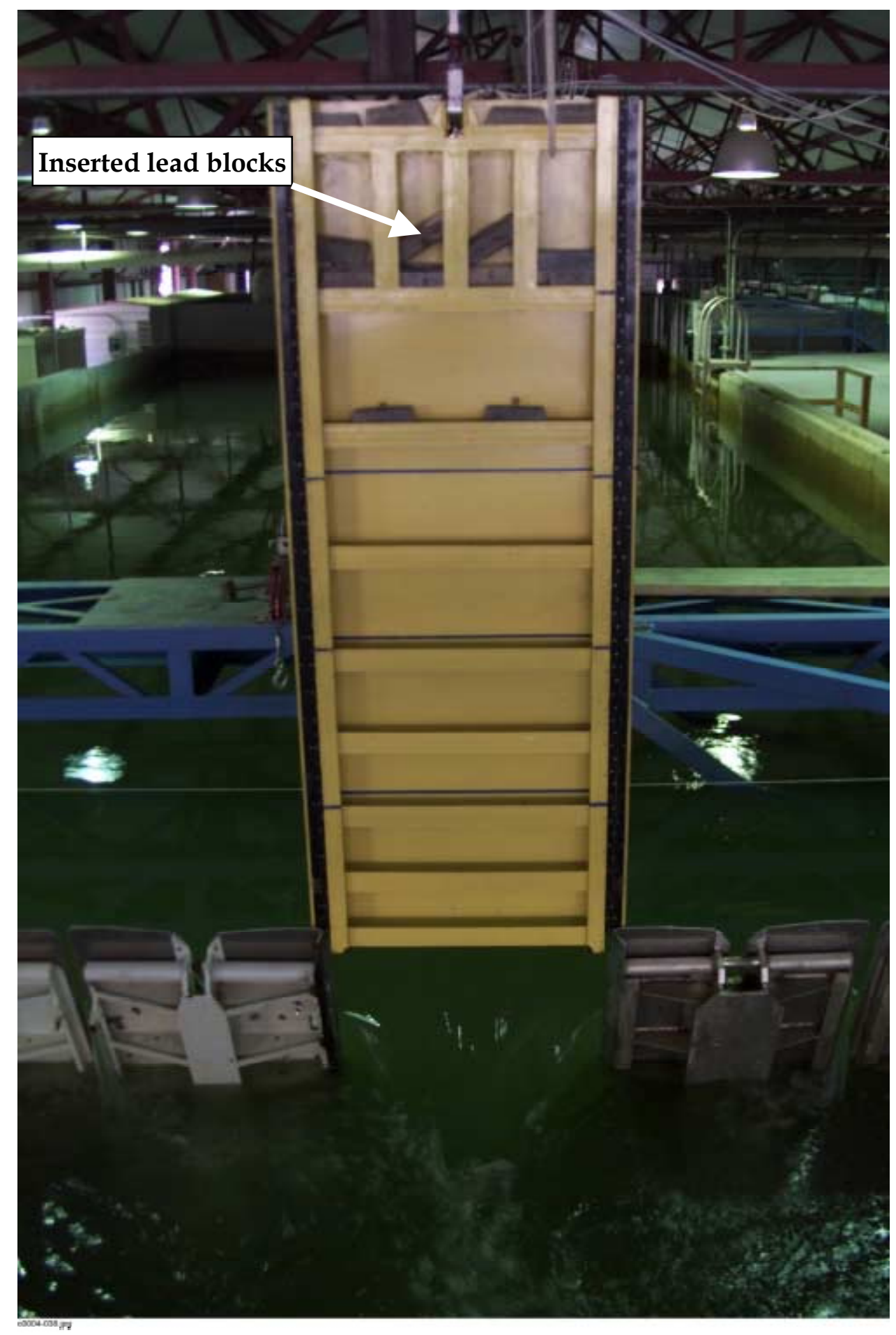

Figure 7. View from the catwalk, looking upstream at the blank in the raised position for installation. The blank has been weighted with $68.32 \mathrm{lb}$ of lead positioned in the upper three channels. Headwater 301; Tailwater 294; 7-ft differential 


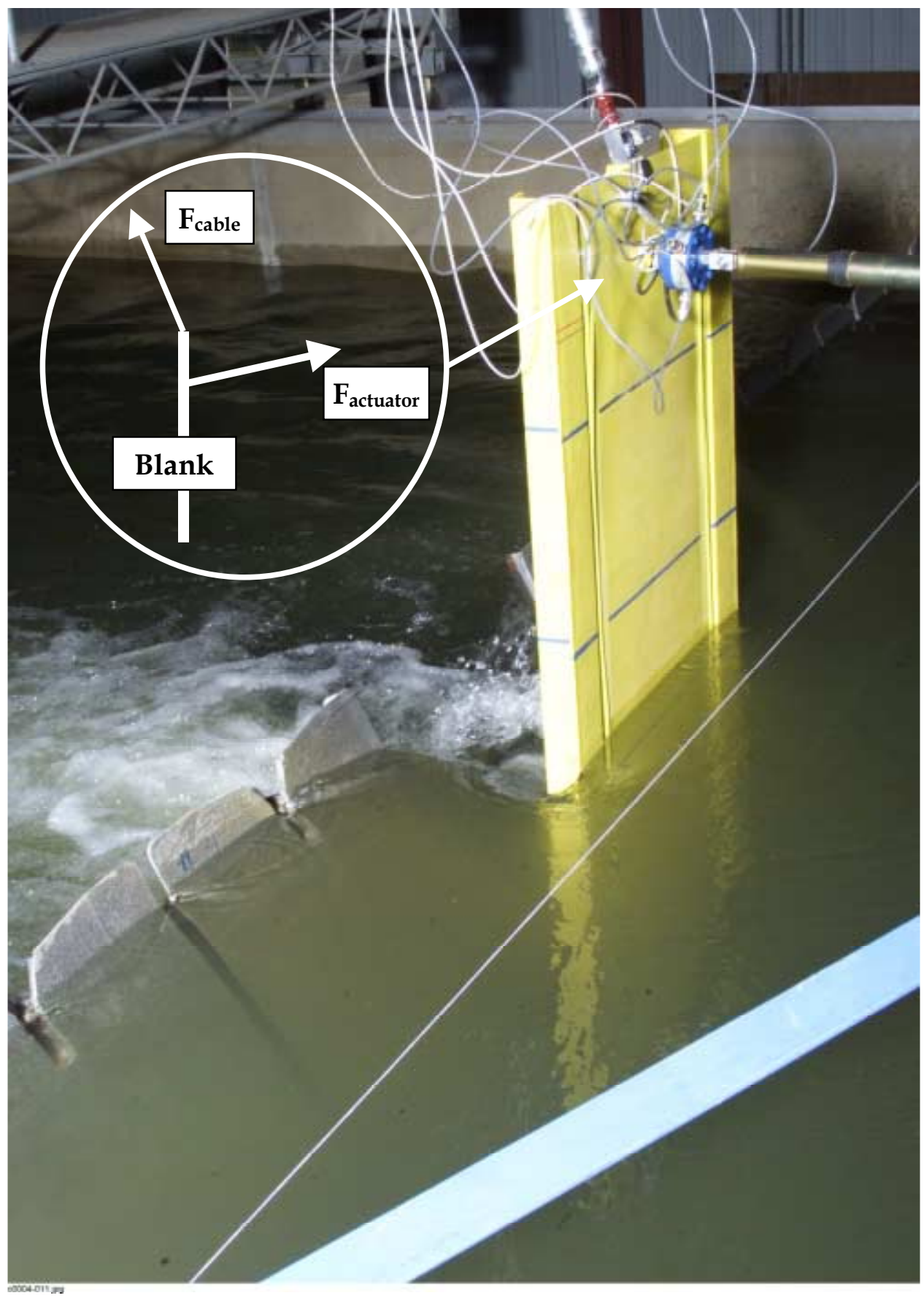

Figure 8. View from the walk, looking downstream at the blank at el 287 and an angle of 90 deg. Headwater 301, Tailwater 294; 7-ft differential 


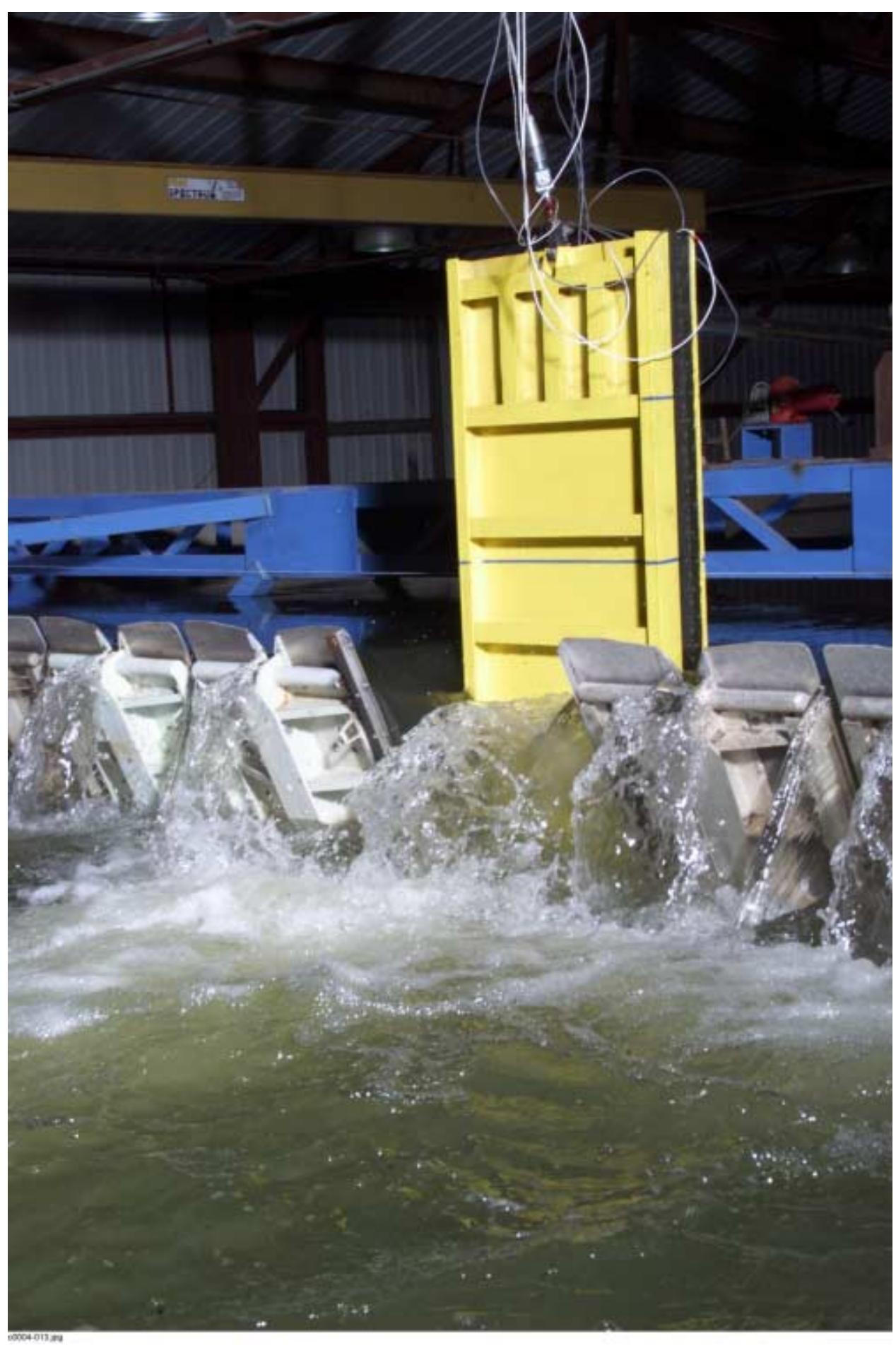

Figure 9. View from the walk, looking upstream at the blank at el 287 and an angle of 90 deg. Headwater 301, Tailwater 294; 7-ft differential 


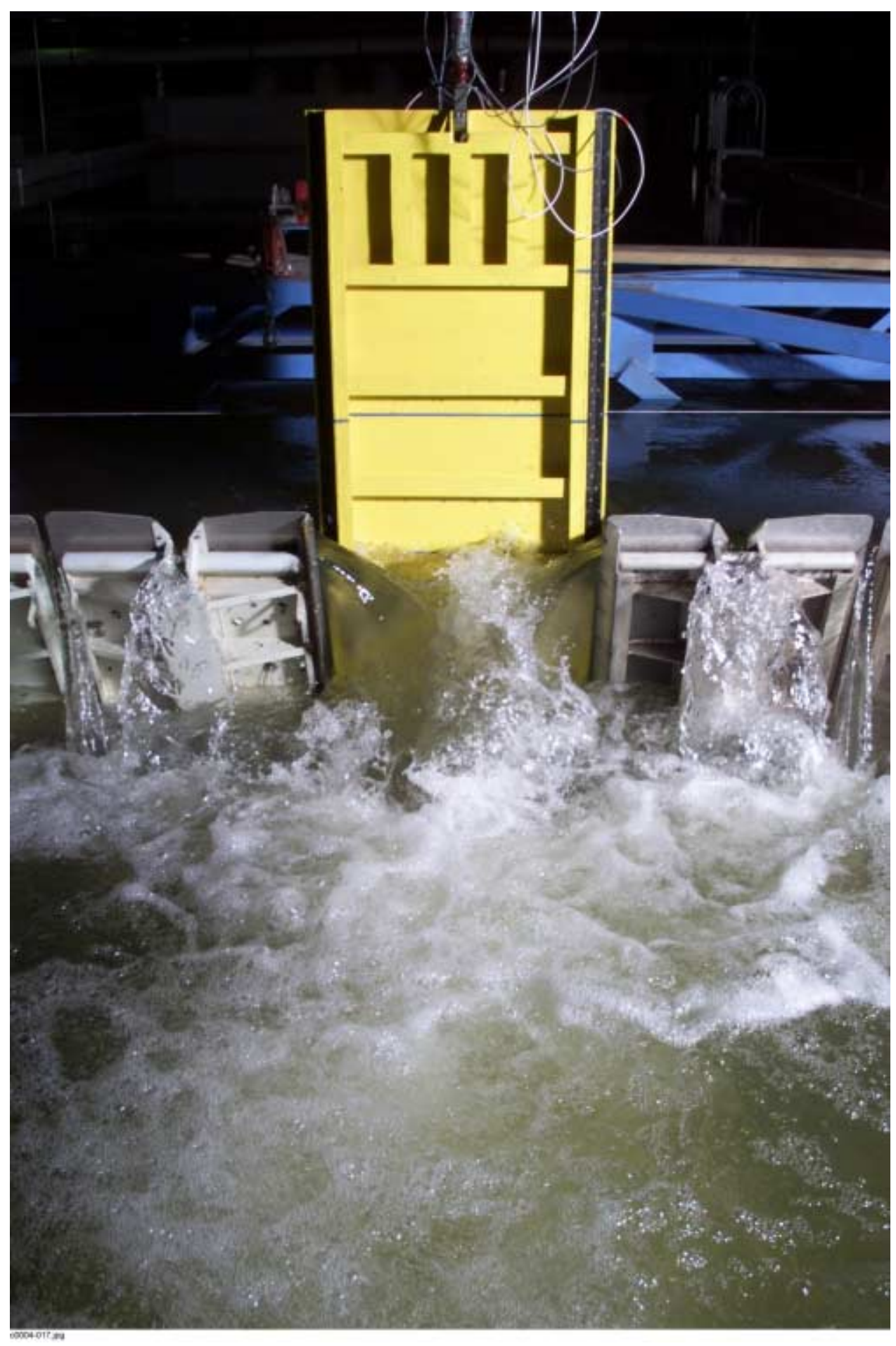

Figure 10. View from the catwalk, looking upstream at the blank at el 287 and an angle of 90 deg. Headwater 301, Tailwater 294; 7-ft differential 


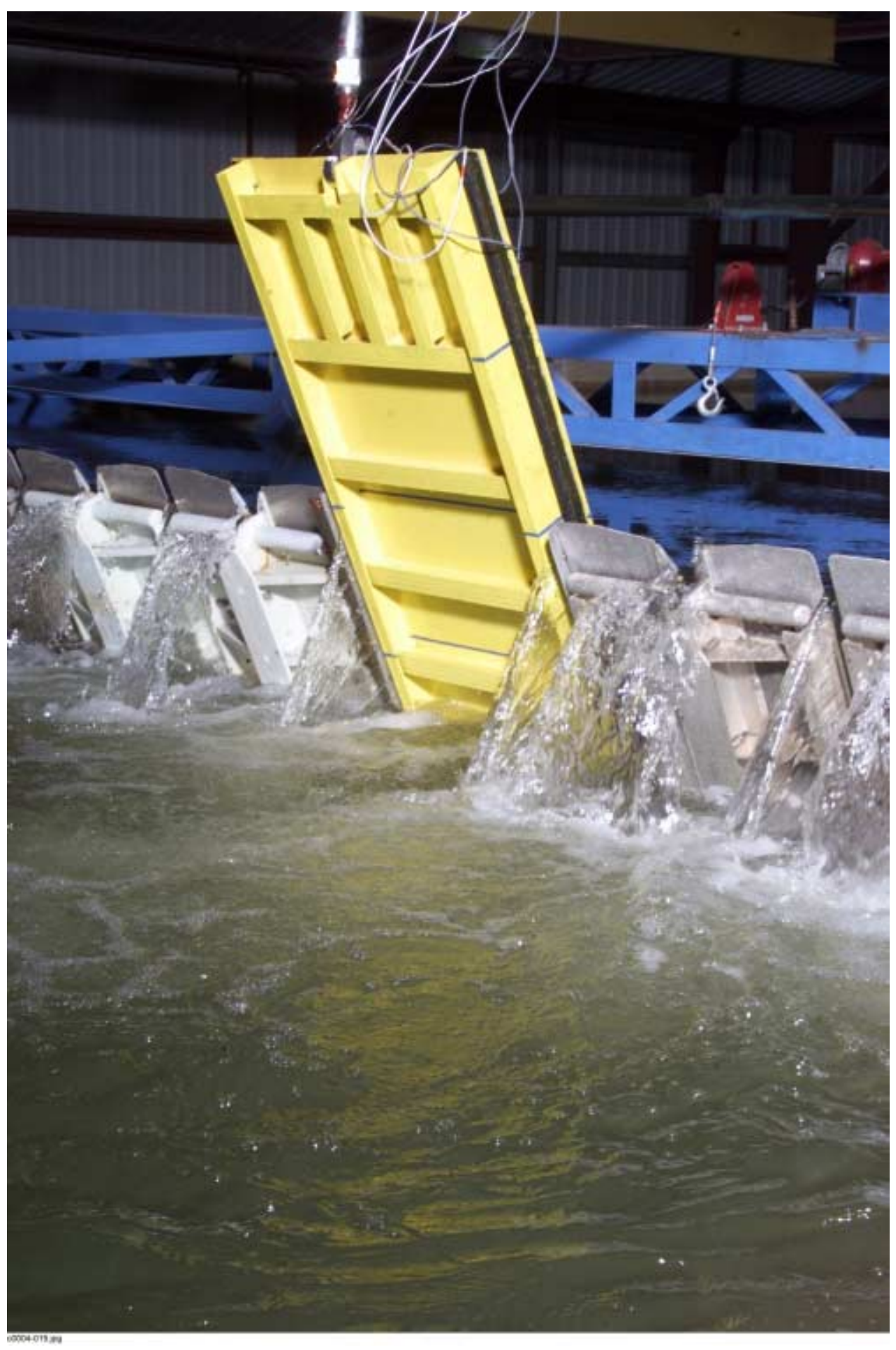

Figure 11. View from the walk, looking upstream at the blank at el 287 and an angle of 65 deg. Headwater 301, Tailwater 294; 7-ft differential 


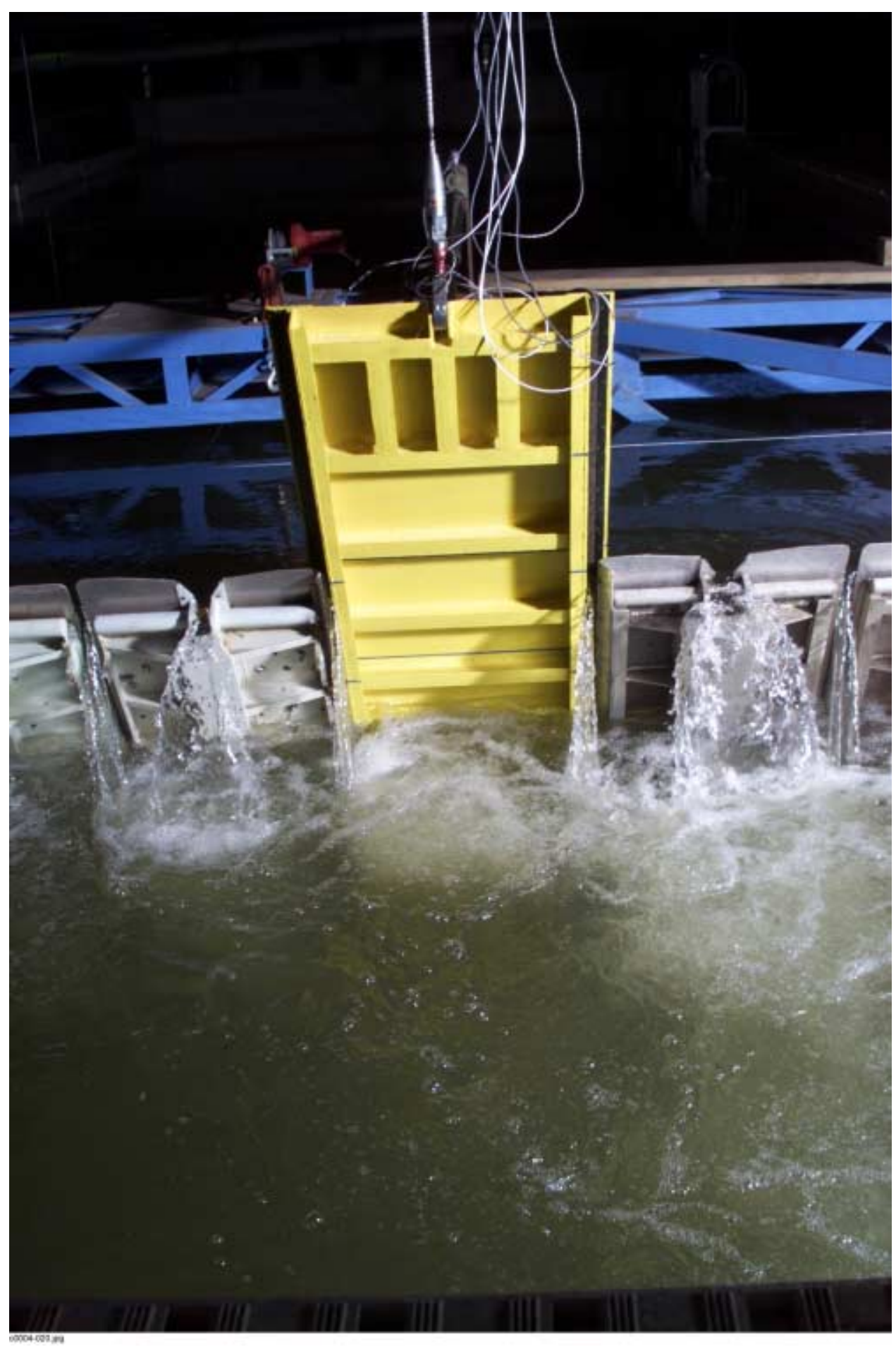

Figure 12. View from the catwalk, looking upstream at the blank at el 287 and an angle of 65 deg. Headwater 301, Tailwater 294; 7-ft differential 


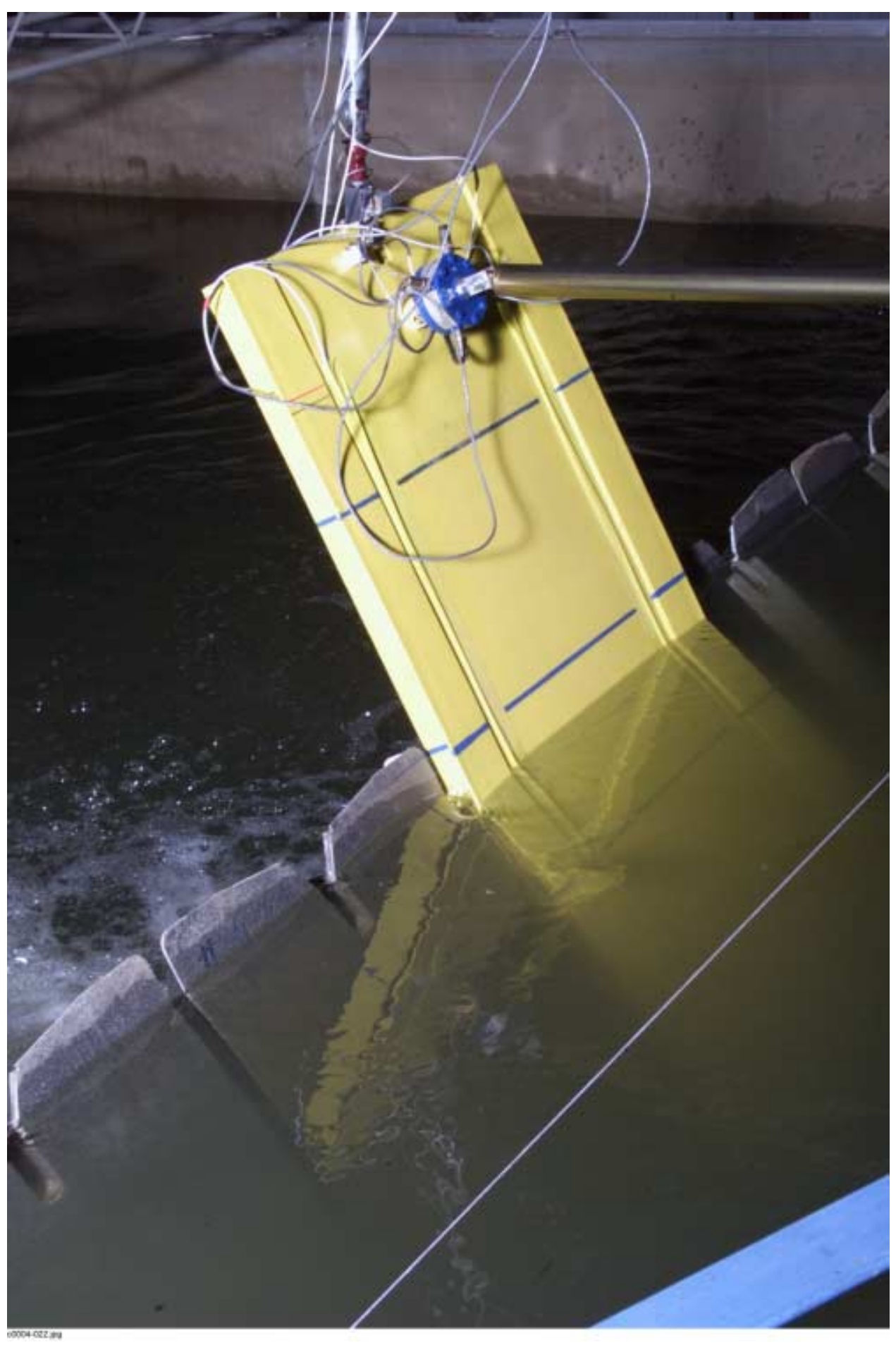

Figure 13. View from the walk, looking downstream at the blank at el 287 and an angle of 65 deg. Headwater 301, Tailwater 294; 7-ft differential 


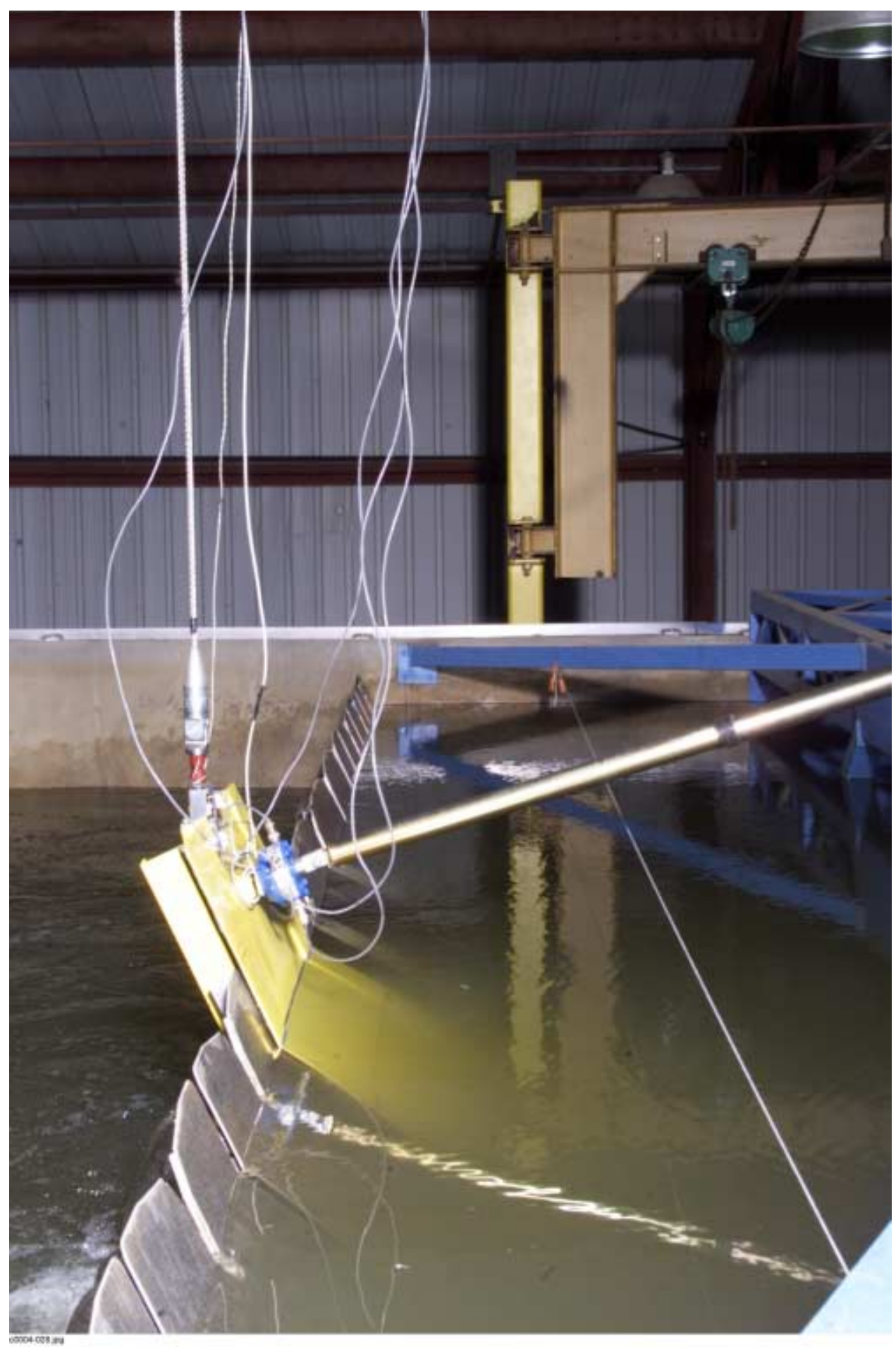

Figure 14. View of the blank, seated on wicket gate \#5 at an angle of $65 \mathrm{deg}$, prior to removal. Headwater 300; Tailwater 295; 5-ft differential 


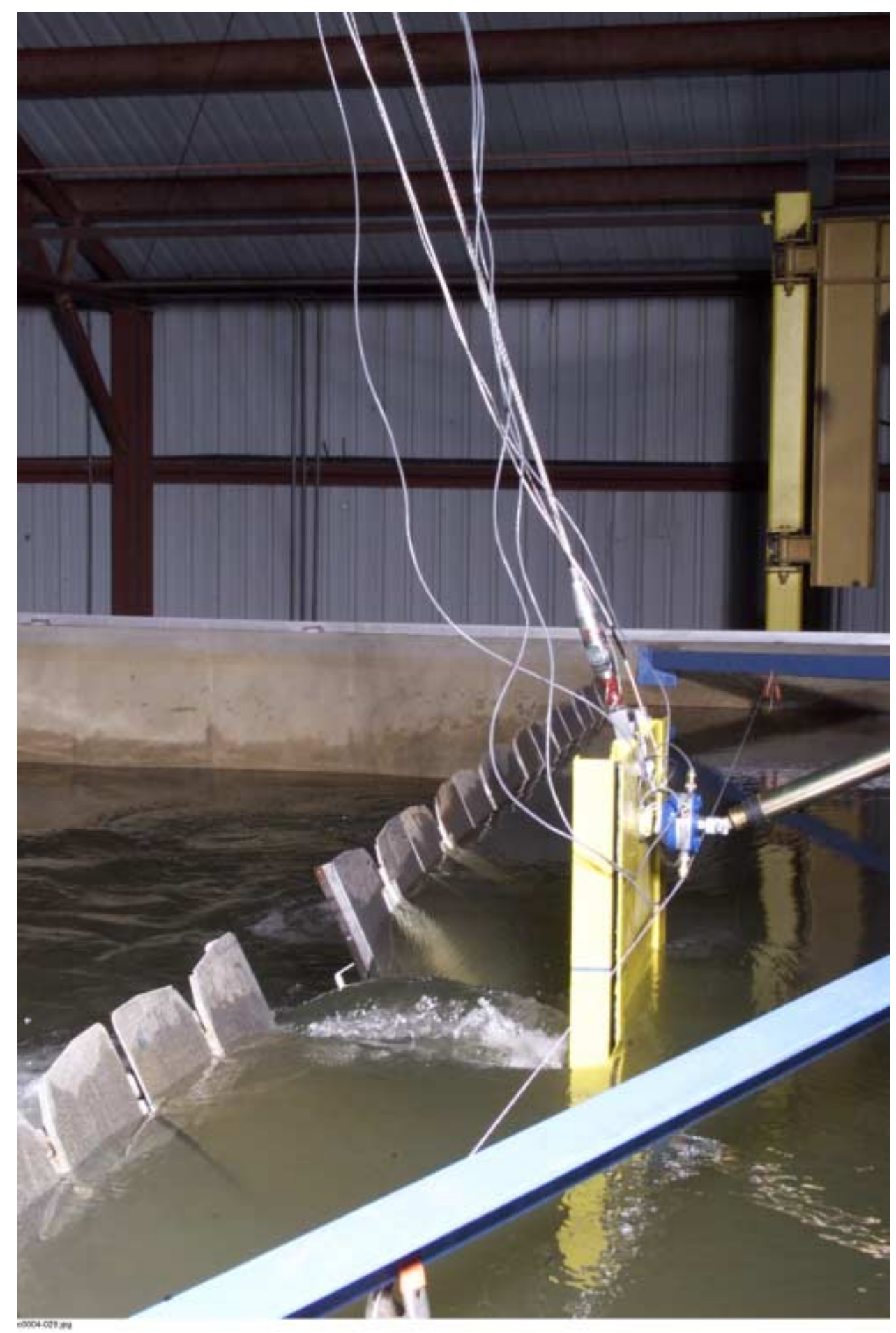

Figure 15. View of the blank, at a 90-deg angle, in the process of being removed. Headwater 300; Tailwater 295; 5-ft differential 


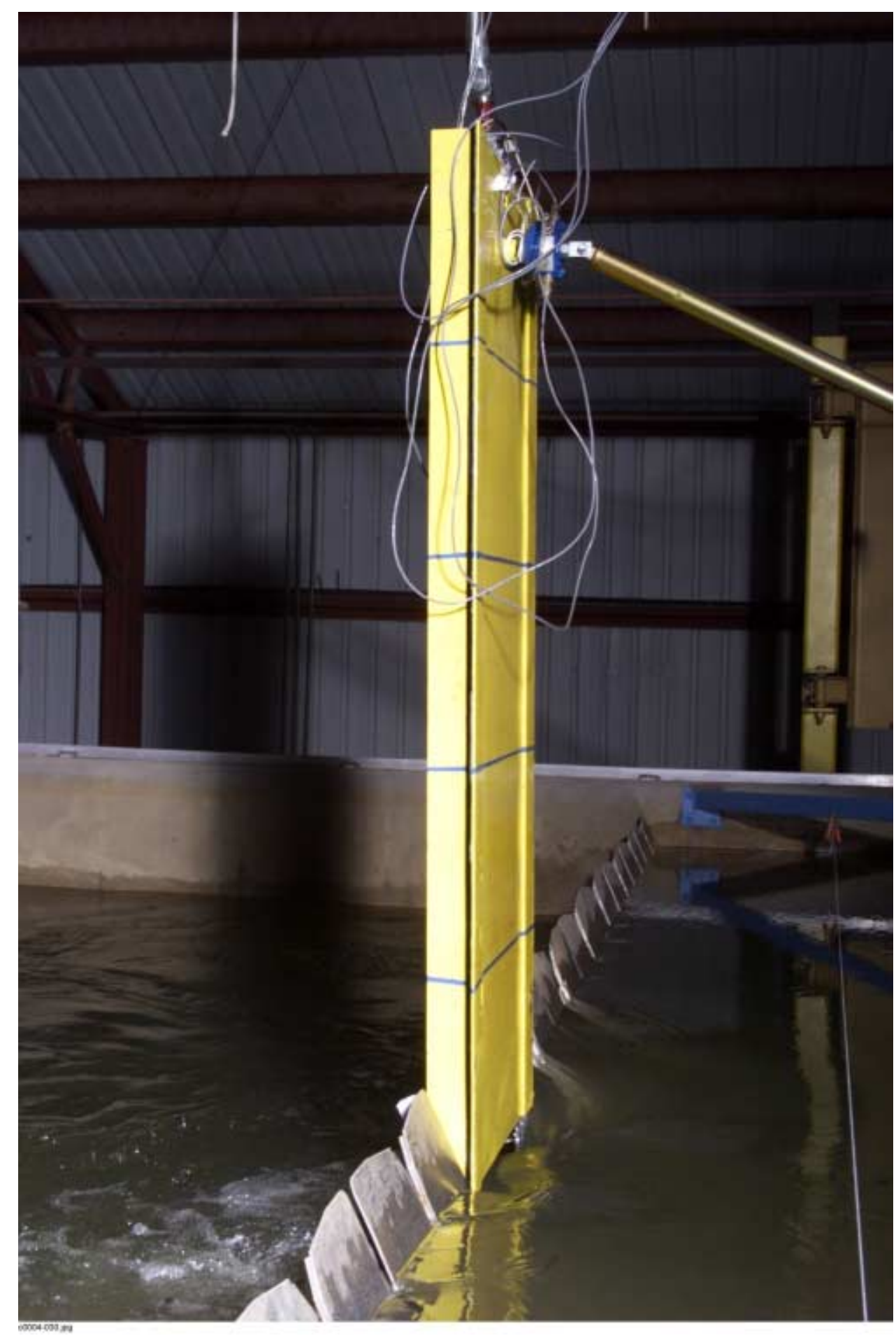

Figure 16. View from the walk as the bottom of the blank clears the water surface during the removal process. Headwater 300; Tailwater 295; 5 -ft differential 
Part C; Blank removal; cylinder disconnected:

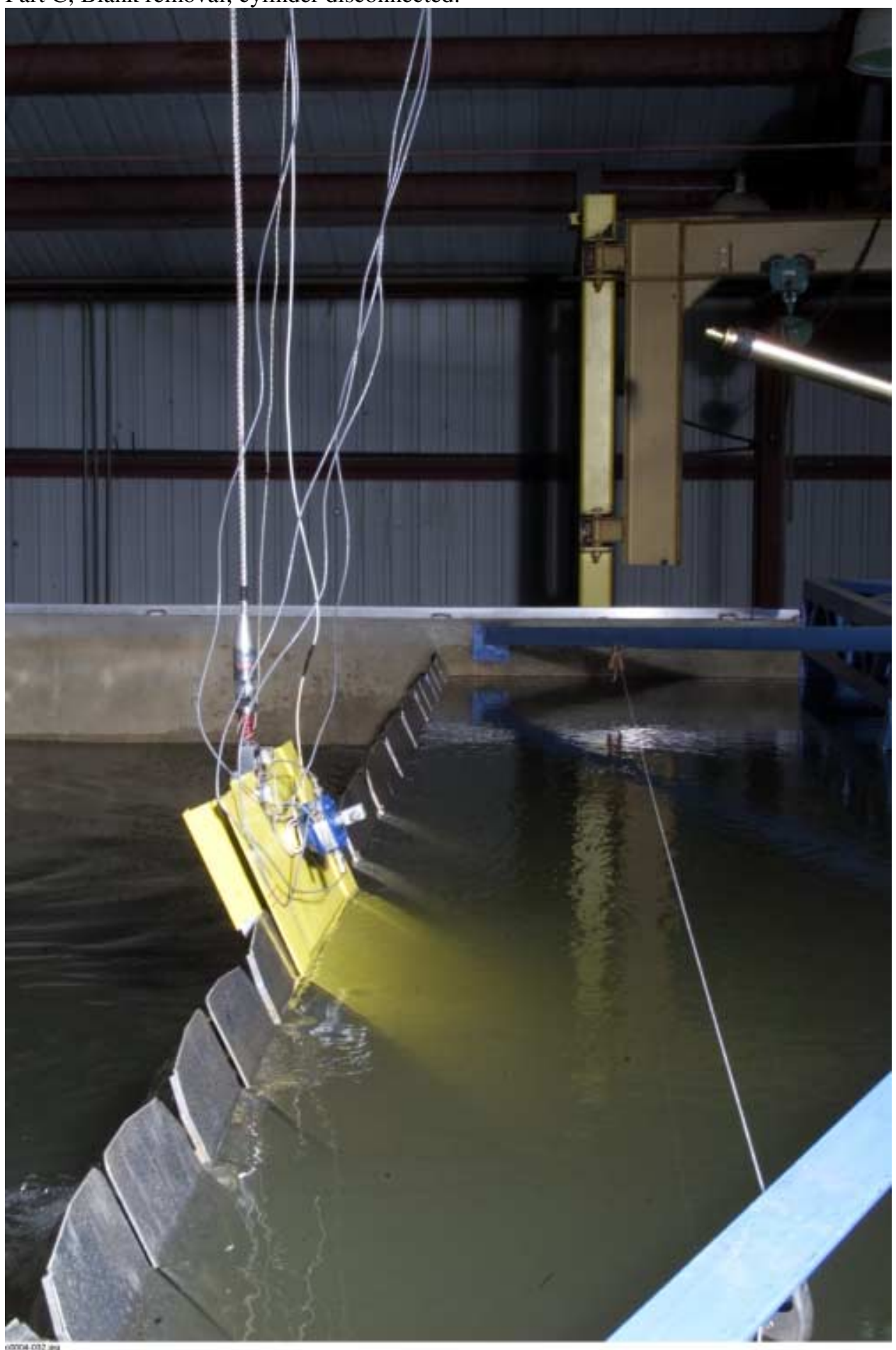

Figure 17. View of the blank, seated on wicket gate \#5 at an angle of $65 \mathrm{deg}$, prior to removal. Headwater 300; Tailwater 295; 5-ft differential 


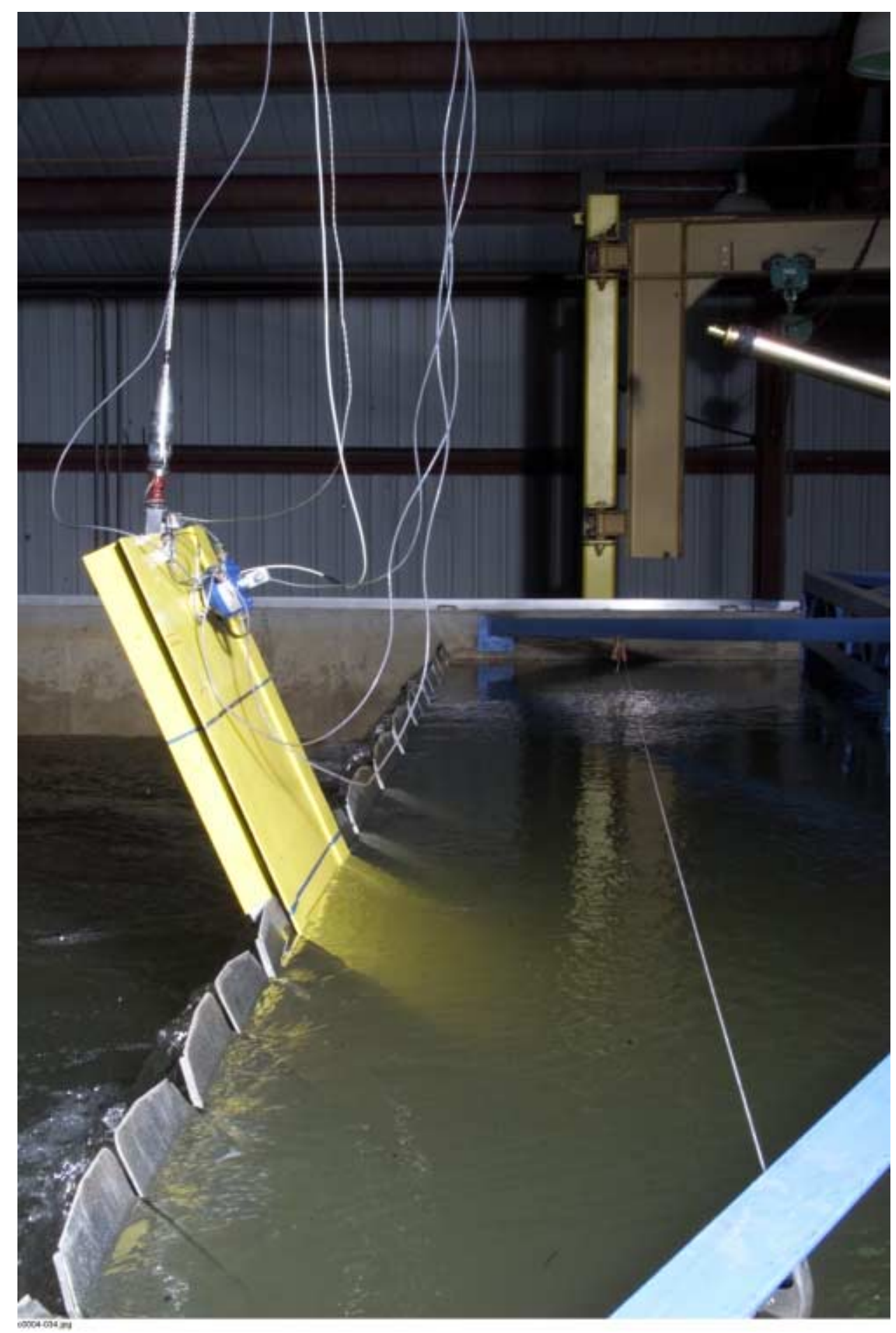

Figure 18. View from the walk of the blank approximately half way out of the water, still at approximately a 65-deg angle. Headwater 300;

Tailwater 295; 5-ft differential 


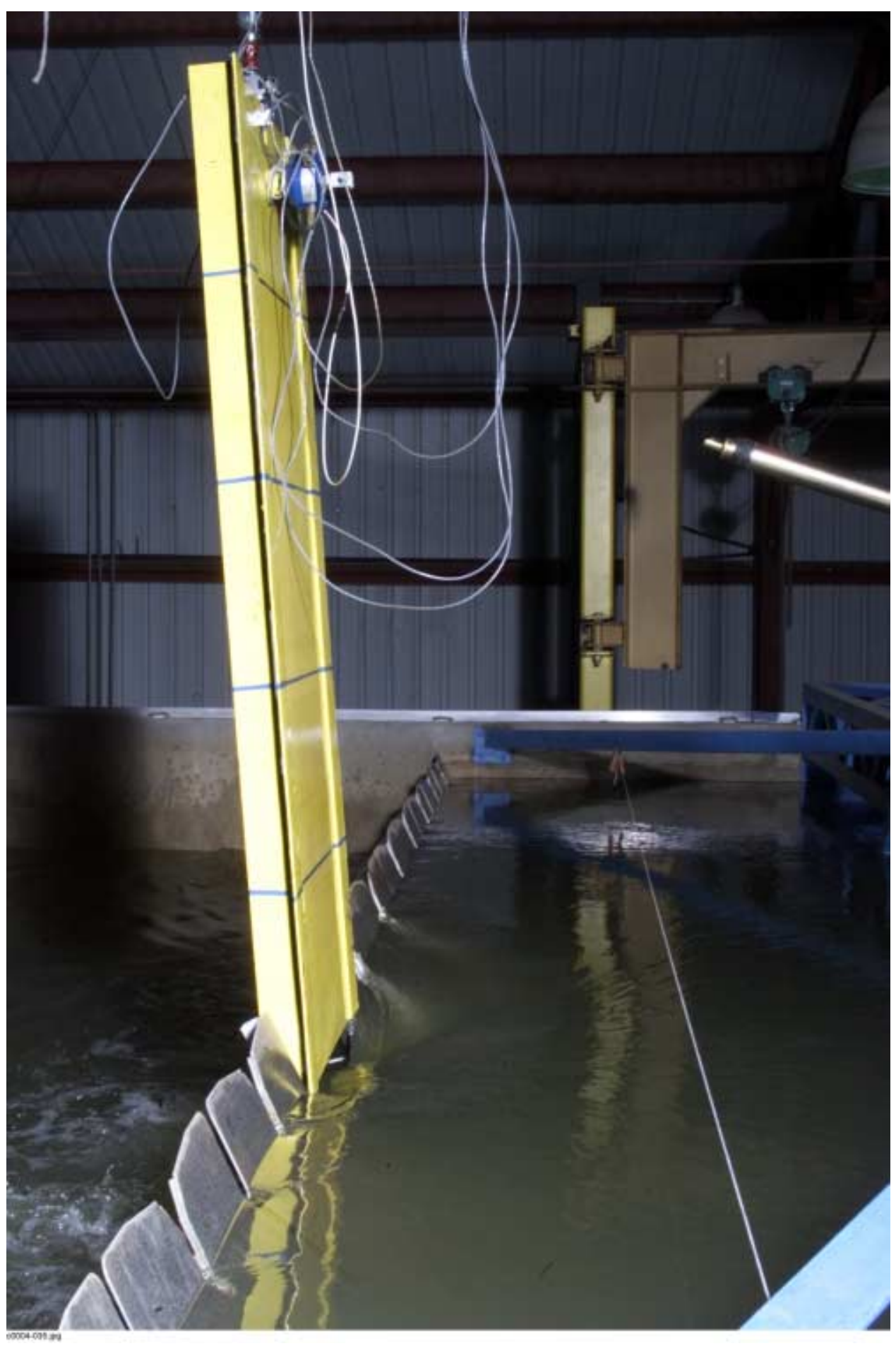

Figure 19. View from the walk as the bottom of the blank clears the water surface during the removal process. Headwater 300; Tailwater 295; 5 -ft differential 


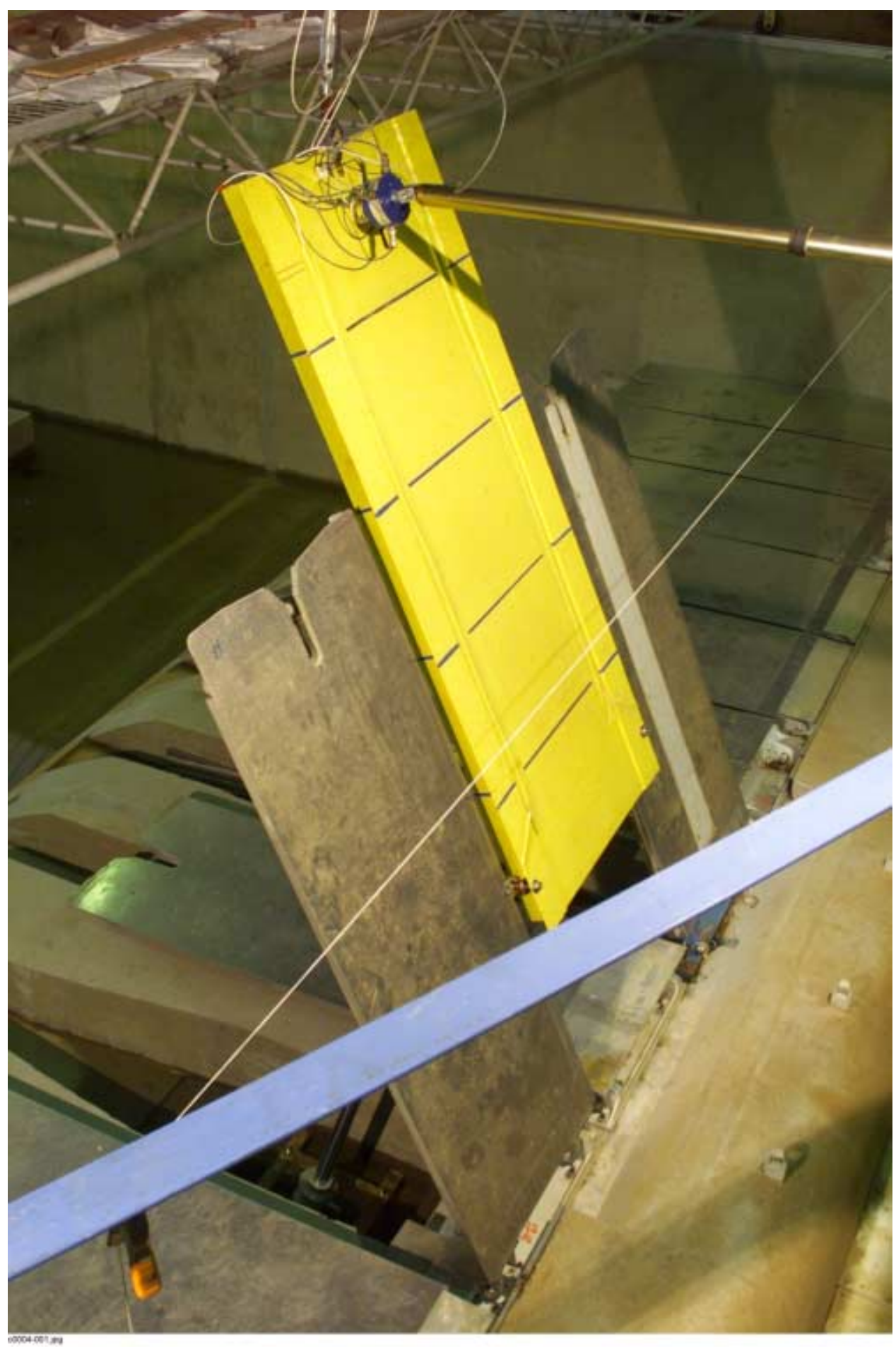

Figure 20. View from the walk, looking downstream at the wicket blank and wicket gates \#4, \#5, and \#6. The bottom of the blank is at el 287 and at an angle of 65 deg. Dry bed photo 


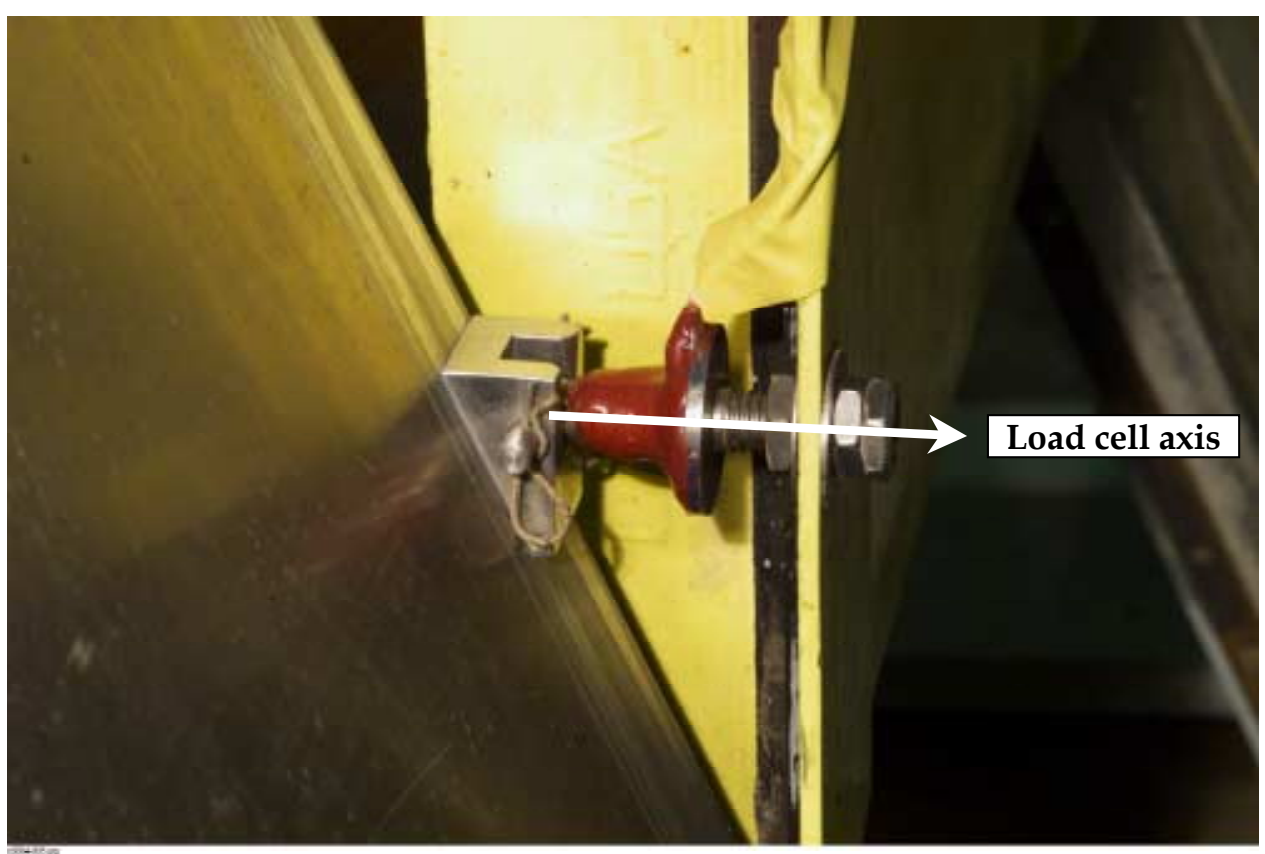

Figure 21. Closeup view of one load cell, showing contact between wicket gate \#4 and the load cell attached to the blank. The bottom of the blank is at el 287 and at an angle of 90 deg. Dry bed photo 


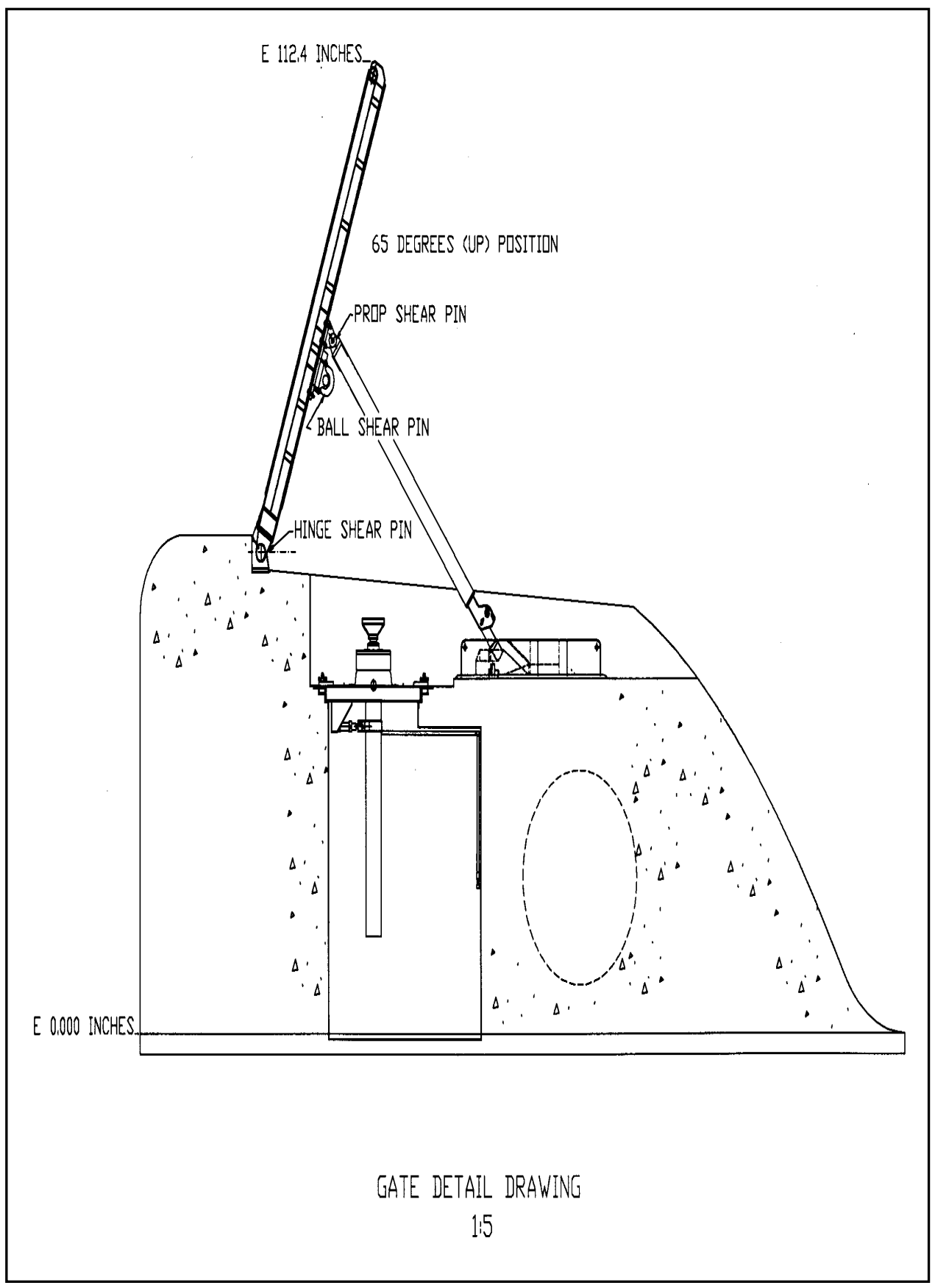

Figure 22. Instrumentation shear pin locations on instrumented gate 


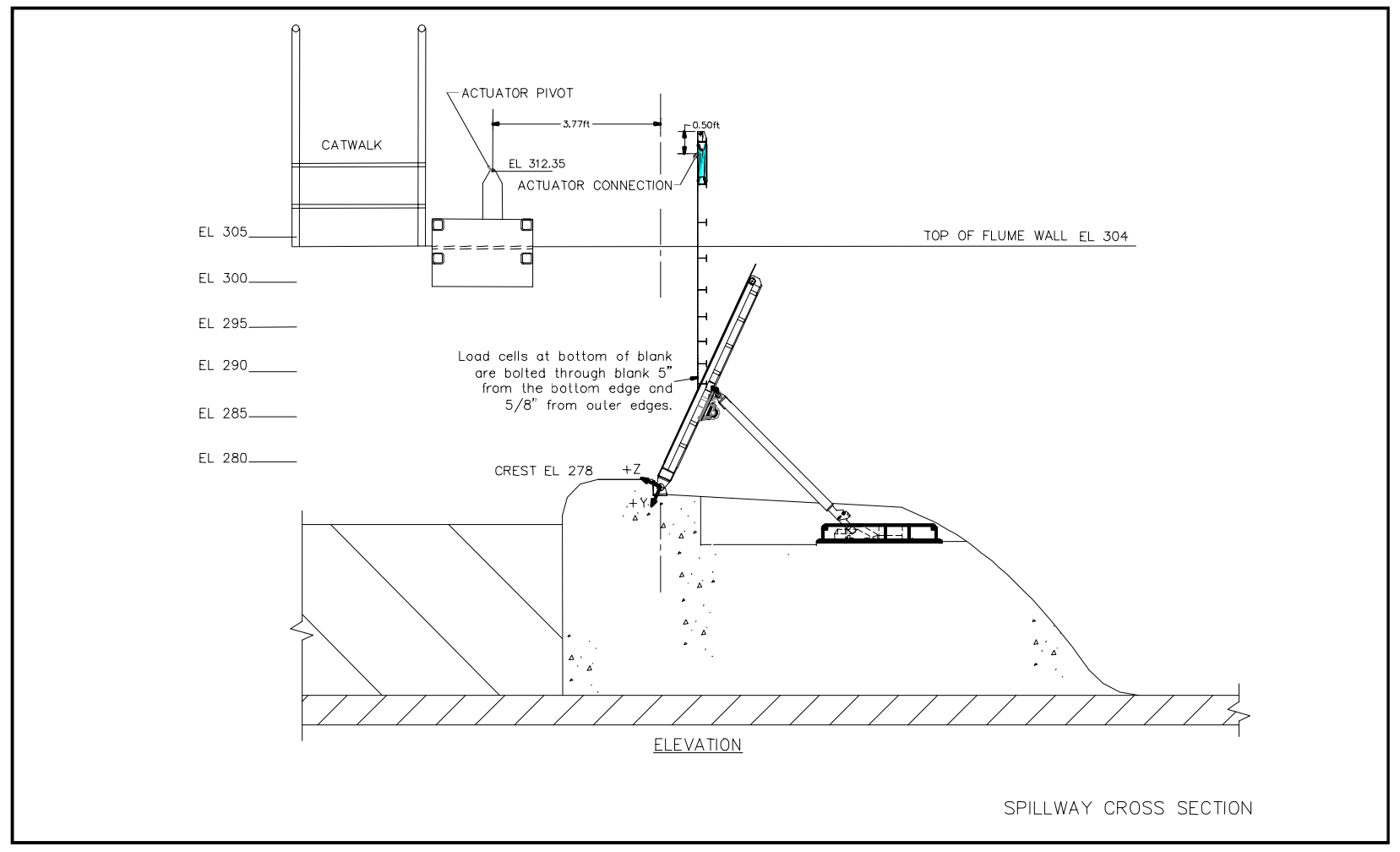

Figure 23. Blank gate orientation on the spillway cross section 
Part C; Blank installation; cylinder disconnected:

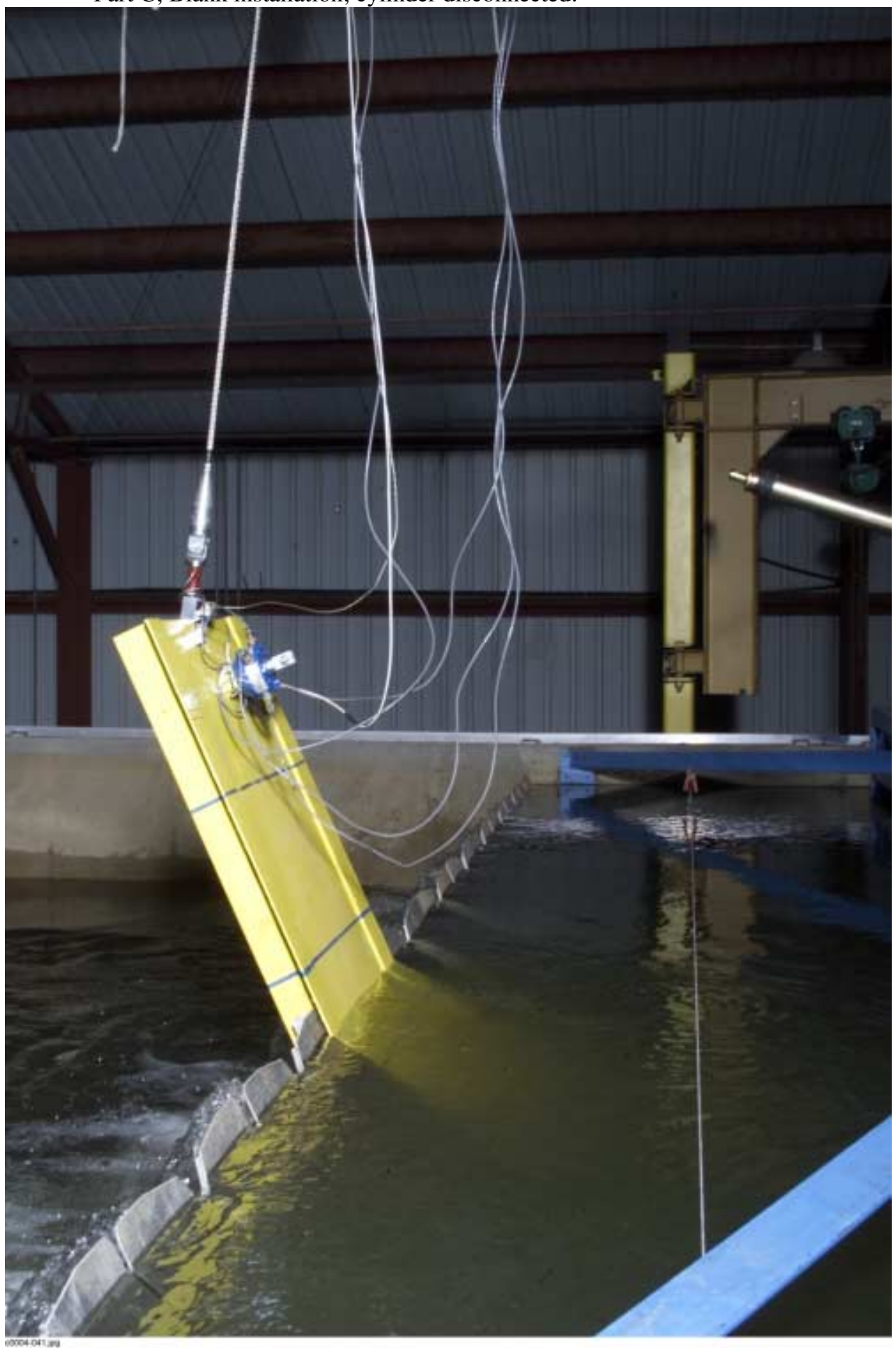

Figure 24. View from the walk looking downstream, as the blank is approximately half way submerged in the flow. The blank is weighted with $68.32 \mathrm{lb}$ of lead positioned in the upper three channels. Headwater 301; Tailwater 294; 7-ft differential 


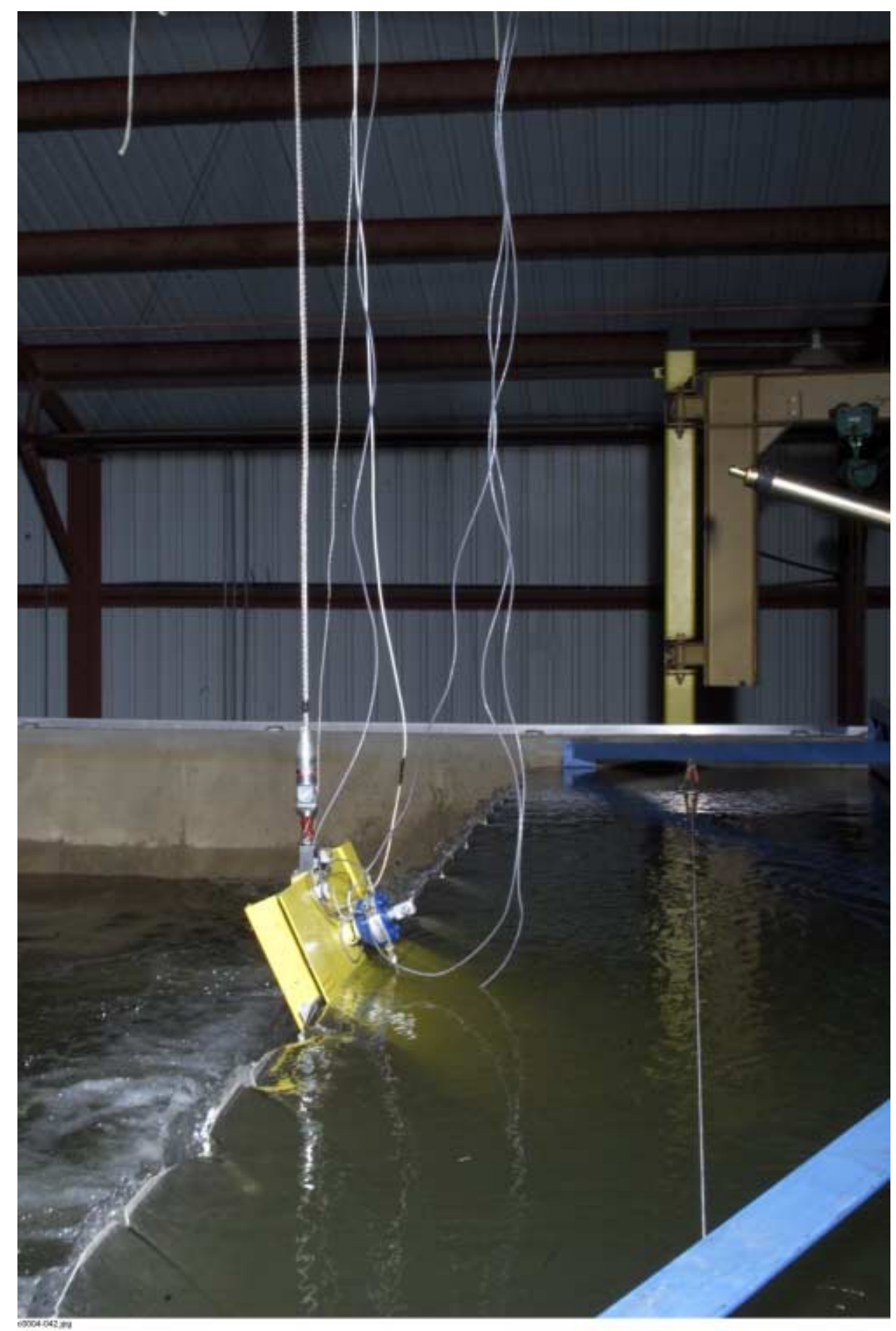

Figure 25. View from the walk, looking downstream at the blank submerged in the flow and seated on wicket gate \#5. The blank is weighted with $68.32 \mathrm{lb}$ of lead positioned in the upper three channels. Headwater 301; Tailwater 294; 7-ft differential 


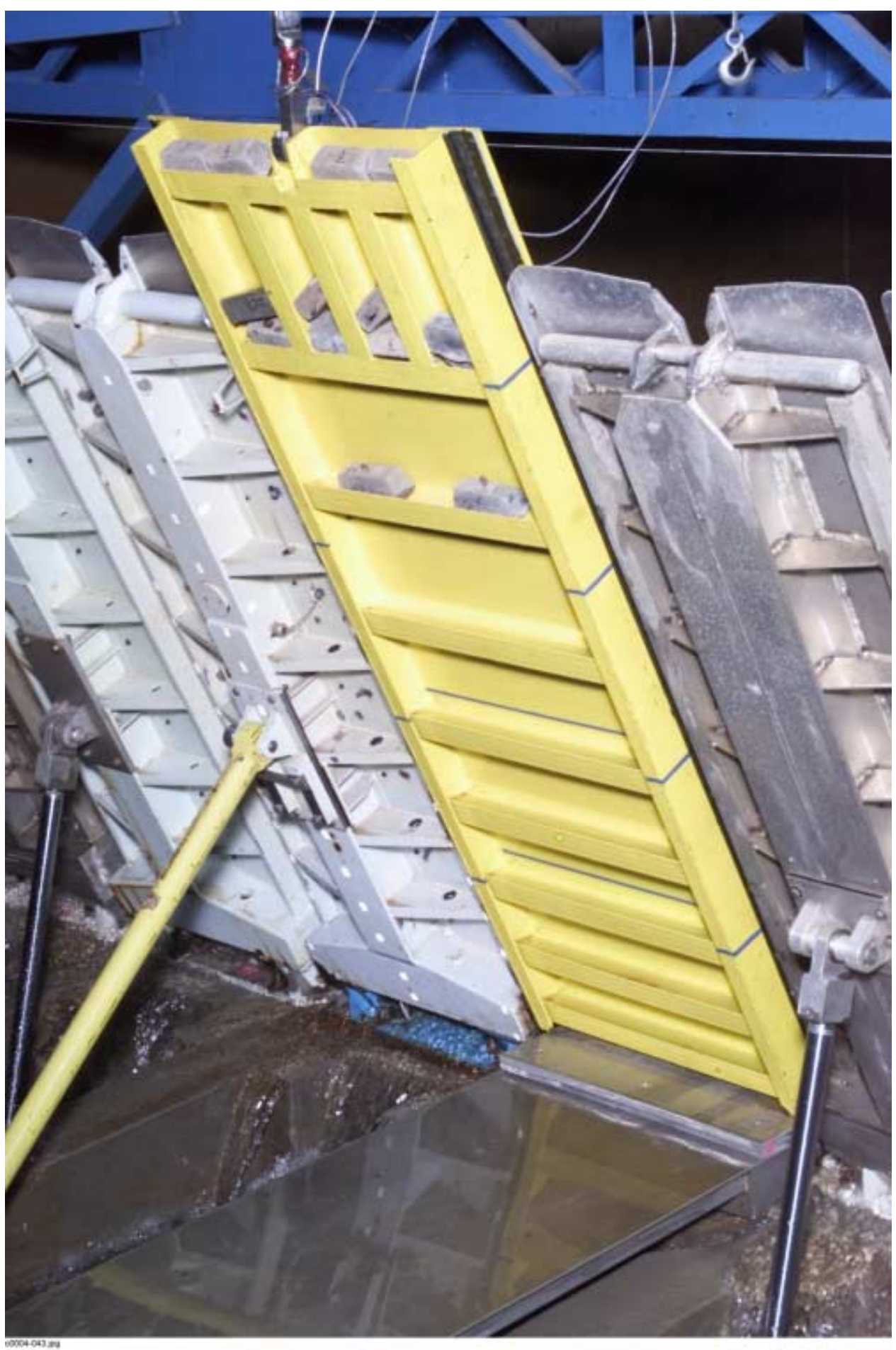

Figure 26. View from the walk, looking upstream at the blank seated on wicket gate \#5, showing the weights located in the top three channels. Dry bed photograph 


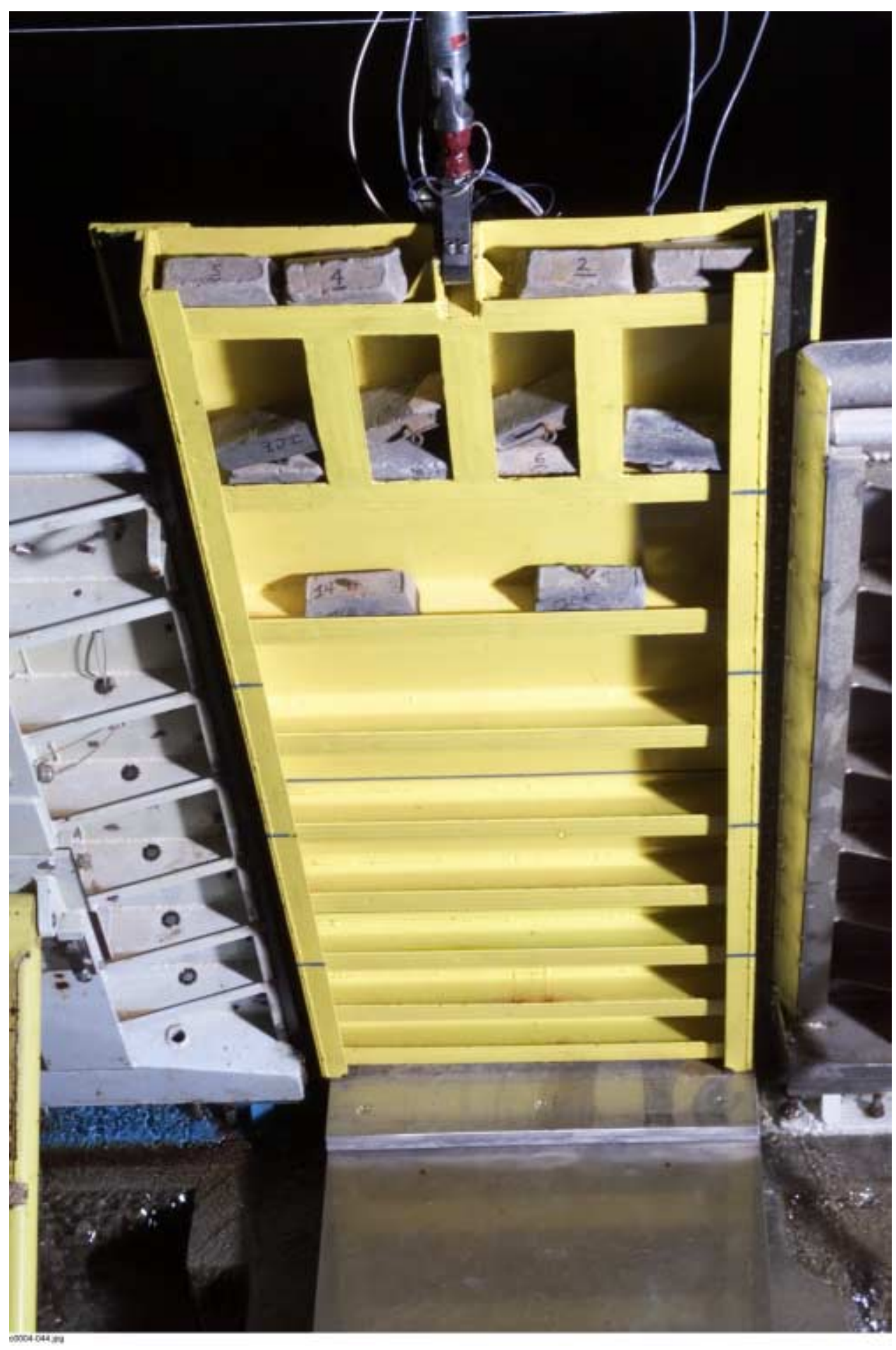

Figure 27. View from the catwalk, looking upstream at the blank seated on wicket gate \#5, showing the weights located in the top three channels. Dry bed photograph 


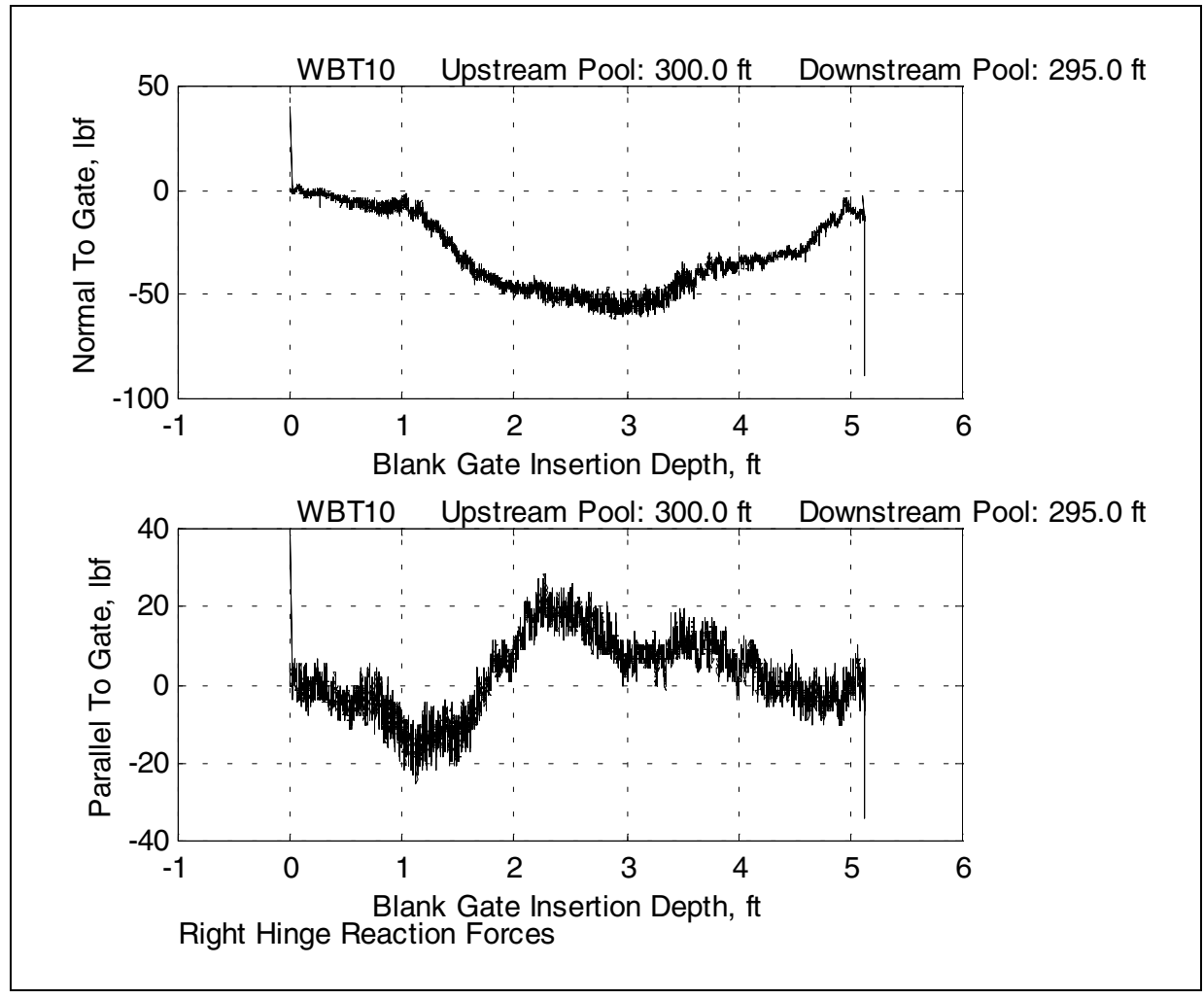

Figure 28. Right hinge reactions for OLMWBT1

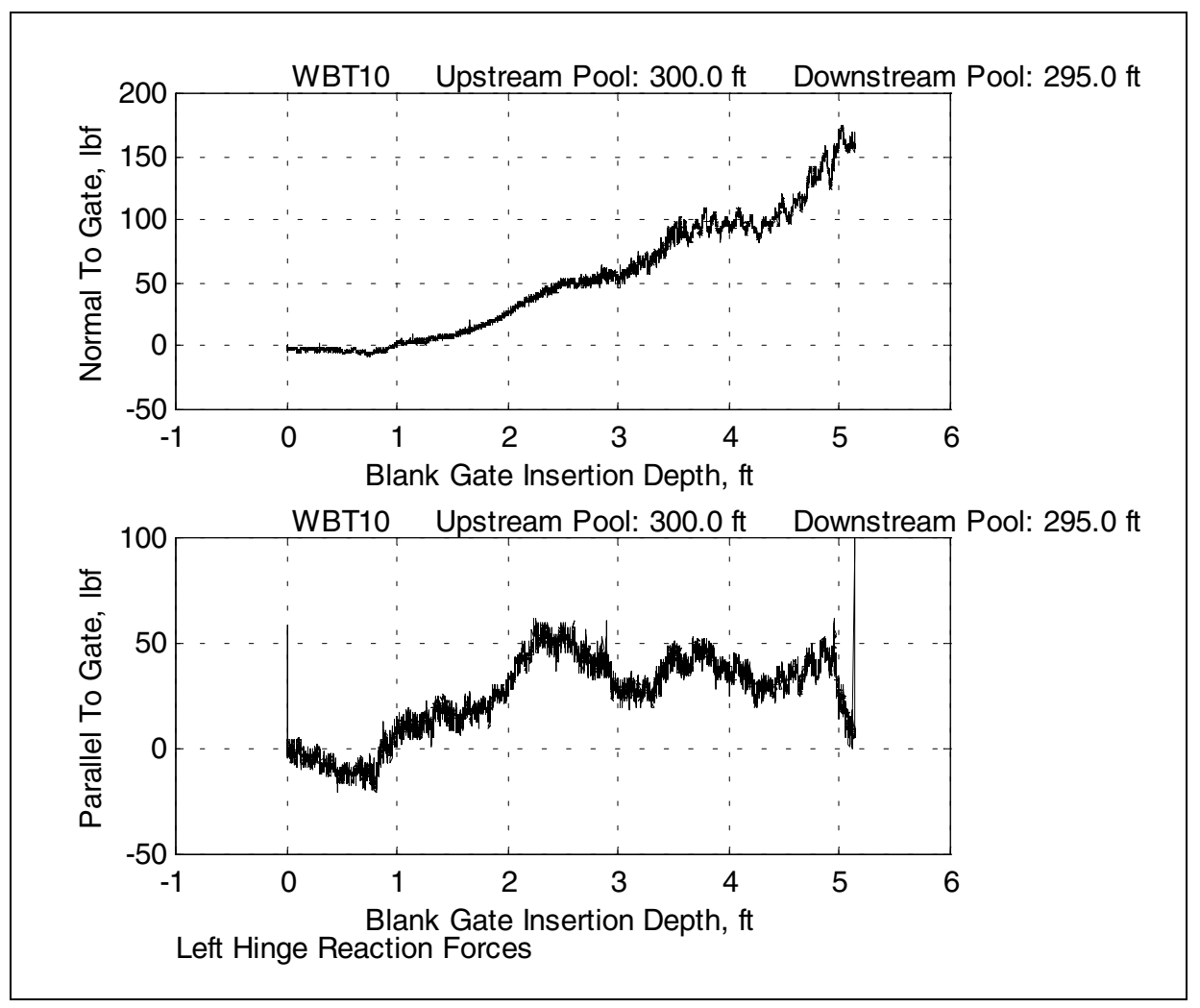

Figure 29. Left hinge reactions for test OLMWBT1 


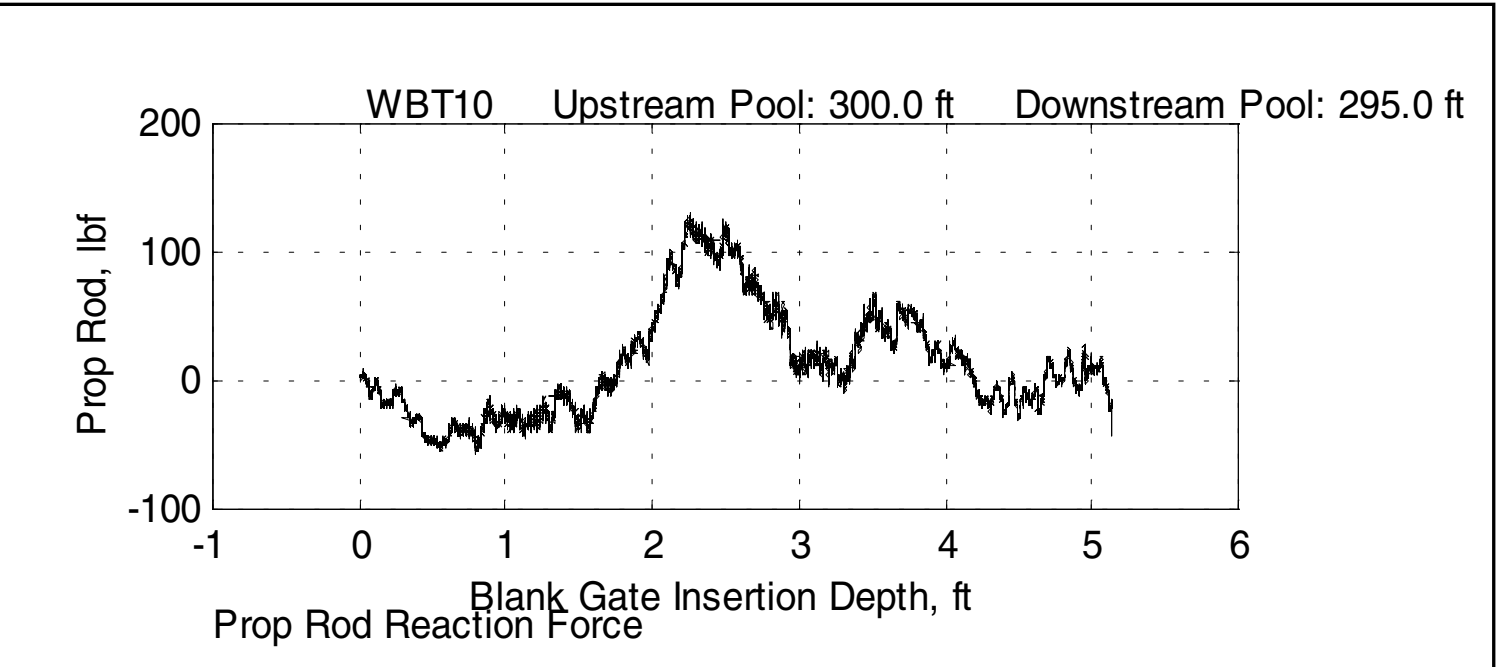

Figure 30. Prop rod force for test OLMWBT1

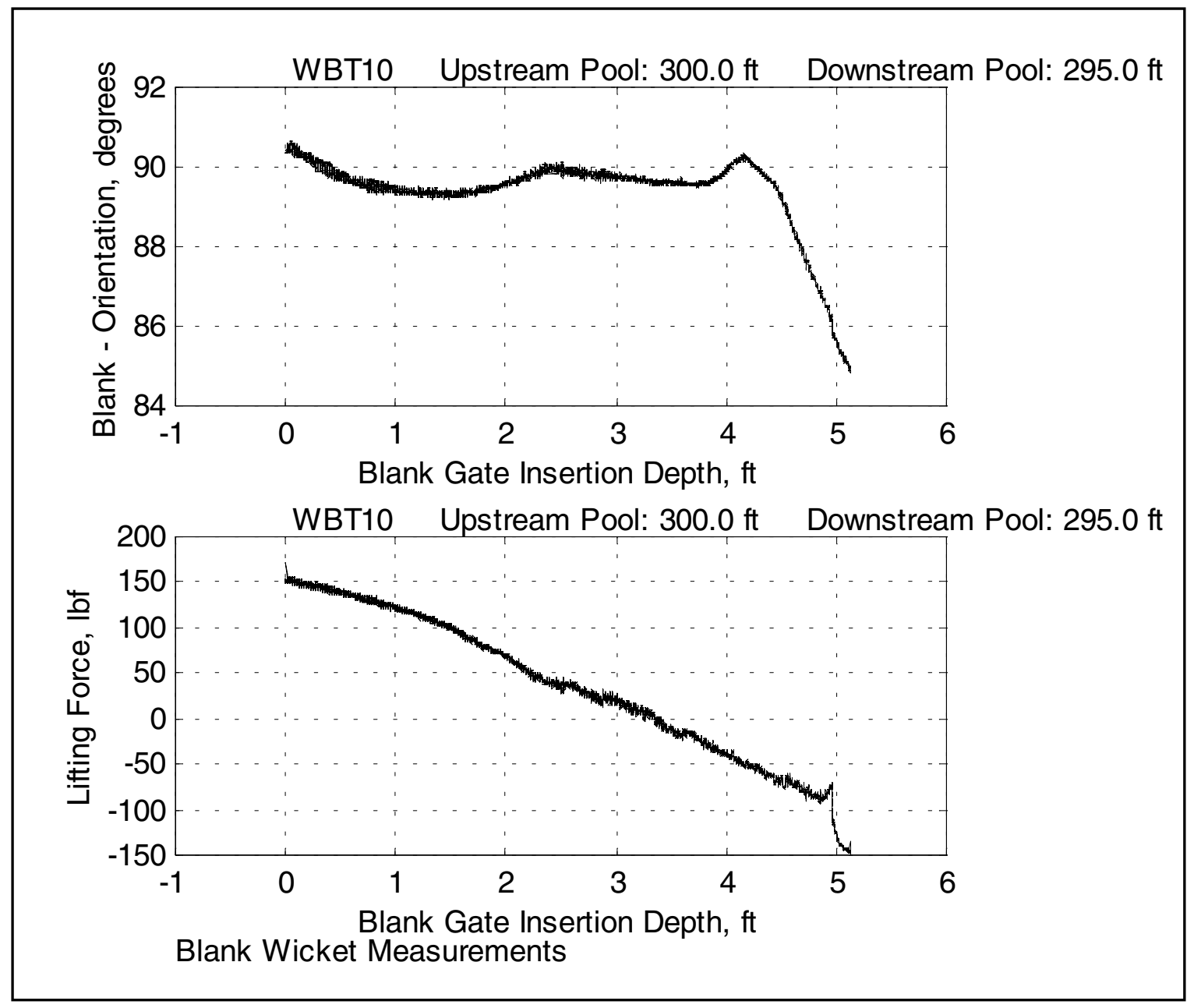

Figure 31. Lifting force and blank orientation for test OLMWBT1 


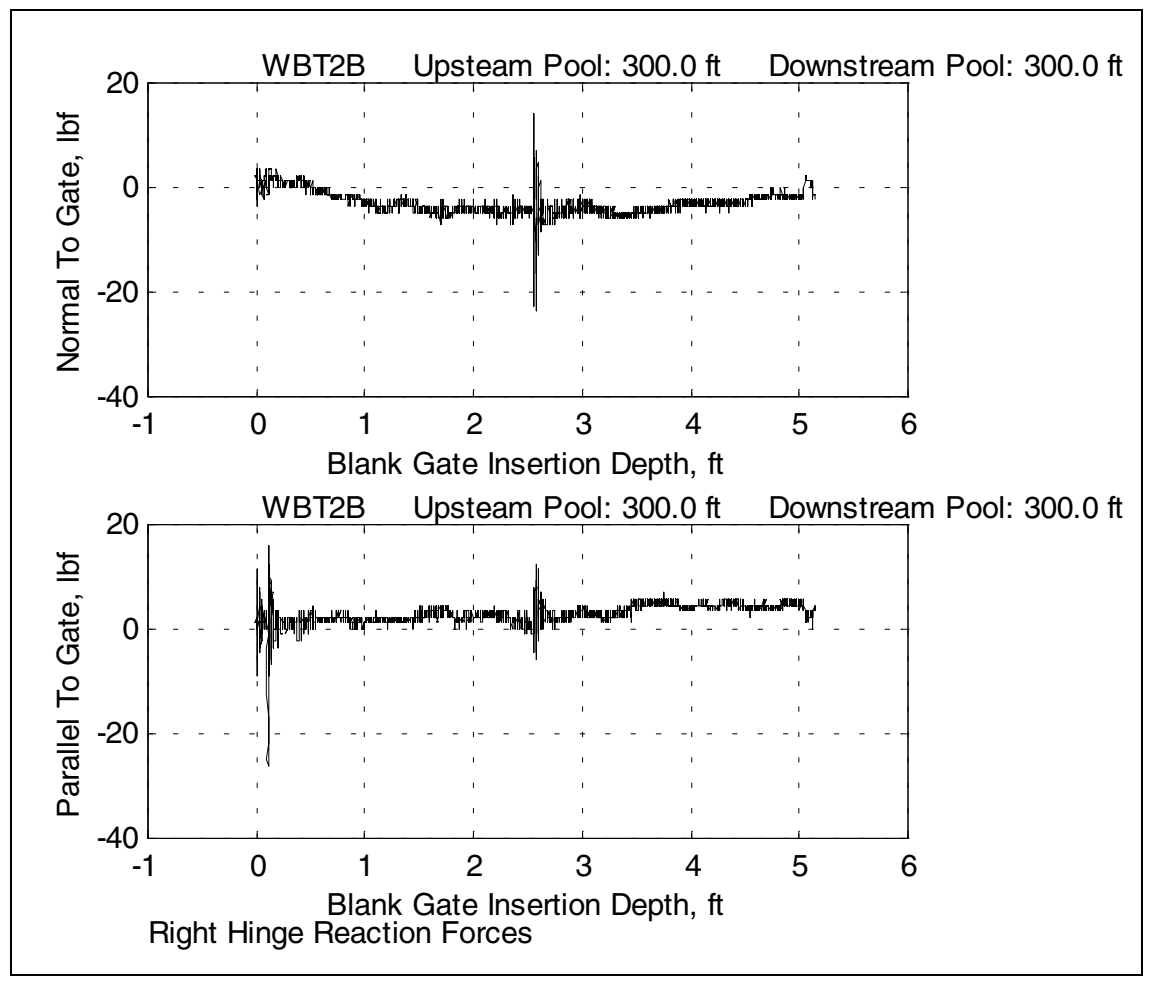

Figure 32. Right hinge reactions for OLMW2B

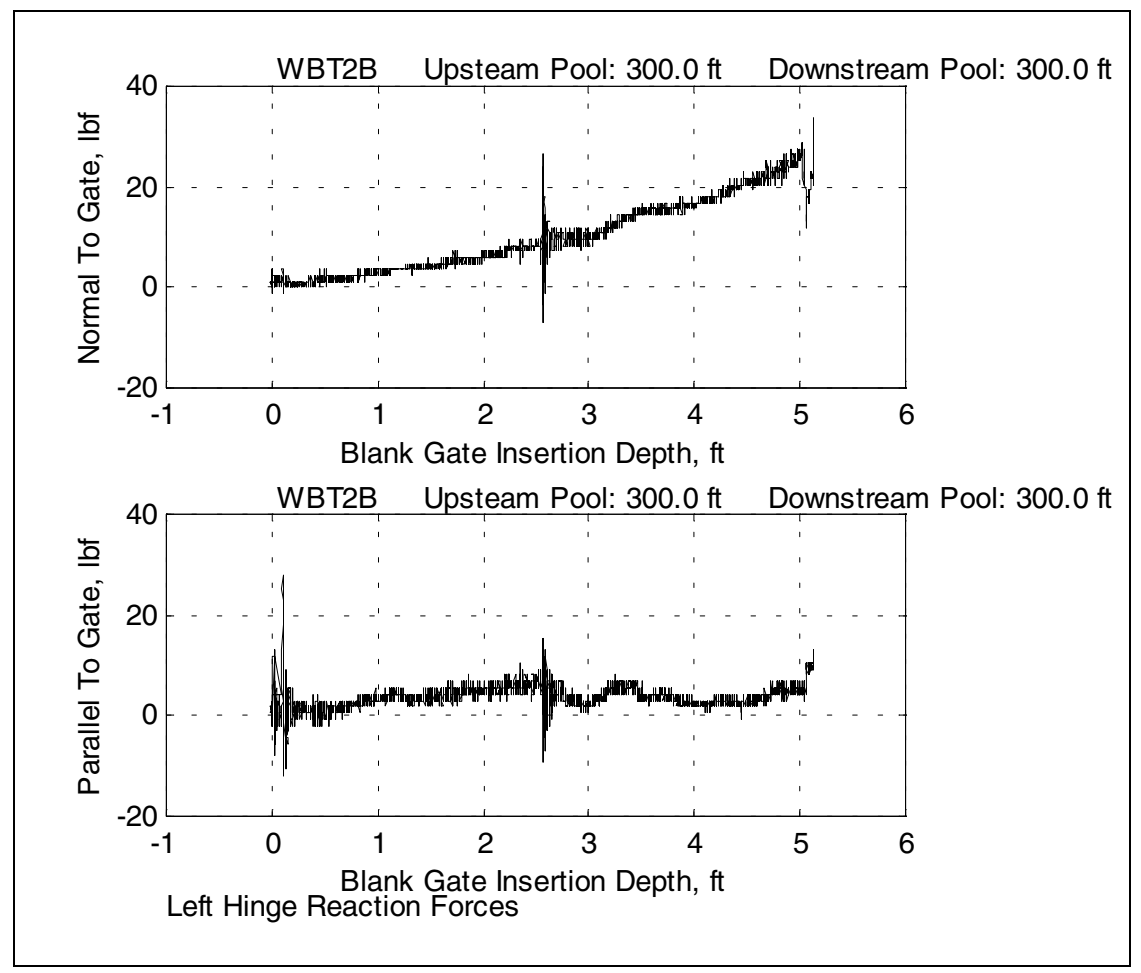

Figure 33. Left hinge reactions for test OLMWBT2B 


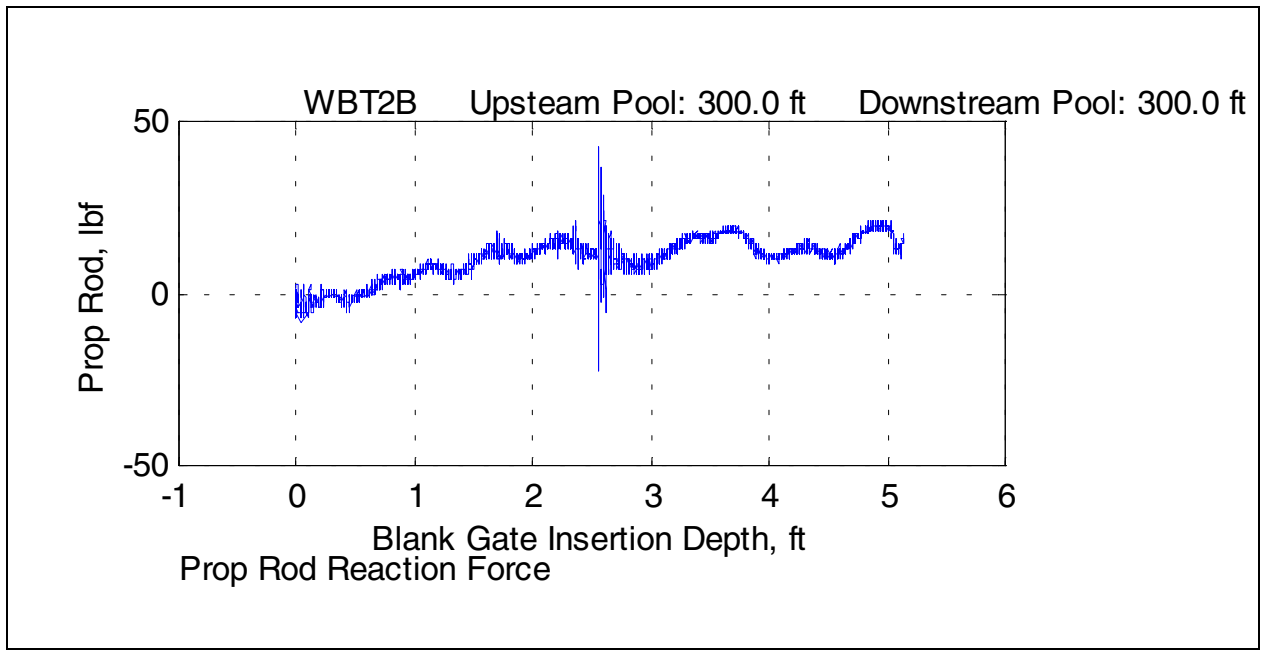

Figure 34. Prop rod force for test OLMWB2B

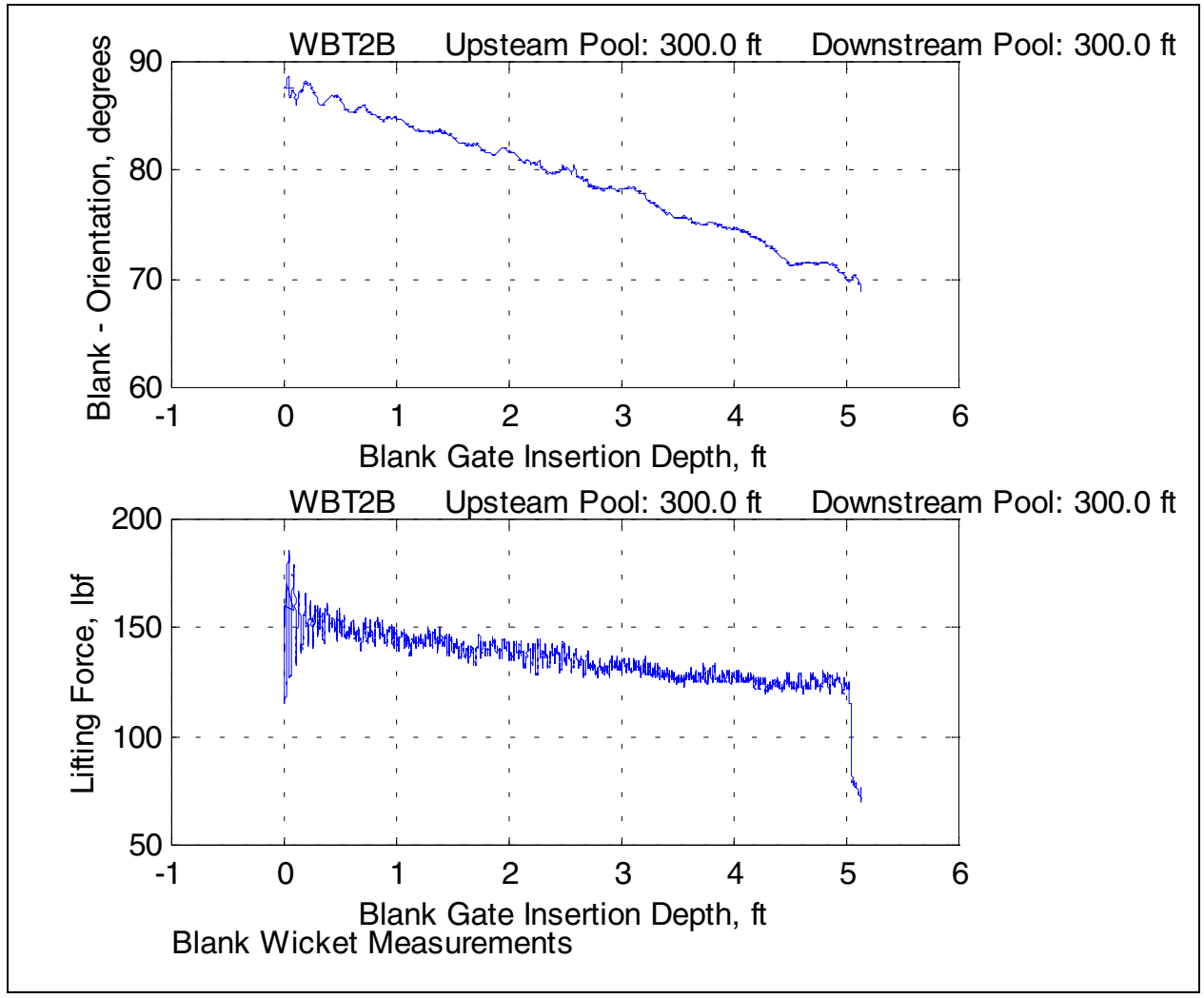

Figure 35. Lifting force and blank orientation for test OLMWBT2B 


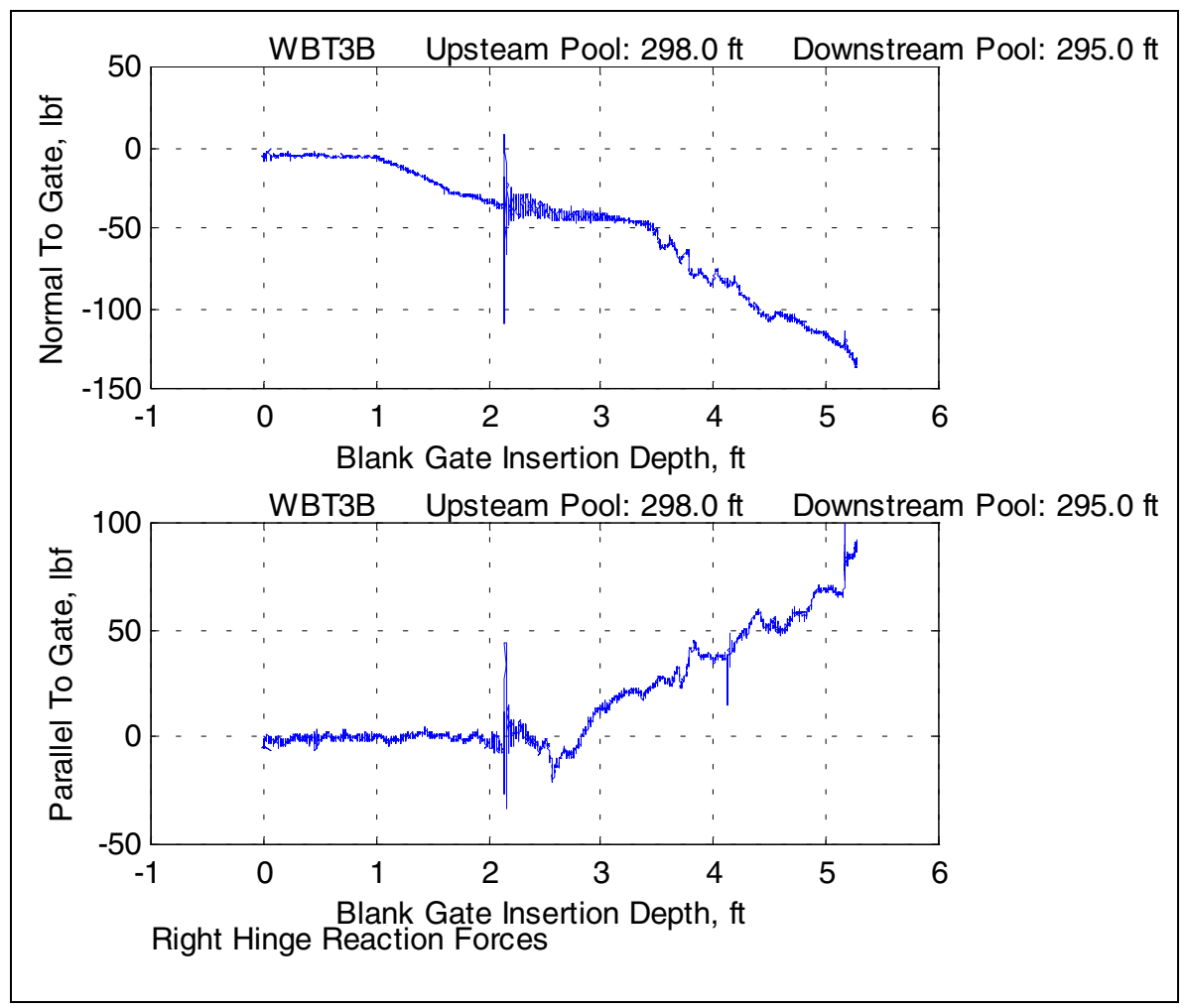

Figure 36. Right hinge reactions for OLMWBT3B

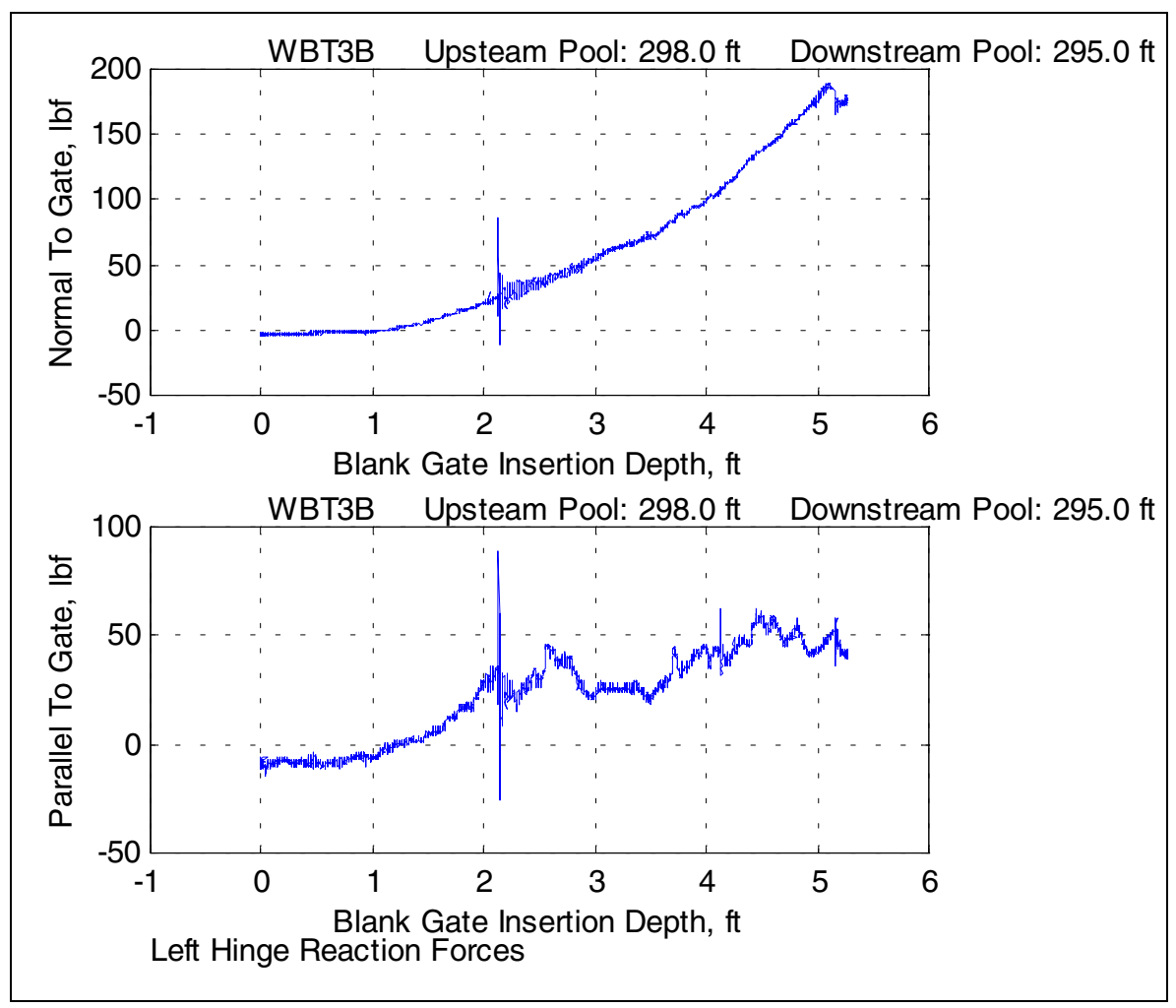

Figure 37. Left hinge reactions for OLMWBT3B 


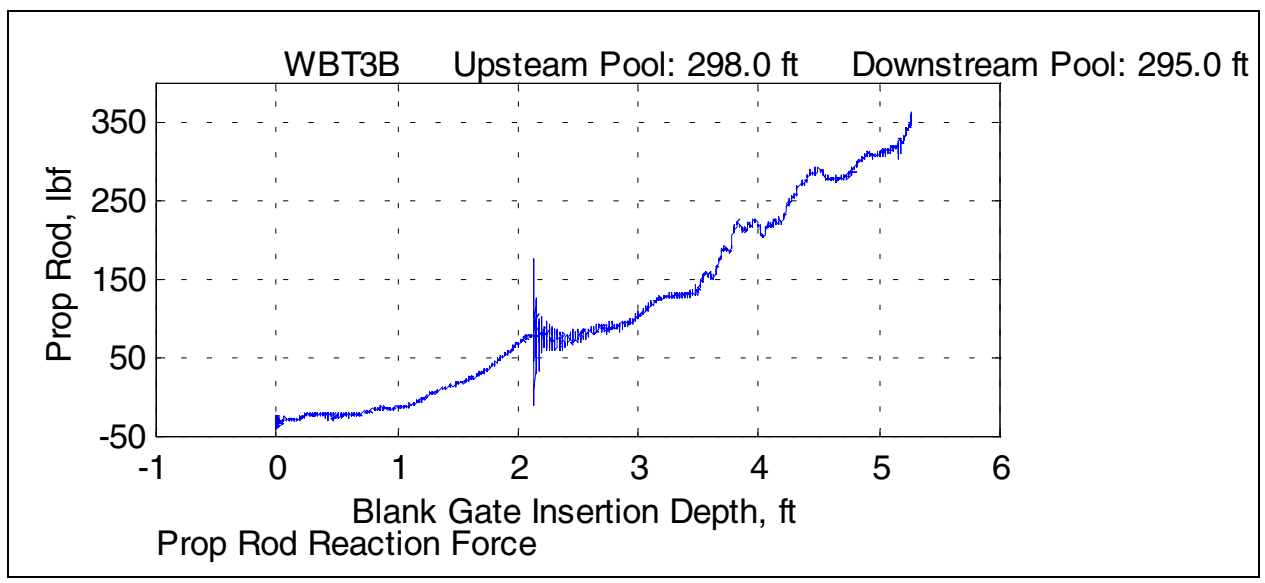

Figure 38. Prop rod force for test OLMWBT3B

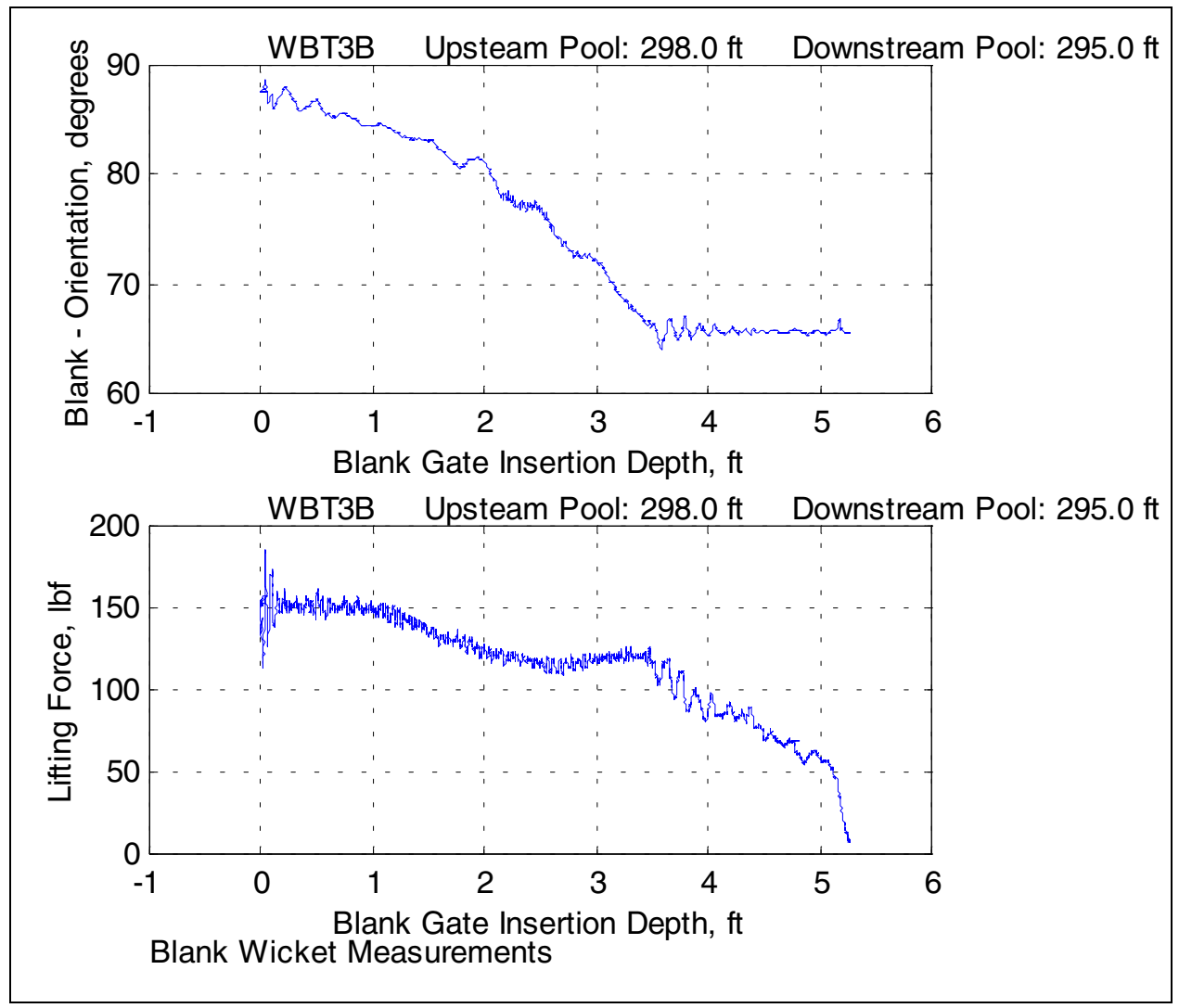

Figure 39. Lifting force and blank orientation for test OLMWBT3B 


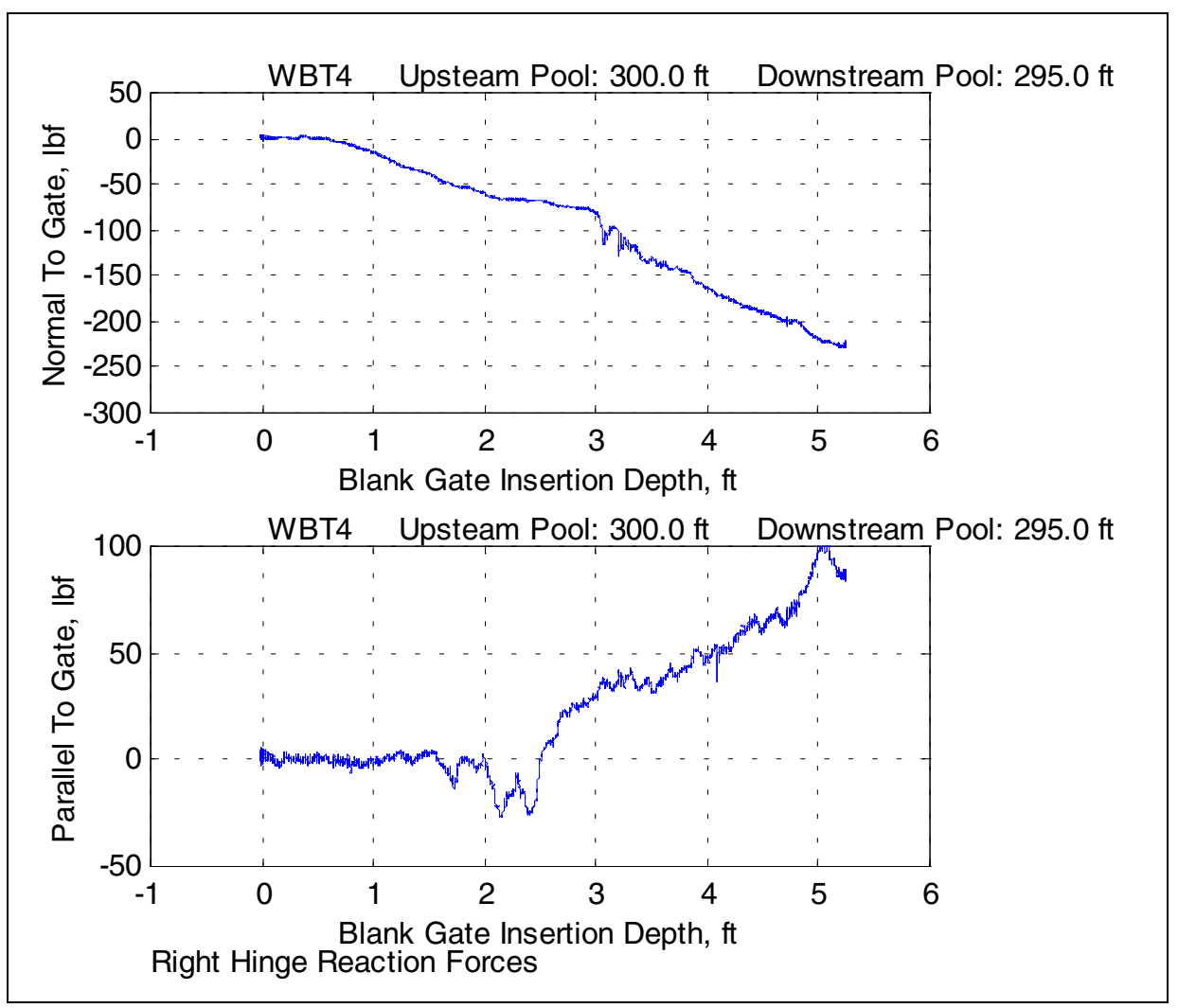

Figure 40. Right hinge reactions for OLMWBT4

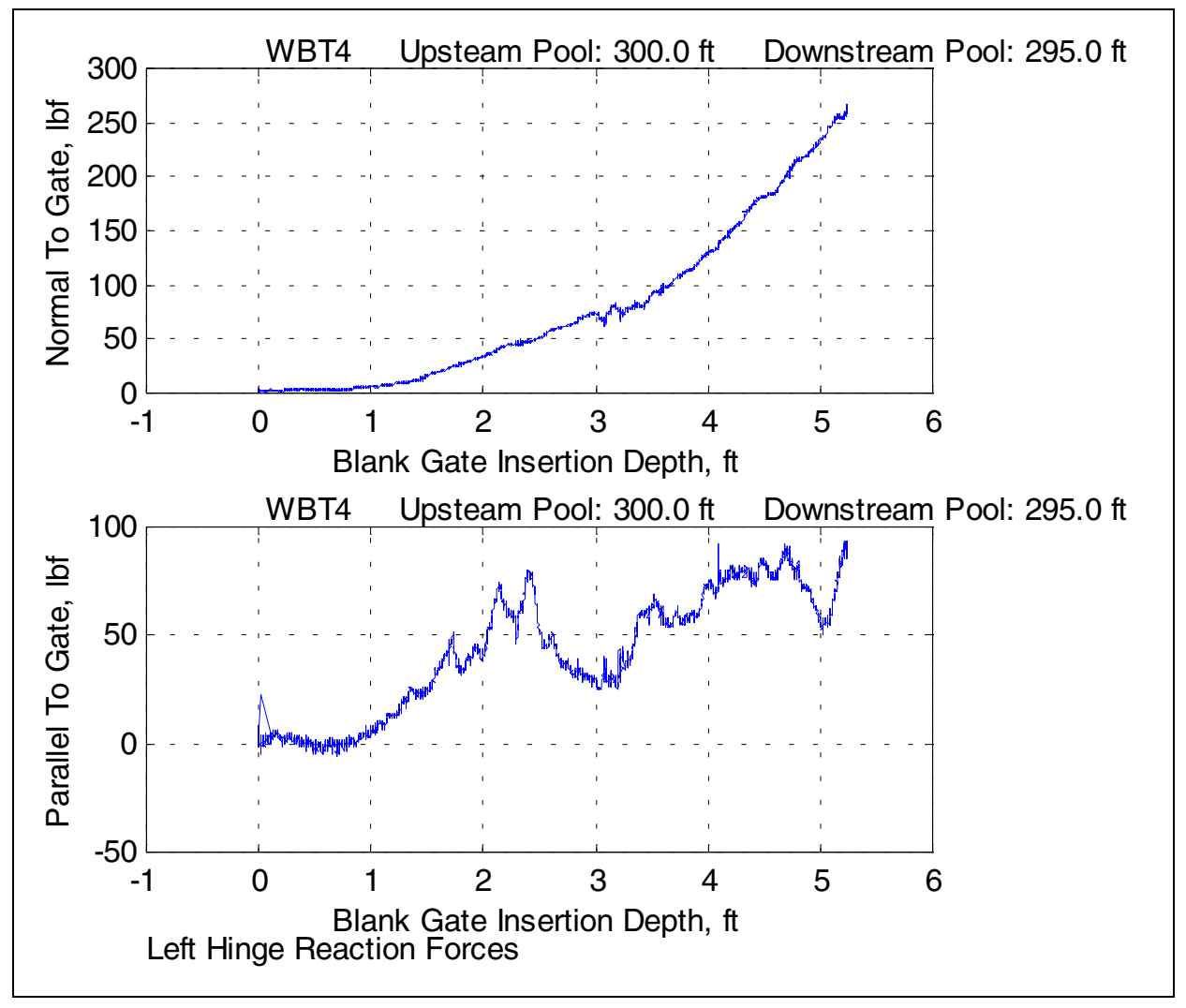

Figure 41. Left hinge reactions for OLMWBT4 


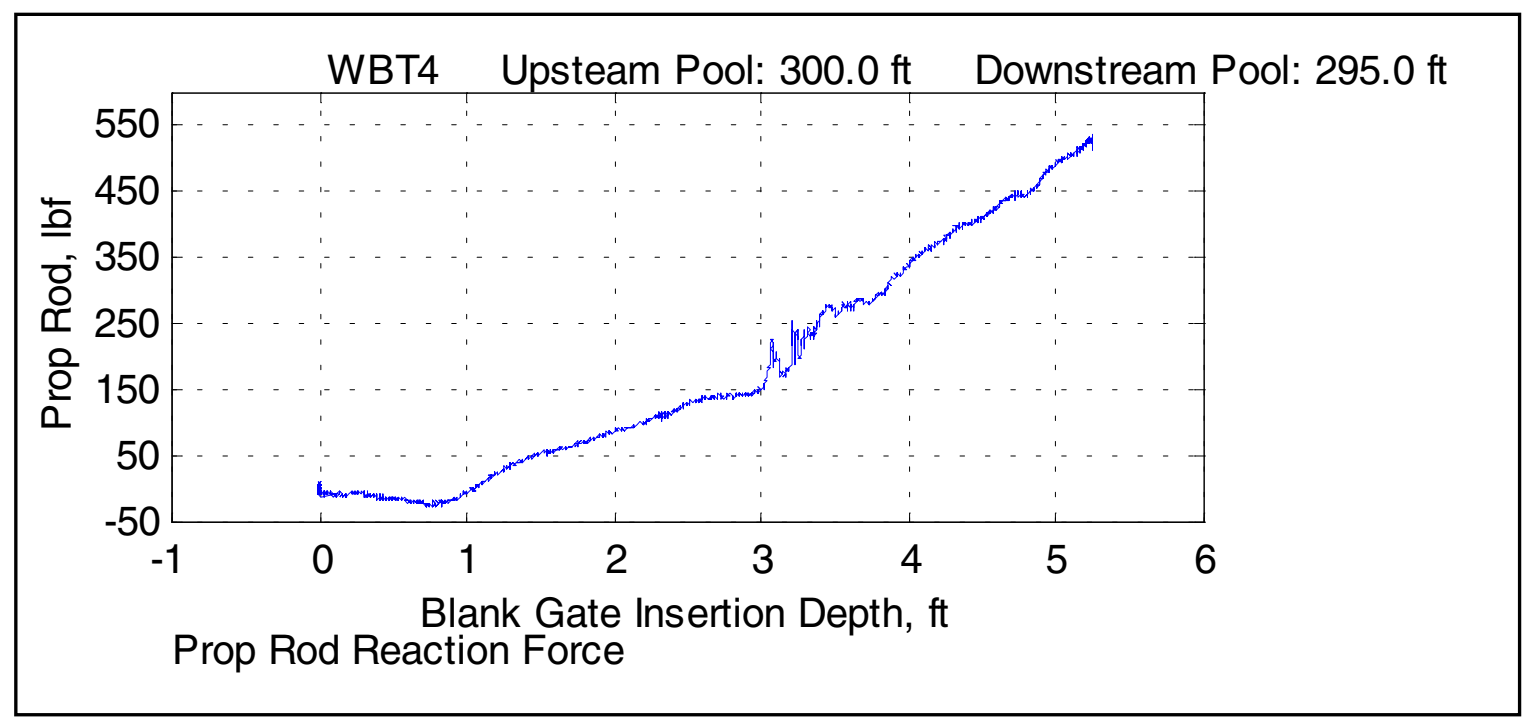

Figure 42. Prop rod force for test OLMWBT4

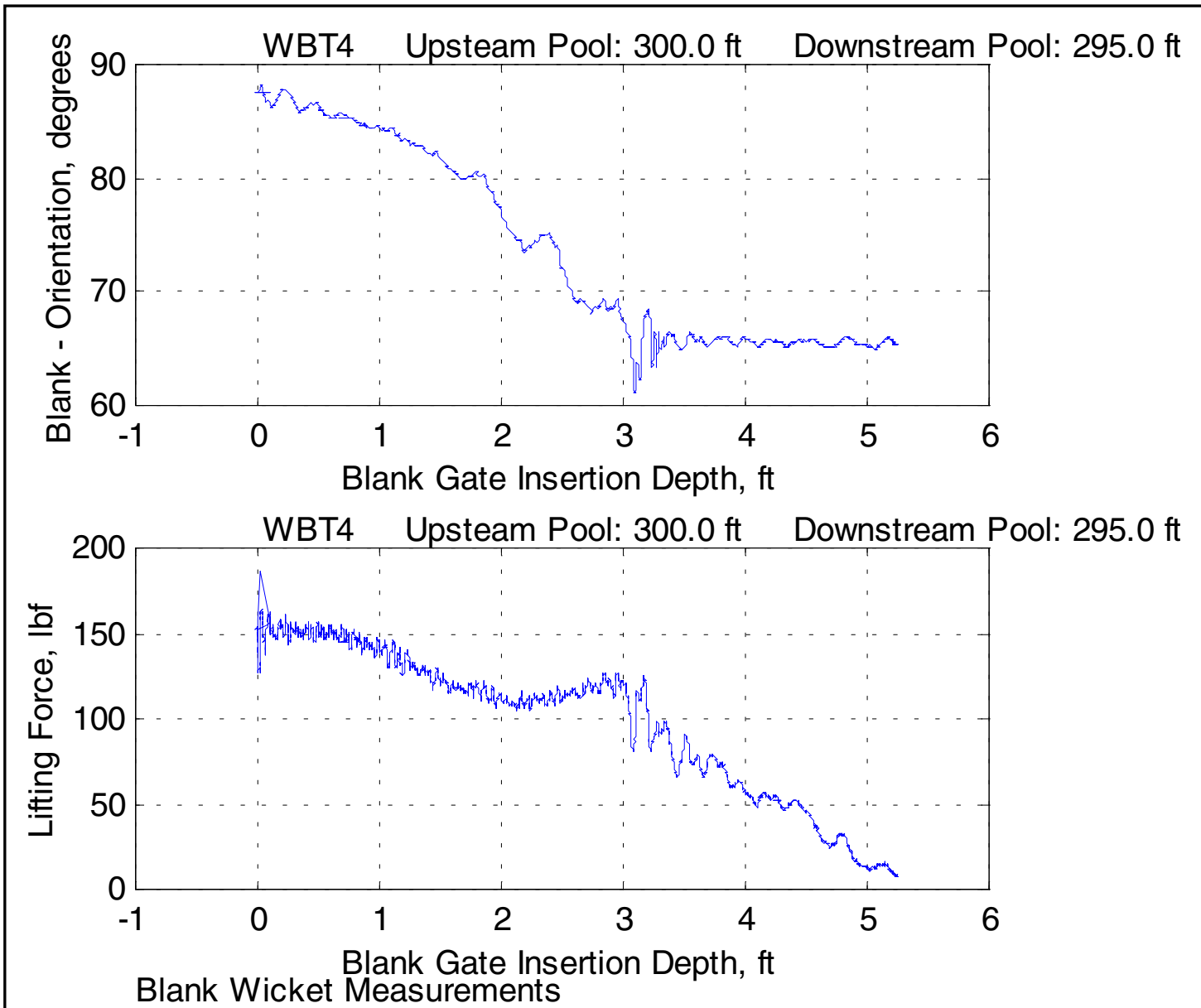

Figure 43. Lifting force and blank orientation for test OLMWBT4 


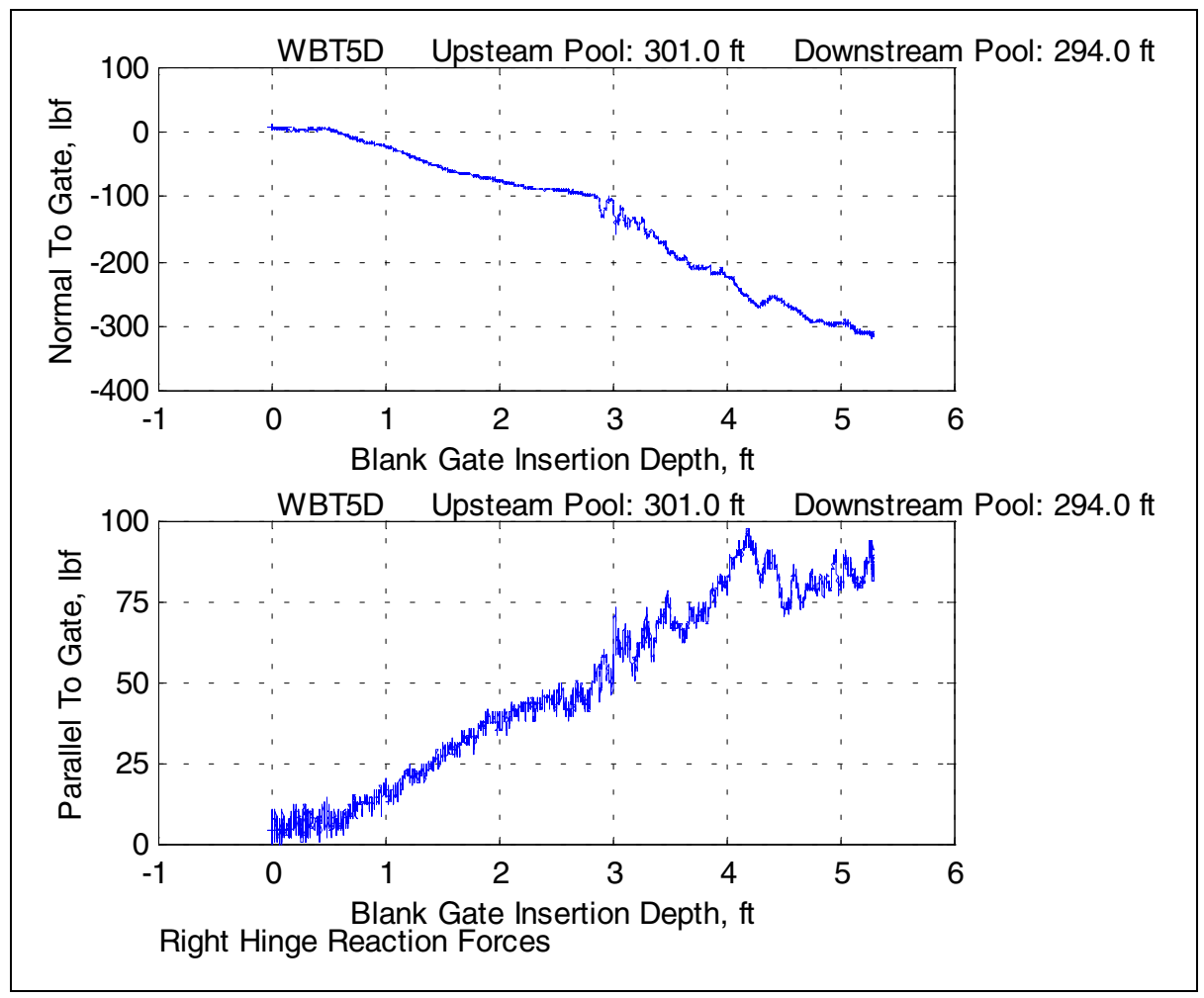

Figure 44. Right hinge reactions for OLMWBT5D

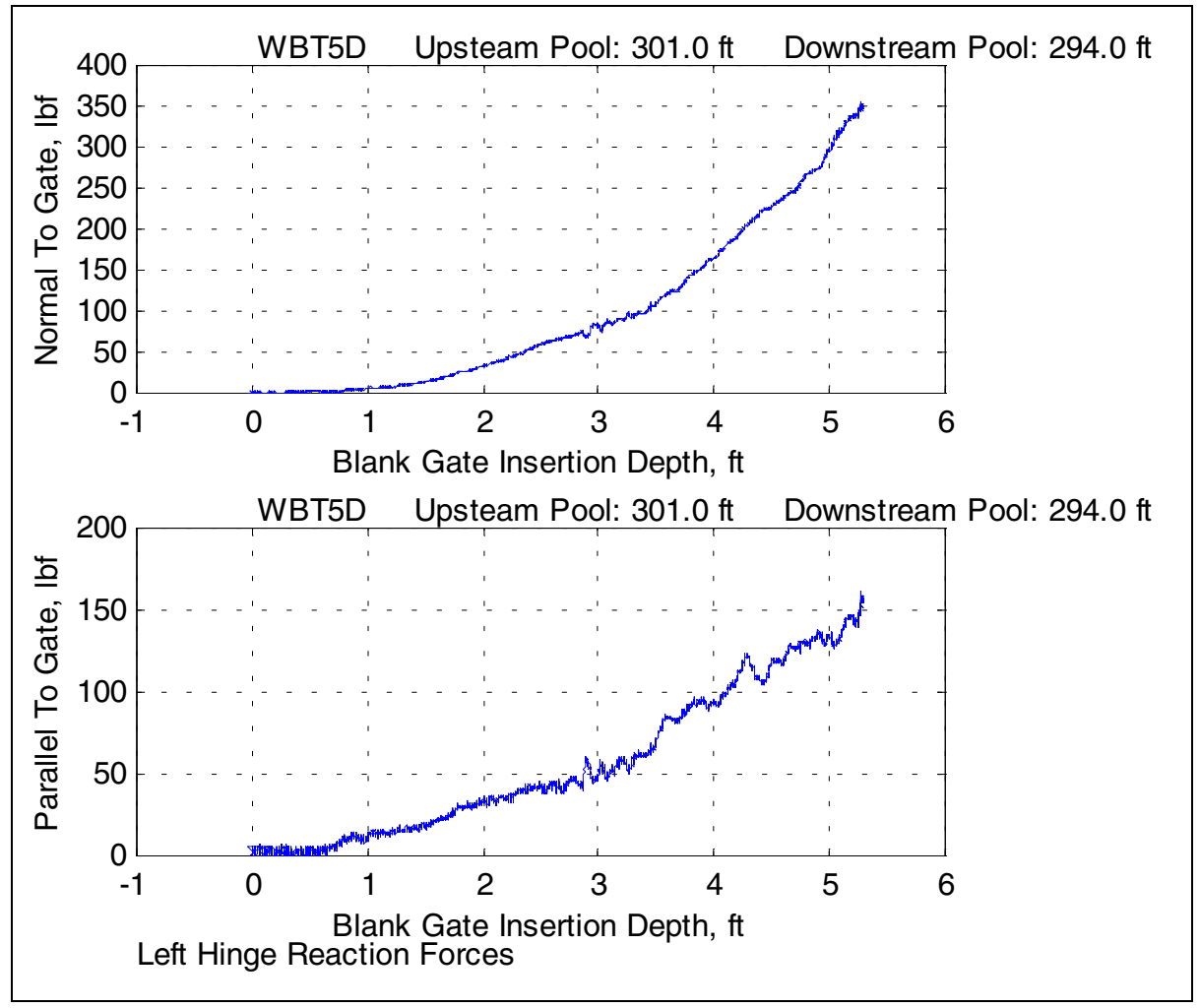

Figure 45. Left hinge reactions for OLMWBT5D 


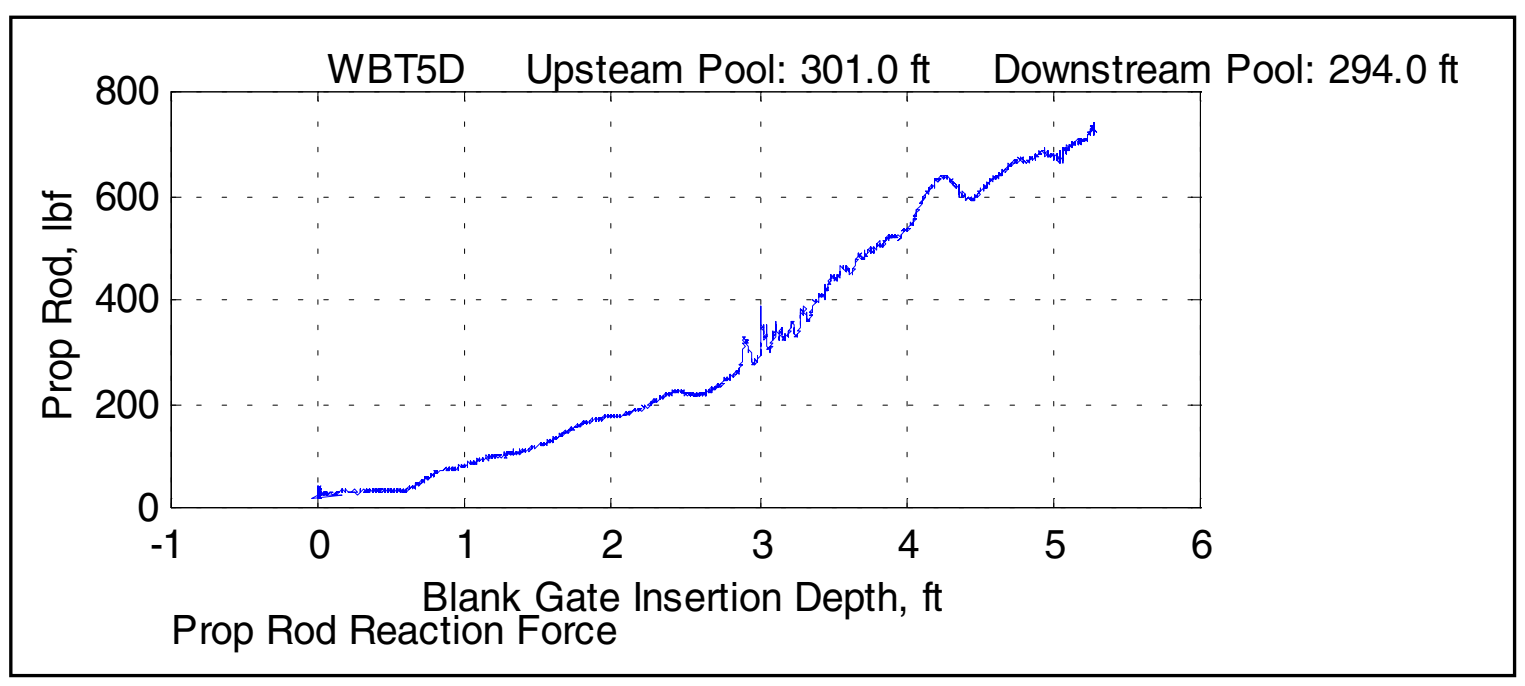

Figure 46. Prop rod force for test OLMWBT5D

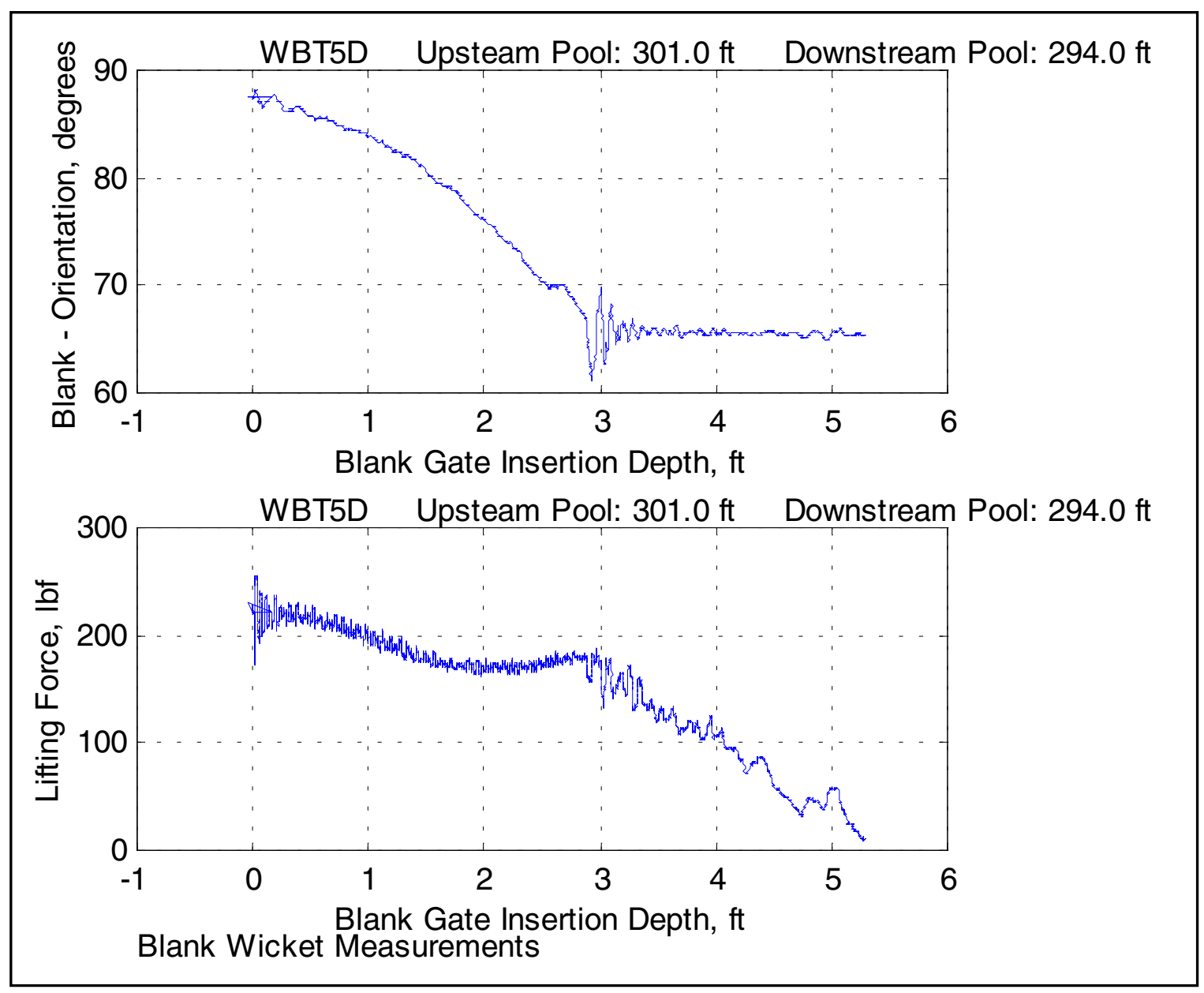

Figure 47. Lifting force and blank orientation for test OLMWBT5D 


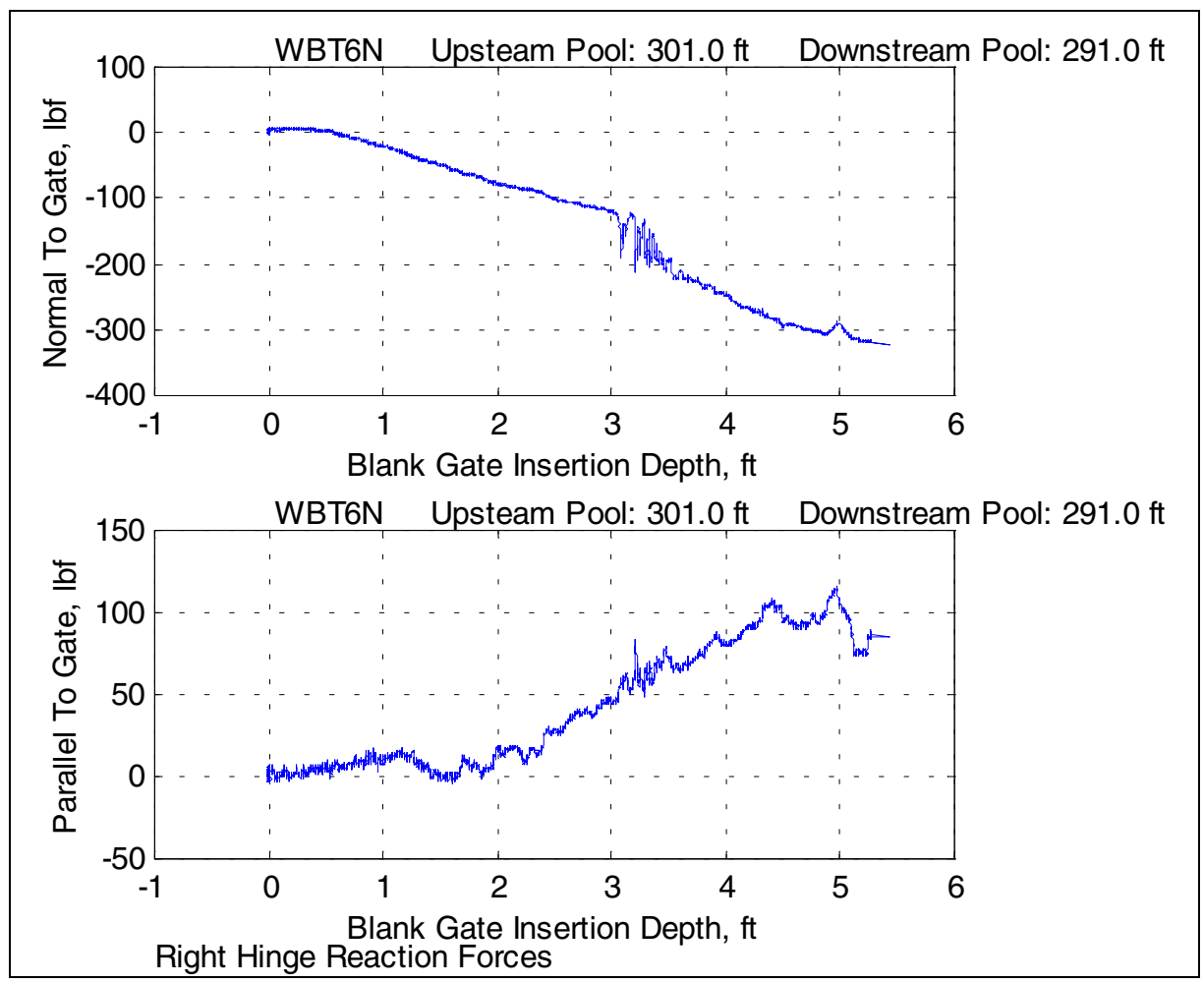

Figure 48. Right hinge reactions for test OLMWBT6N

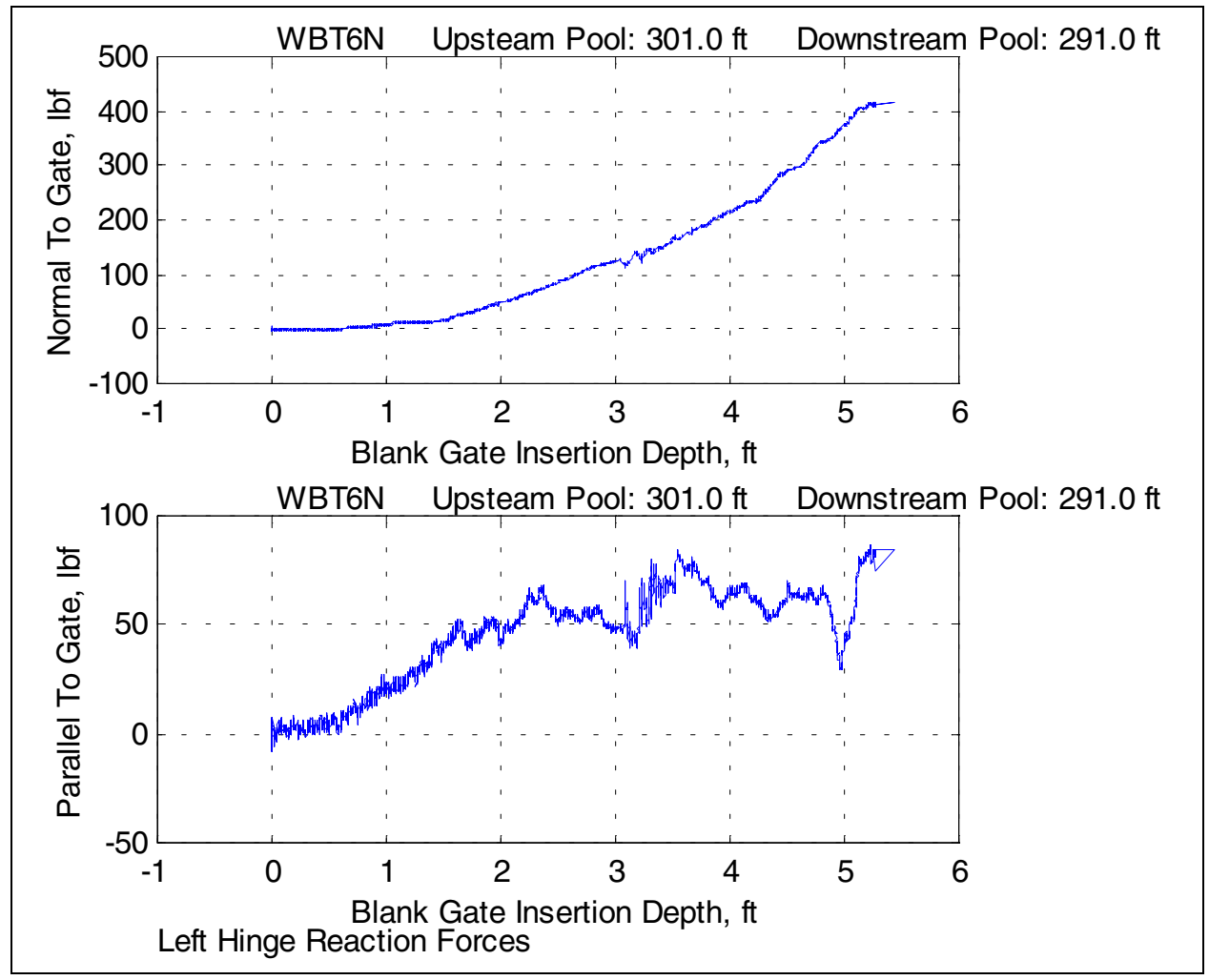

Figure 49. Left hinge reactions for OLMWBT6N 


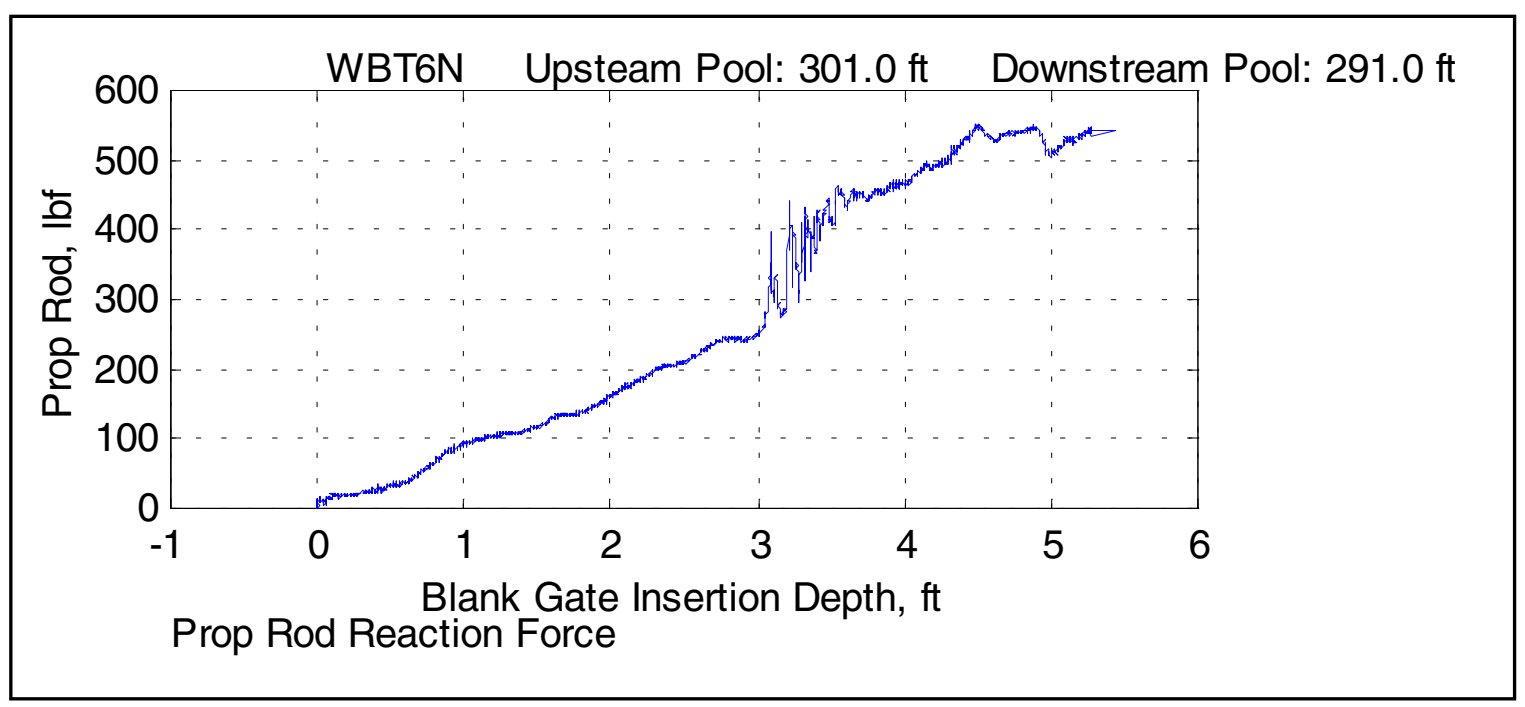

Figure 50. Prop rod force for test OLMWBT6N

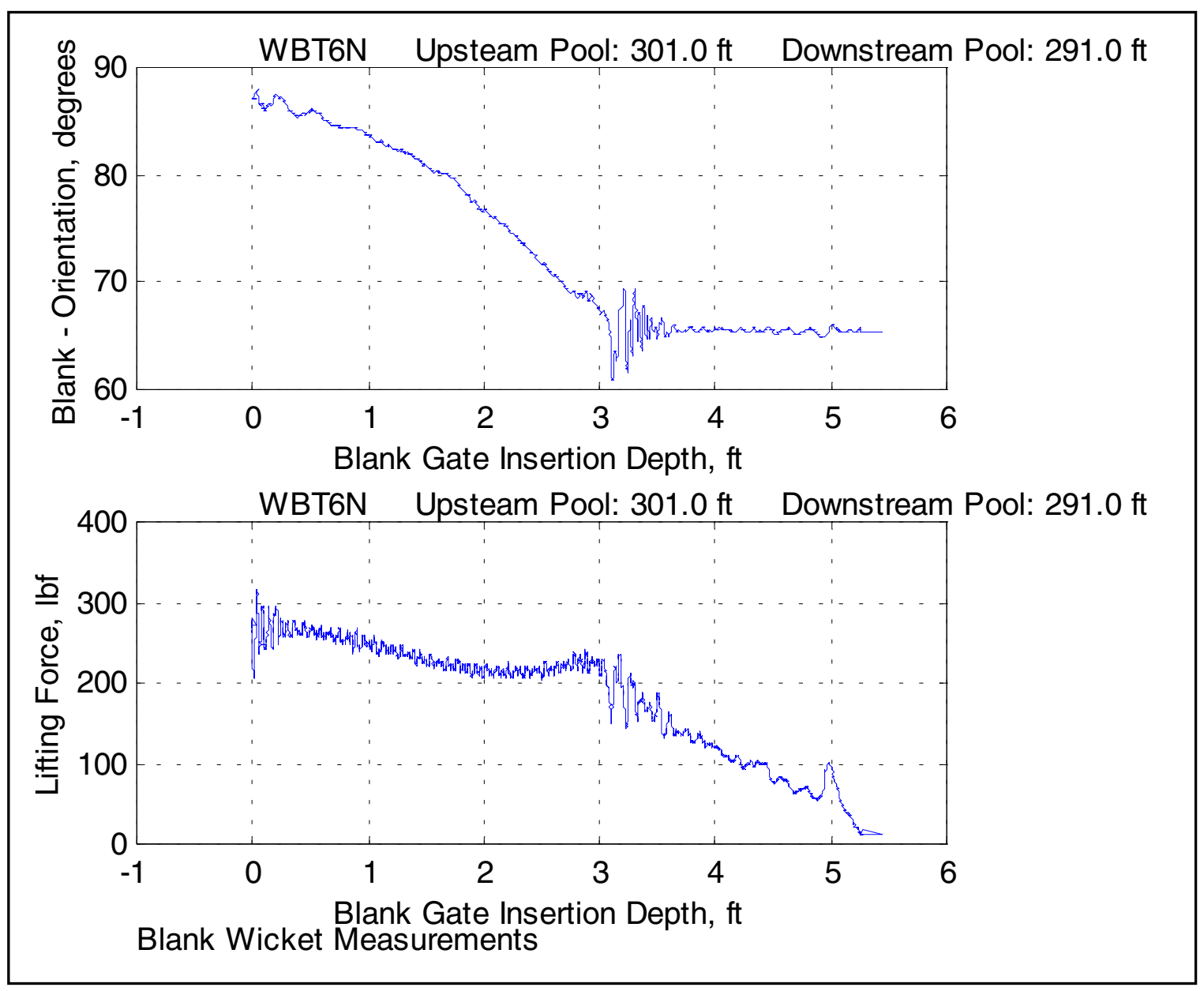

Figure 51. Lifting force and blank orientation for test OLMWBT6N 


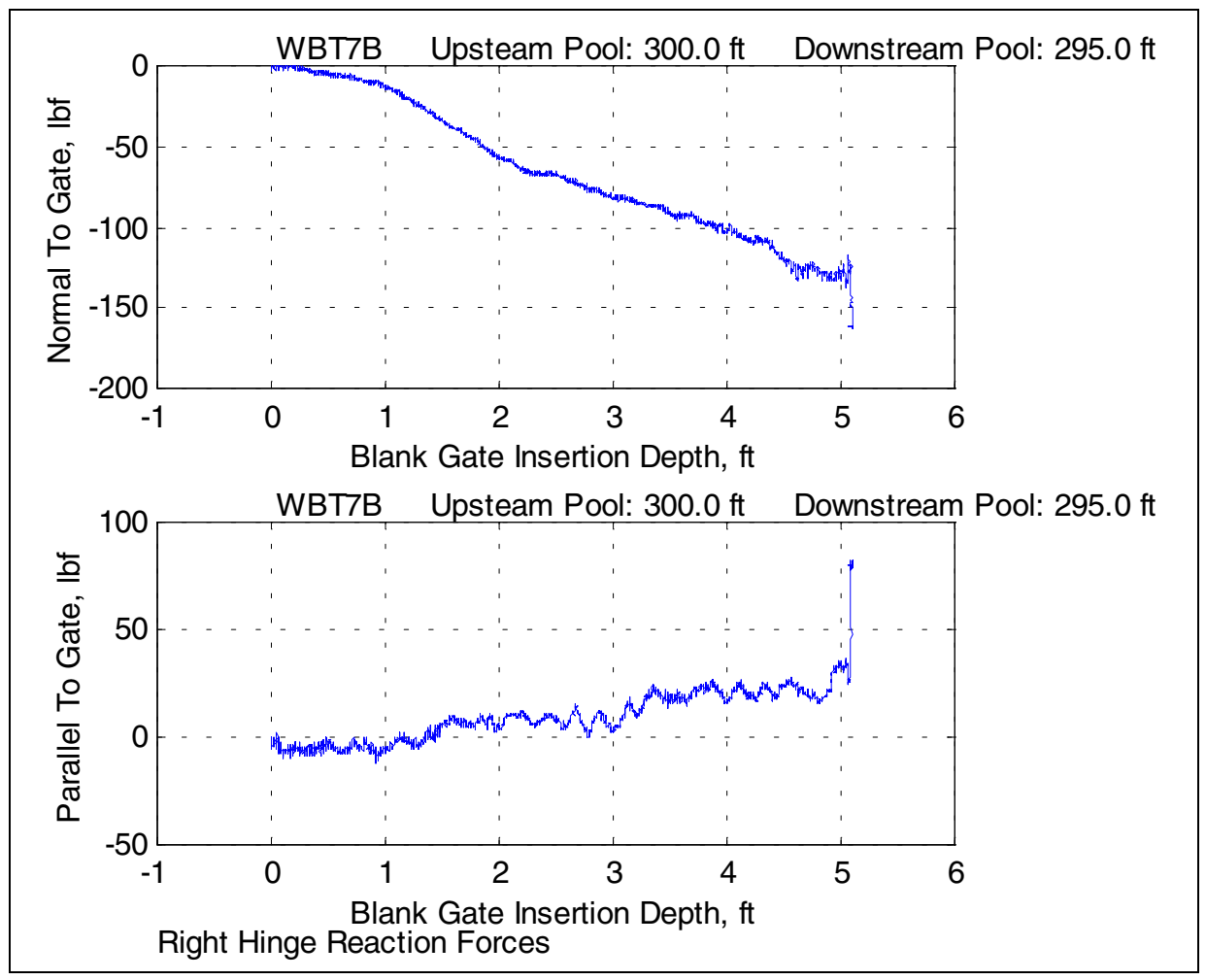

Figure 52. Right hinge reactions for OLMWBT7B

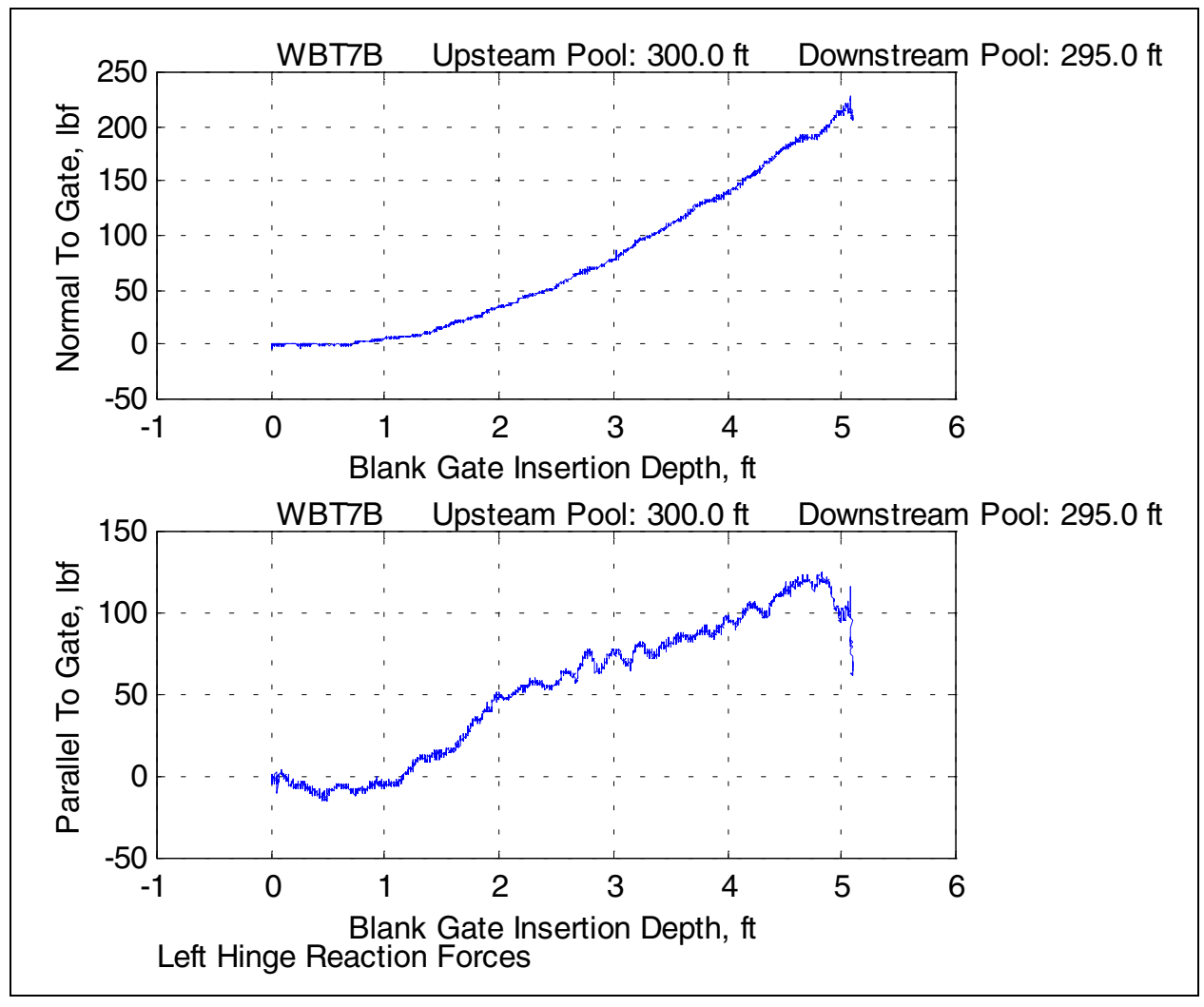

Figure 53. Left hinge reactions for OLMWBT7B 


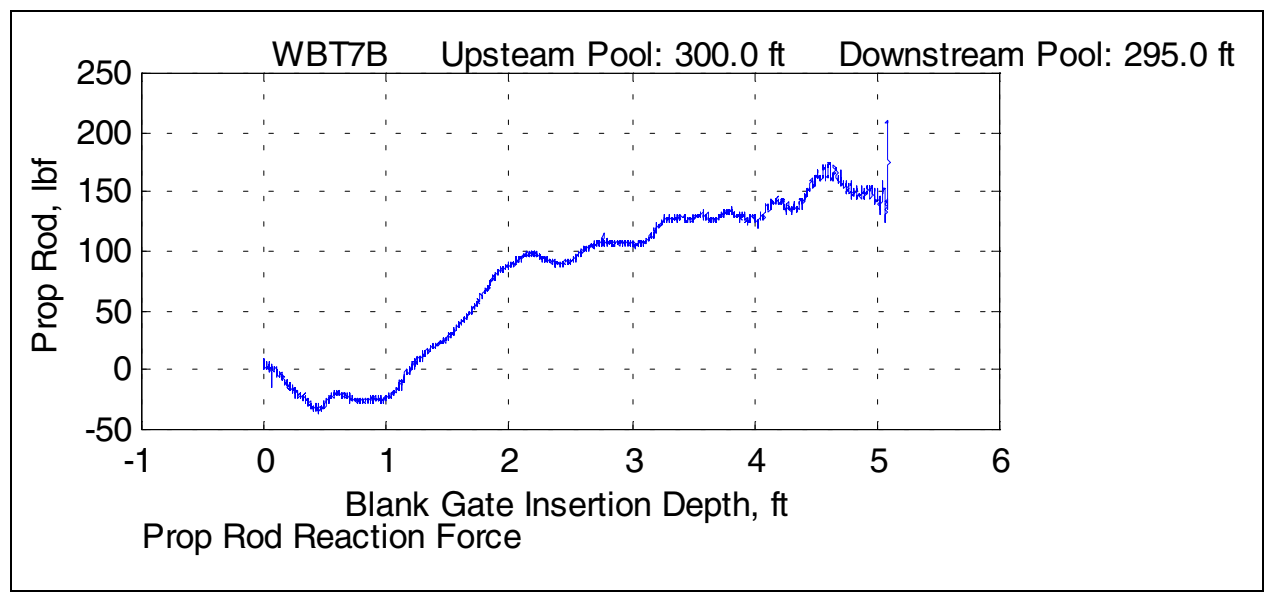

Figure 54. Prop rod force for test OLMWB7B

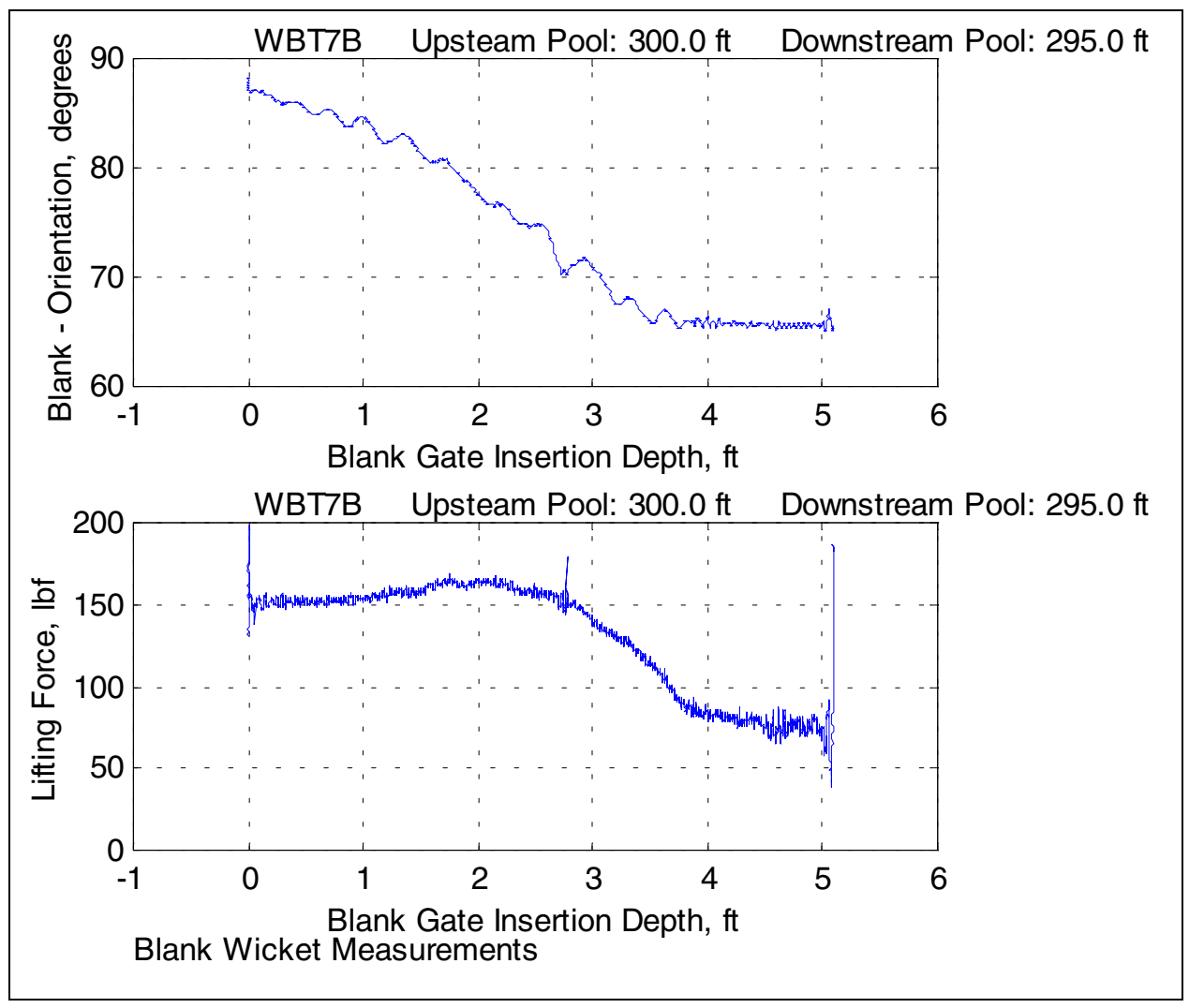

Figure 55. Lifting force and blank orientation for test OLMWBT7B 


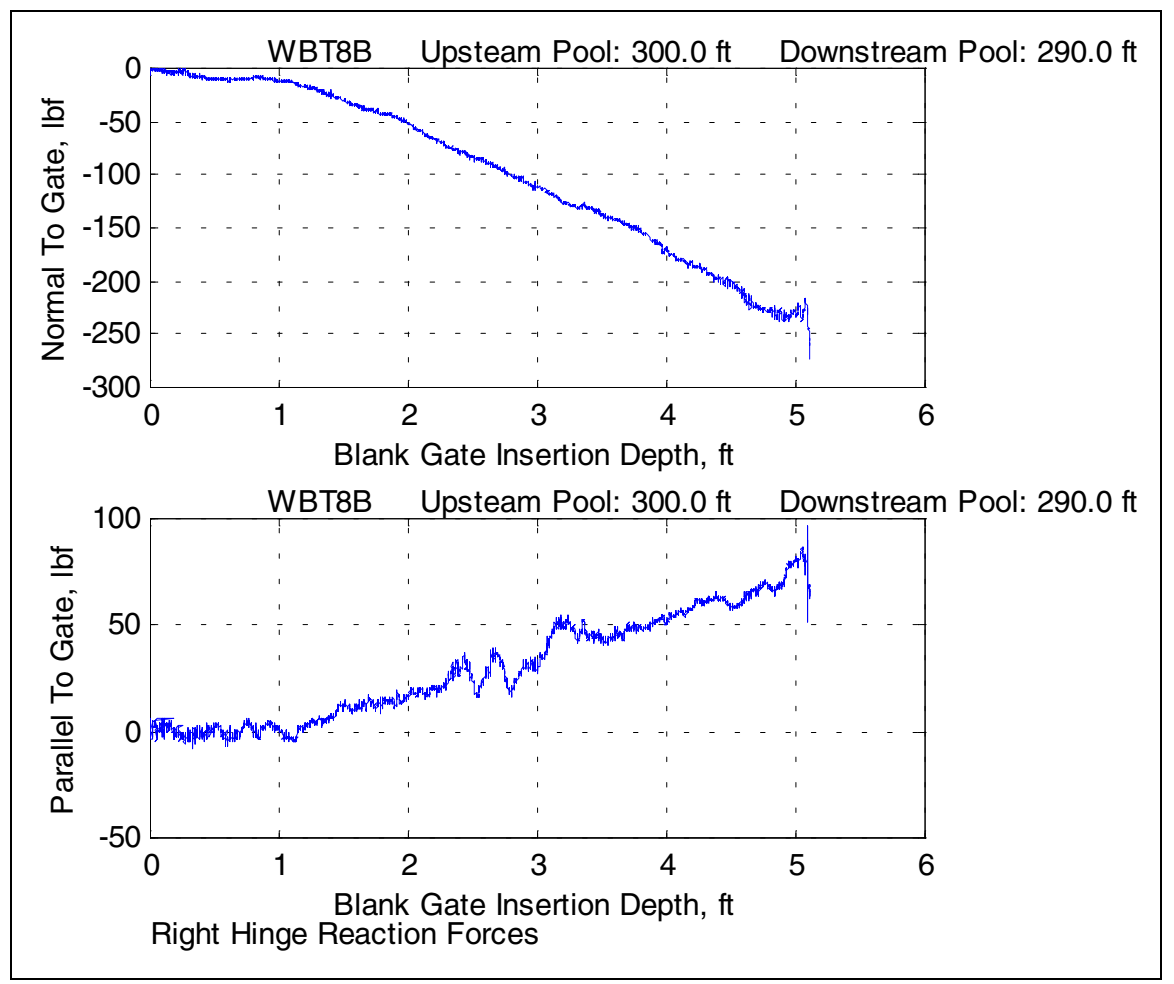

Figure 56. Right hinge reactions for OLMWBT8B

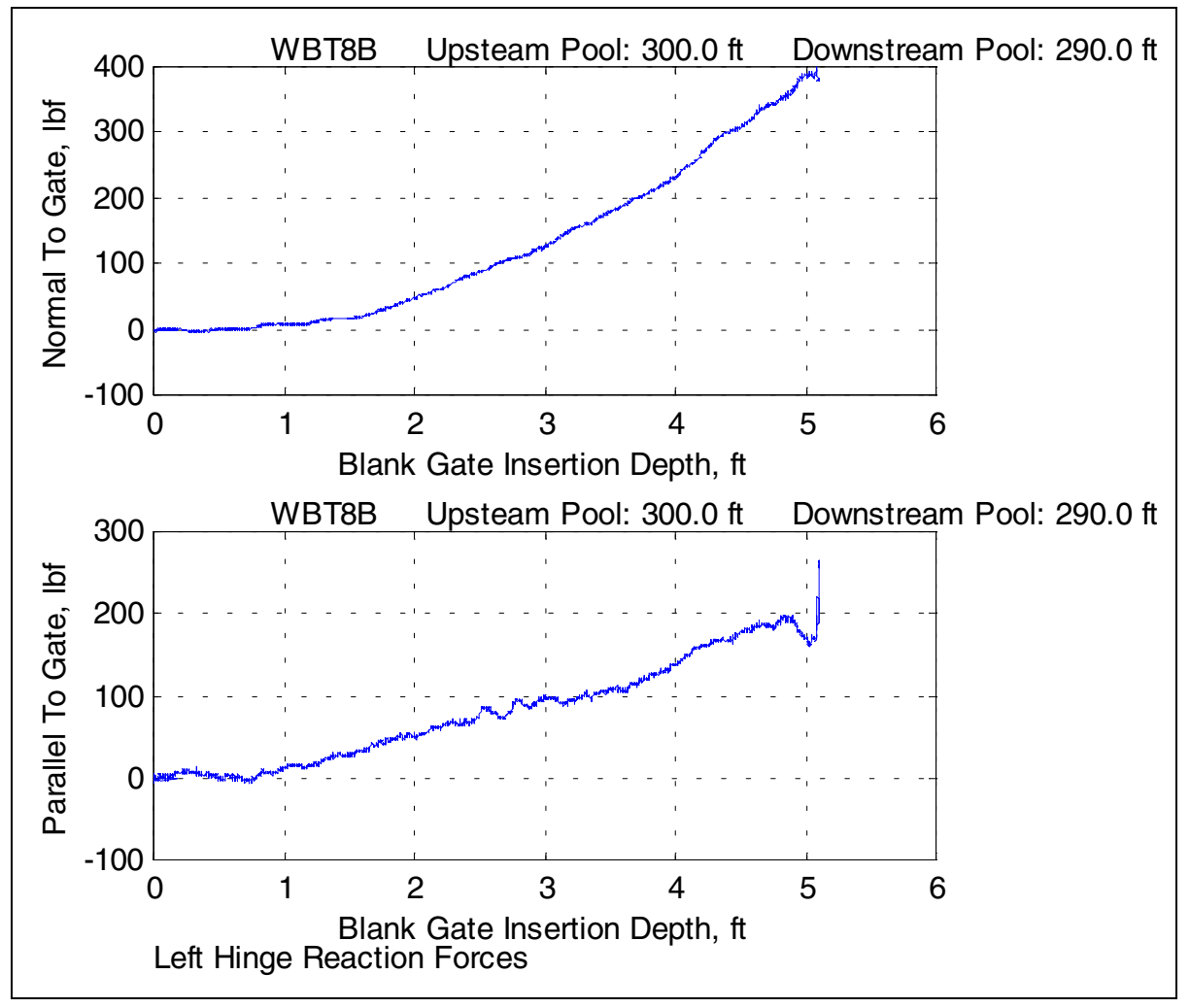

Figure 57. Left hinge reactions for OLMWBT8B 


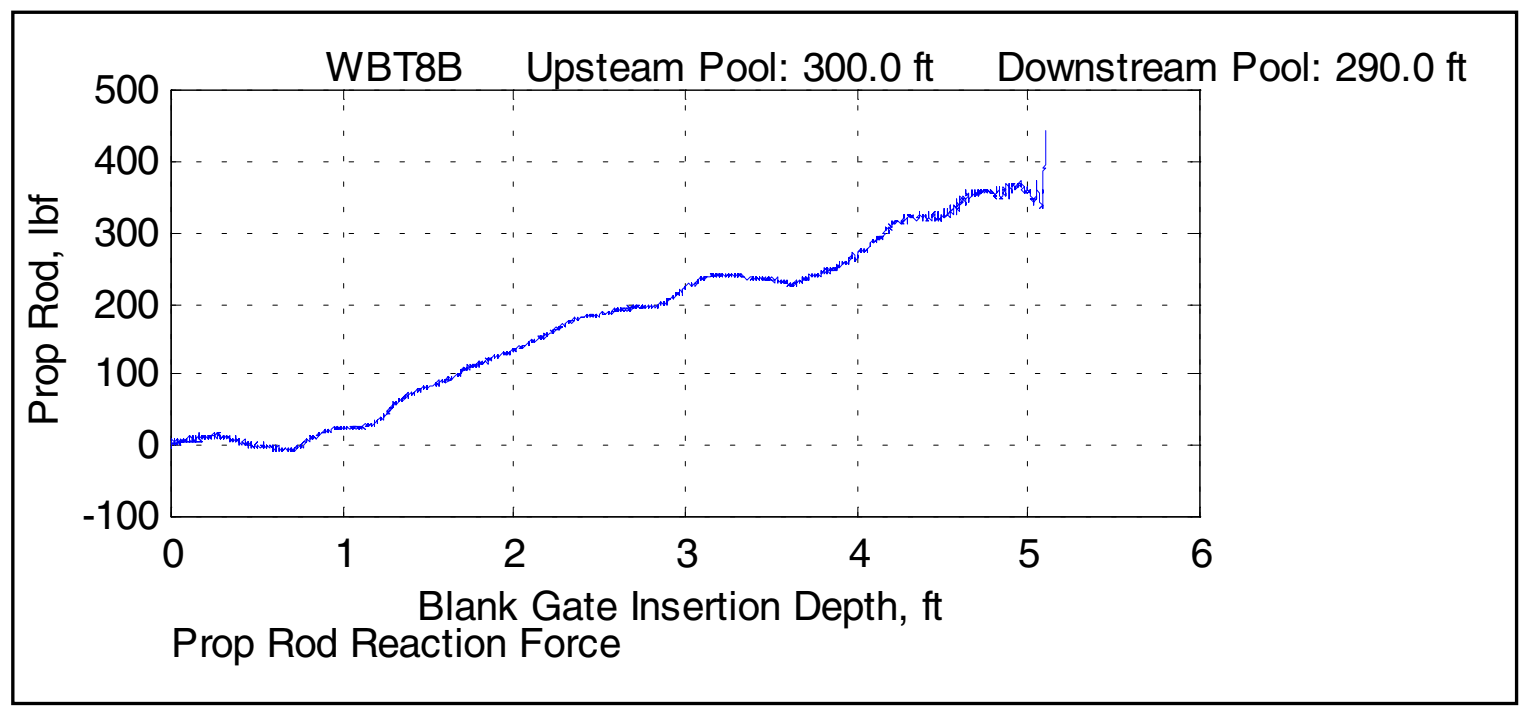

Figure 58. Prop rod force for test OLMWBT8B

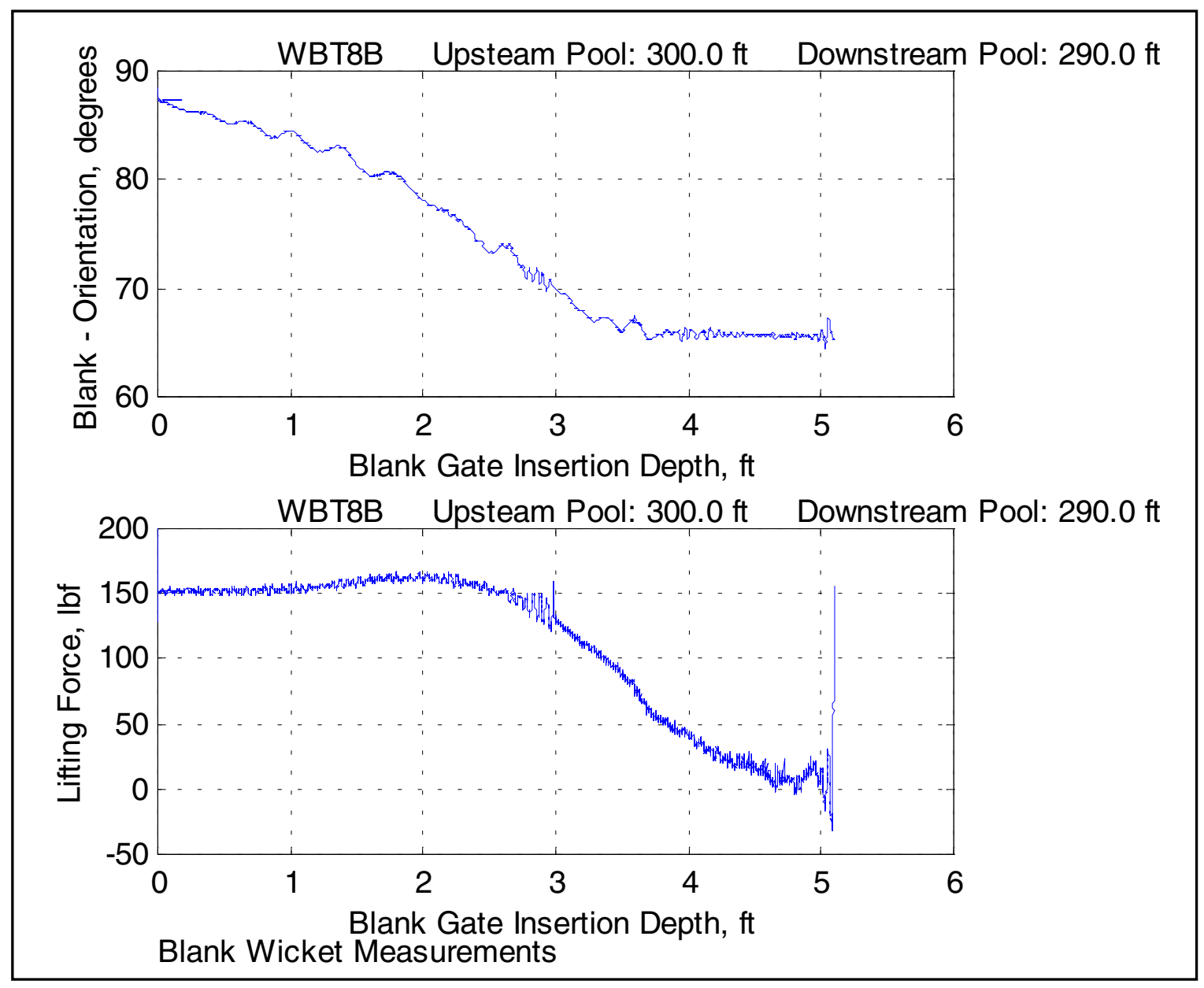

Figure 59. Lifting force and blank orientation for test OLMWBT8B 


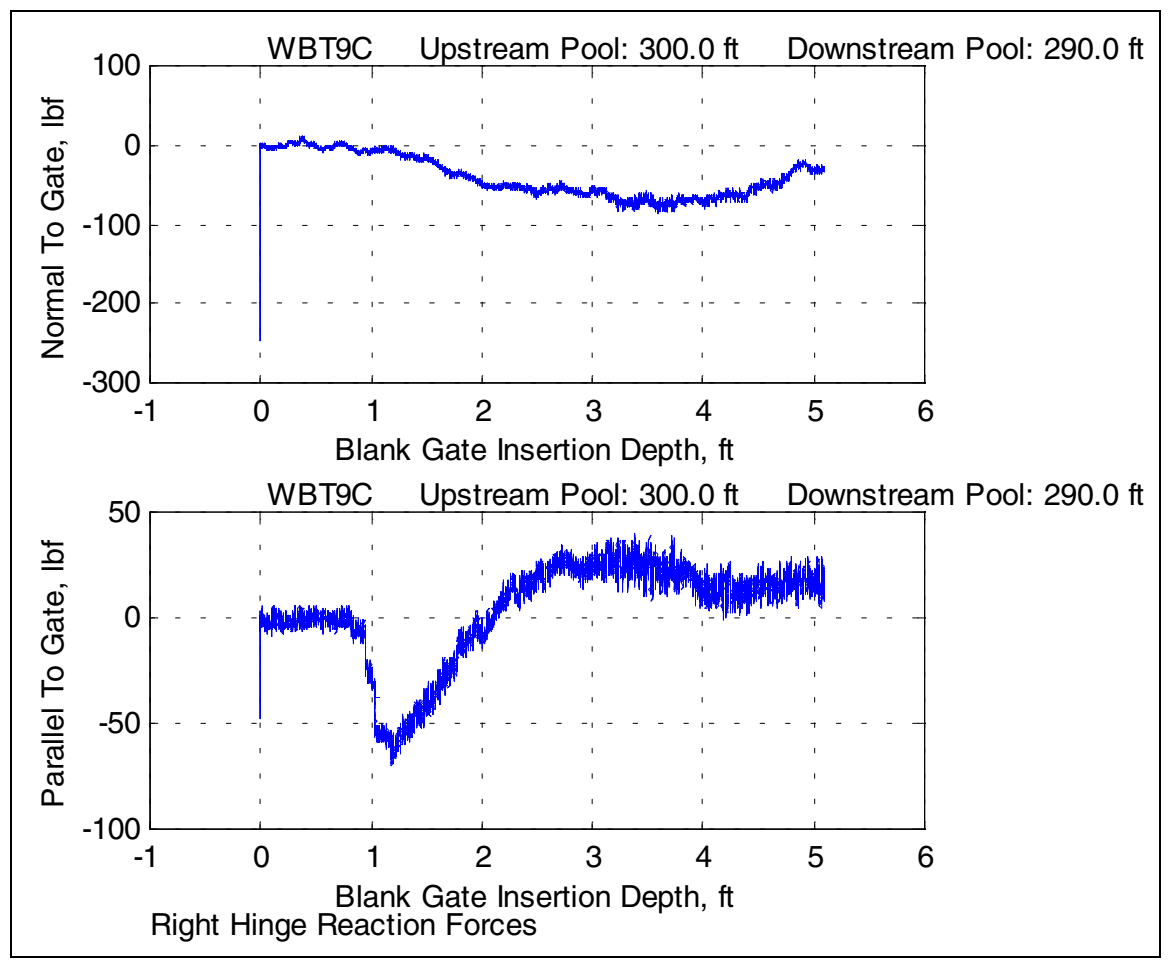

Figure 60. Right hinge reactions for OLMWBT9C

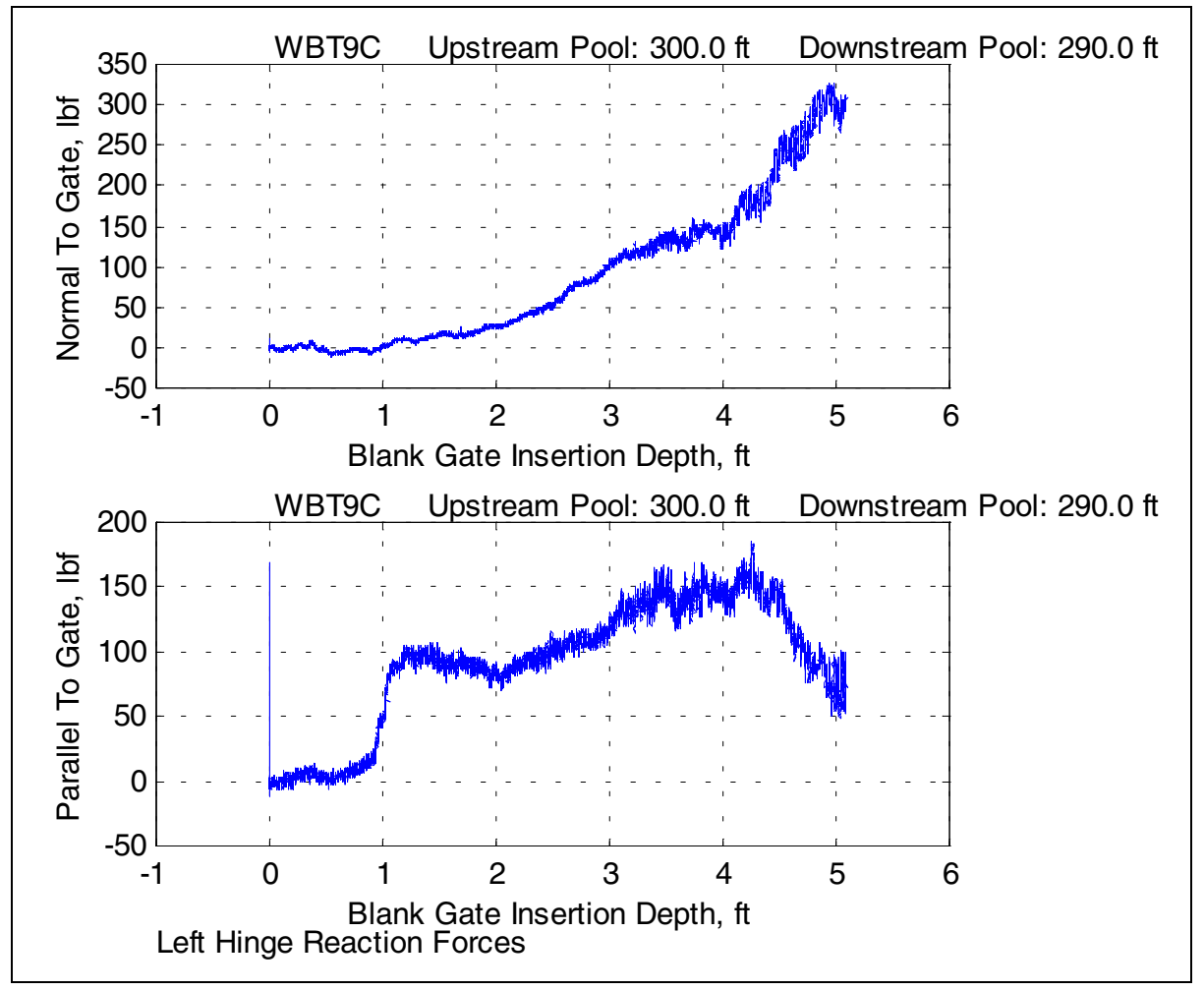

Figure 61. Left hinge reactions for OLMWBT9C 


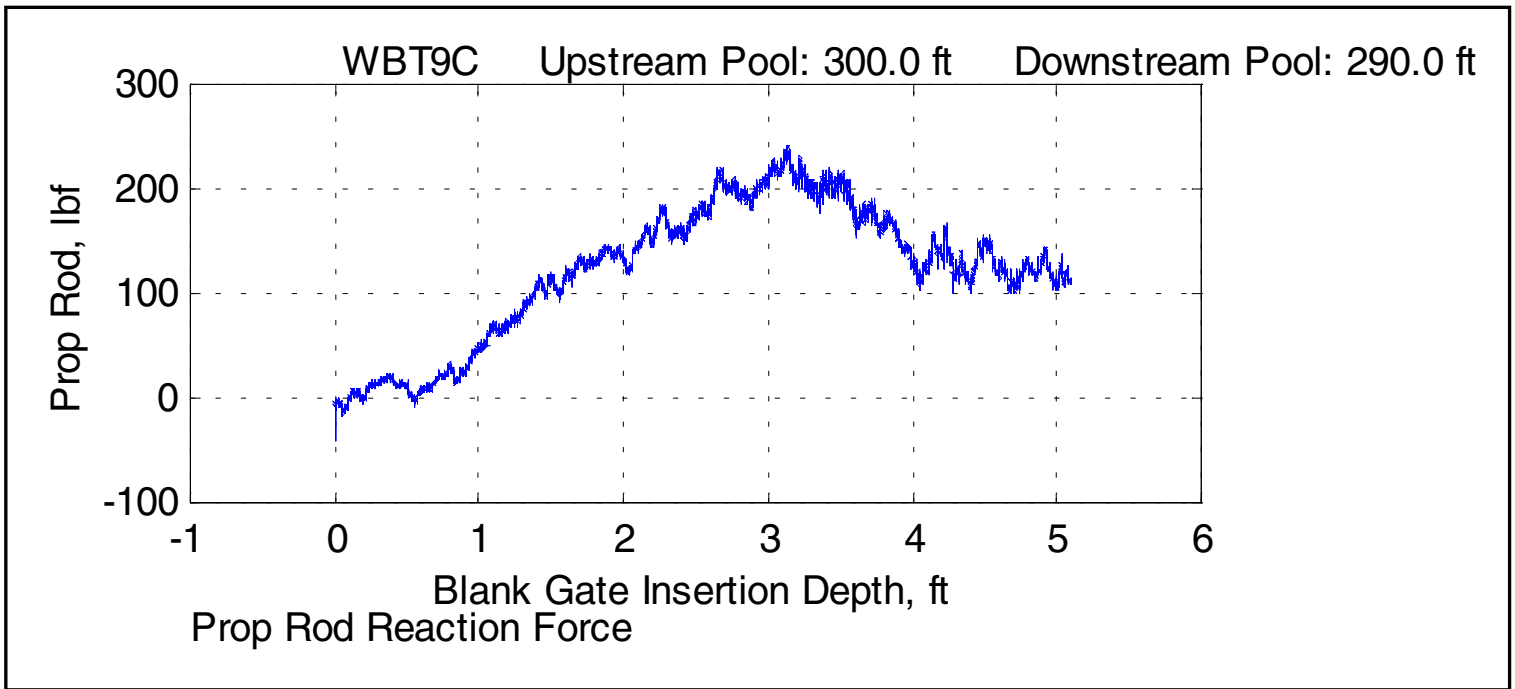

Figure 62. Prop rod force for test OLMWBT9C

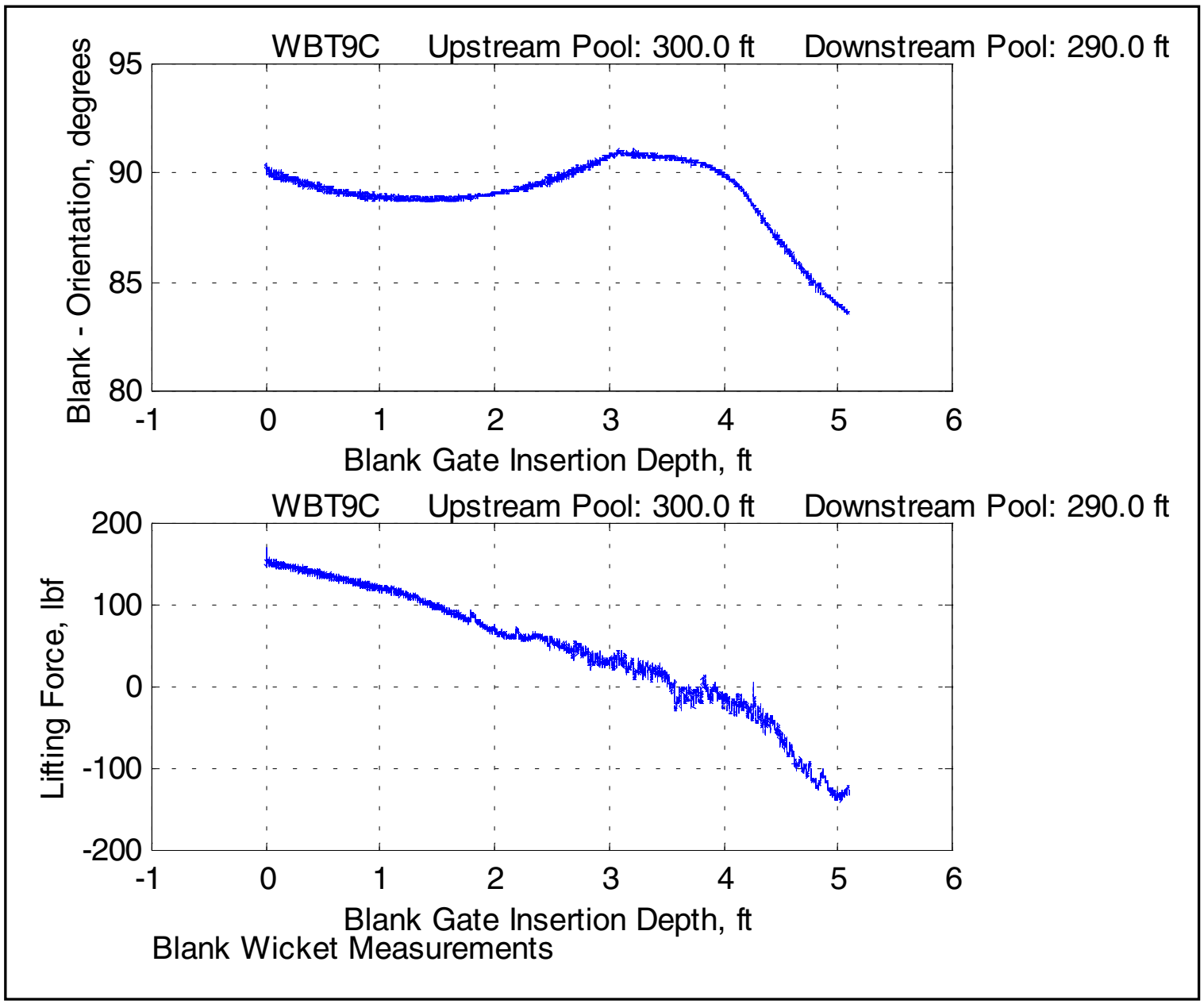

Figure 63. Lifting force and blank orientation for test OLMWBT9C 


\section{Appendix A Show Drawings}




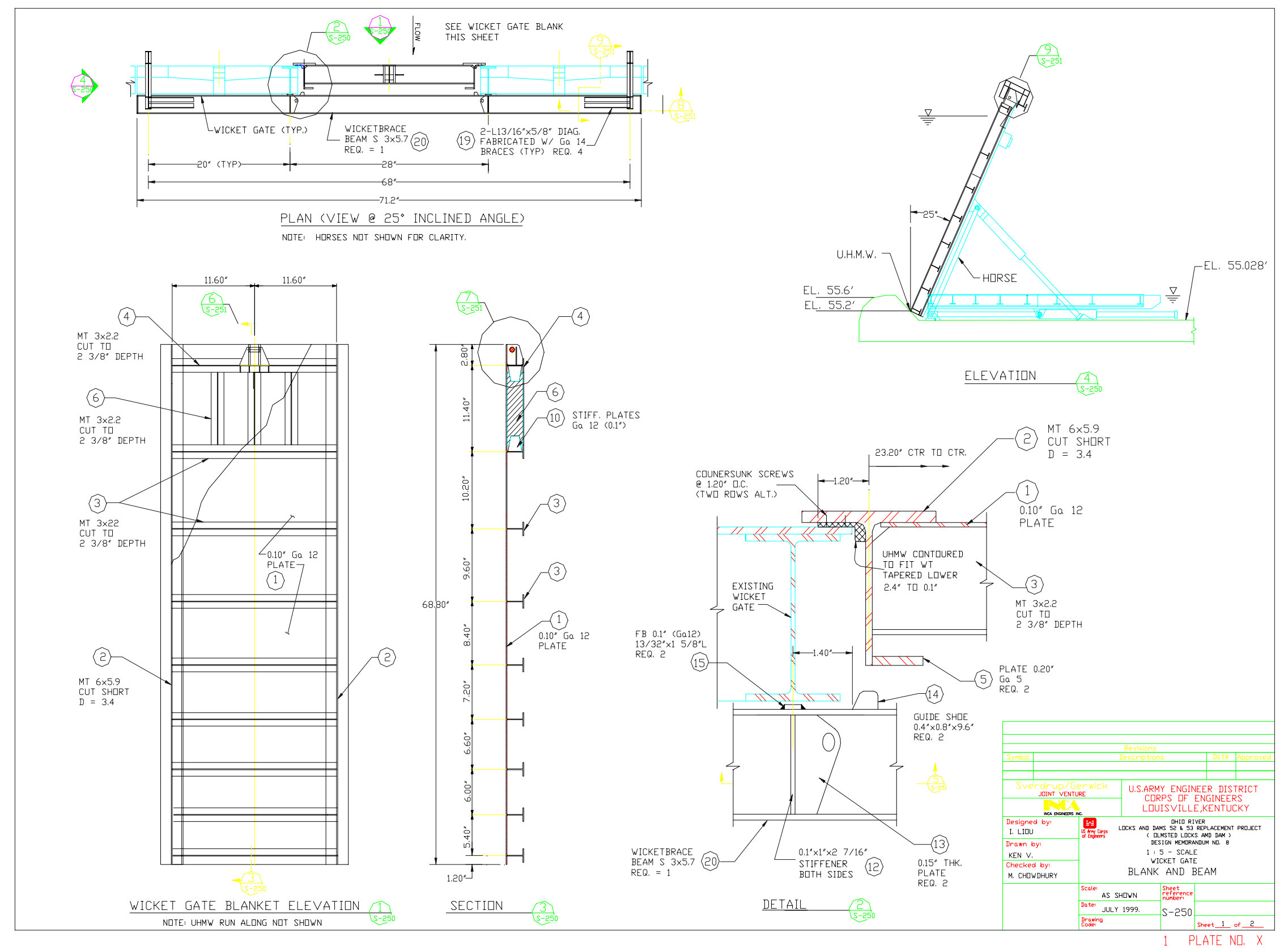




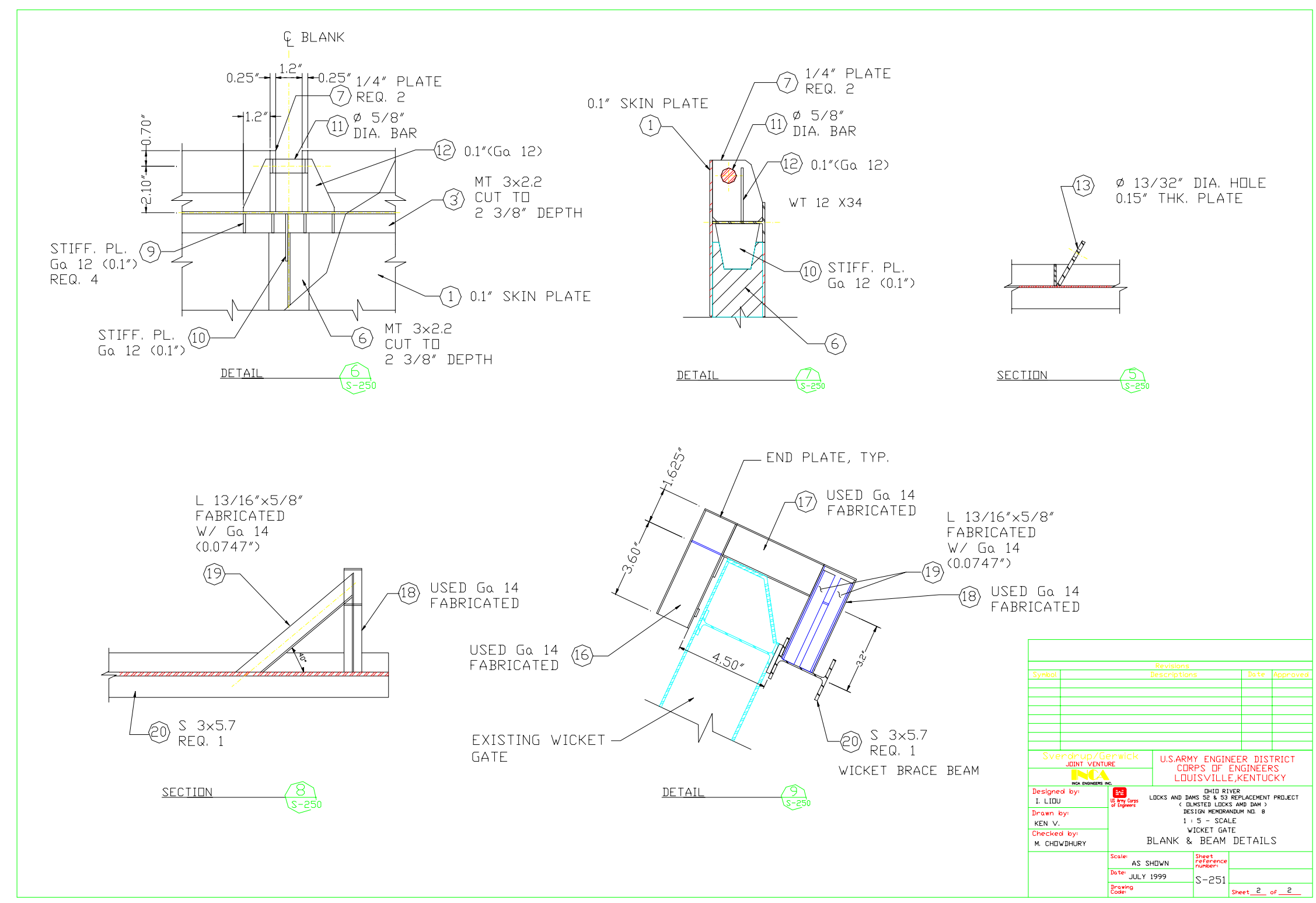


Public reporting burden for this collection of information is estimated to average 1 hour per response, including the time for reviewing instructions, searching existing data sources, gathering and maintaining the data needed, and completing and reviewing the collection of information. Send comments regarding this burden estimate or any other aspect of this collection of information, including suggestions for reducing this burden, to Washington Headquarters Services, Directorate for Information Operations and Reports, 1215 Jefferson Davis Highway, Suite 1204, Arlington, VA 22202-4302, and to the Office of Management and Budget, Paperwork Reduction Project (0704-0188), Washington, DC 20503.

\begin{tabular}{|l|l|l|l}
\hline 1. AGENCY USE ONLY (Leave blank) & 2. $\begin{array}{l}\text { REPORT DATE } \\
\text { September } 2000\end{array}$ & $\begin{array}{l}\text { 3. } \\
\text { REPORT TYPE AND DATES COVERED } \\
\text { Final report }\end{array}$
\end{tabular}

4. TITLE AND SUBTITLE

Olmsted Wicket Blank Experiment in 1:5-Scale Hydraulic Flume Model

5. FUNDING NUMBERS

6. AUTHOR(S)

Mostafiz R. Chowdhury, W. Glenn Davis

7. PERFORMING ORGANIZATION NAME(S) AND ADDRESS(ES)

U.S. Army Engineer Research and Development Center

Structures and Coastal and Hydraulics Laboratories

3909 Halls Ferry Road, Vicksburg, MS 39180-6199

8. PERFORMING ORGANIZATION REPORT NUMBER

ERDC TR-00-7

9. SPONSORING/MONITORING AGENCY NAME(S) AND ADDRESS(ES)

10. SPONSORING/MONITORING

U.S. Army Corps of Engineers, Washington, DC 20314-1000

U.S. Army Engineer District, Louisville, Louisville, KY 40201-0059 AGENCY REPORT NUMBER

\section{SUPPLEMENTARY NOTES}

12a. DISTRIBUTION/AVAILABILITY STATEMENT

12b. DISTRIBUTION CODE

Approved for public release; distribution is unlimited

13. ABSTRACT (Maximum 200 words)

The experimental results for wicket blank tested in the 1:5-scale hydraulic flume model are presented in this document. The results of this model investigation provide guidance to design necessary equipment and appurtenances for wicket blank operations in the field. The wicket blank will be used during the maintenance operation to facilitate the removal of any jammed wicket gate for various blank operations. No significant operational problems were discovered during this investigation. The wicket blank and the proposed installation and removal procedures proved to be adequate.

14. SUBJECT TERMS Hydraulic model Olmsted Locks \& Dam

Olmsted wicket blank

Scaled physical model
15. NUMBER OF PAGES 73

16. PRICE CODE
17. SECURITY CLASSIFICATION OF REPORT UNCLASSIFIED
18. SECURITY CLASSIFICATION OF THIS PAGE UNCLASSIFIED
19. SECURITY CLASSIFICATION OF ABSTRACT 